\title{
ENERGIA E NUTRIENTES NA DIETA DE ESCOLARES: CONTRASTES ENTRE MUNICÍPIOS BRASILEIROS
}

\section{ELOISE SANTUCCI RIBEIRO}

\author{
Dissertação apresentada à Escola Superior de \\ Agricultura "Luiz de Queiroz", Universidade de \\ São Paulo, para obtenção do título de Mestre em \\ Ciências, Área de Concentração: Ciência e \\ Tecnologia de Alimentos.
}

P I R A C I C A B A

Estado de São Paulo - Brasil

Janeiro - 2005 


\title{
ENERGIA E NUTRIENTES NA DIETA DE ESCOLARES: CONTRASTES ENTRE MUNICÍPIOS BRASILEIROS
}

\section{ELOISE SANTUCCI RIBEIRO}

\author{
Nutricionista
}

Orientador: Profa. Dra. MARINA VIEIRA DA SILVA

\begin{abstract}
Dissertação apresentada à Escola Superior de Agricultura "Luiz de Queiroz", Universidade de São Paulo, para obtenção do título de Mestre em Ciências, Área de Concentração: Ciência e Tecnologia de Alimentos.
\end{abstract}

P I R A C I C A B A

Estado de São Paulo - Brasil

Janeiro - 2005 
Dados Internacionais de Catalogação na Publicação (CIP) DIVISÃO DE BIBLIOTECA E DOCUMENTAÇÃO - ESALQ/USP

Ribeiro, Eloise Santucci

Energia e nutrientes na dieta de escolares: contrastes entre municípios brasileiros

Eloise Santucci Ribeiro. - - Piracicaba, 2005.

100 p. : il.

Dissertação (Mestrado) - - Escola Superior de Agricultura Luiz de Queiroz, 2005.

Bibliografia.

1. Adolescência 2. Alimentação escolar 3. Consumo de alimentos 4. Desenvolvimento físico 5. Dieta 6. Educação nutricional 7. Estado nutricional 8. Infância 9. Necessidade energética 10. Saúde publica 11. Segurança alimentar I. Título

CDD 613.2

"Permitida a cópia total ou parcial deste documento, desde que citada a fonte - O autor" 


\section{DEDICATÓRIA}

Ao meu marido Marco Aurélio pelo carinho e incentivo, sempre compartilhando os momentos mais alegres e também difíceis da minha vida.

Aos meus filhos Camila, Bianca e Felipe com muito amor.

À minha querida mãe Ivone pelo carinho e dedicação ao longo da minha vida.

À minha querida sogra Maria Aparecida “in memorian” que me traz muitas saudades dos seus conselhos.

Ao amigo Hélcio pelos pertinentes conselhos, sempre otimistas.

Ao Sebastião, pelo carinho e apoio durante a minha ausência de casa. 


\section{AGRADECIMENTOS}

À Deus, por acreditar que uma força maior está presente em nossas vidas para podermos conquistar nossos objetivos.

Devo gratidão em especial à Profa. Marina Vieira da Silva, pelo carinho, respeito e dedicação que ela tem com seus alunos e também pelos seus valiosos conhecimentos que muito contribuíram para o meu crescimento científico.

Aos membros da Banca do Exame de Qualificação: Profa. Dra. Denise Giácomo da Motta, Prof. Dr. Cláudio Rosa Gallo e Profa. Dra. Elizabeth Salay, pelas sugestões para aperfeiçoamento do trabalho.

À FINEP/Ministério da Ciência e Tecnologia pelo financiamento da pesquisa “Avaliação do Programa de Alimentação Escolar”, da qual a presente dissertação integra o módulo III.

À CAPES (Coordenadoria de Aperfeiçoamento do Pessoal de Ensino Superior) pelo auxílio financeiro, por meio de bolsa de estudo.

À Estela Bonilha (Bolsista PIBIC - CNPq - 2001/2002) pela valiosa atuação na construção do banco de dados.

Meu agradecimento aos meus familiares que, mesmo de longe, sempre torceram por mim.

A todos os amigos do curso de Pós-Graduação, em especial a Selma Guidorizzi Pacheco, Fabiana Curti, Aelson Aloir Santana Brum e Marielen de Lima e Silva pelos momentos de descontração e que muito contribuíram e me auxiliaram em meus momentos de dúvidas e dificuldades. 
Às Amigas Daniela Cristina Rossetto Caroba e Michele Sanches por todo o apoio e incentivo nos momentos necessários.

À Vilma Aparecida Sarto Zeferino e Sílvio Douglas D. Bacheta, funcionários do serviço de comutação bibliográfica da ESALQ, pela atenção e simpatia.

Às bibliotecárias Beatriz Helena Giongo, Midian Gustinelli e Silvia Maria Zinsly pela atenção no atendimento e pela contribuição na revisão do trabalho. 


\section{SUMÁRIO}

Página



LISTA DE TABELAS ................................................................................ ix

LISTA DE QUADROS............................................................................. xi

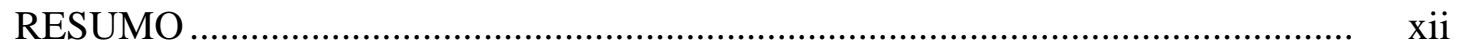

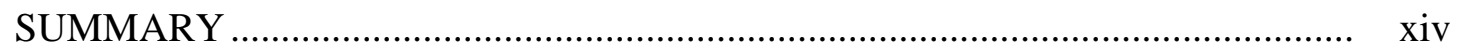

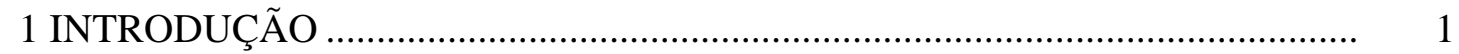

2 REVISÃO DA LITERATURA ................................................................ 6

3 MATERIAL E MÉTODOS .......................................................................... 16

3.1 Definição da amostra...................................................................................... 16

3.2 População de estudo ................................................................................... 20

3.3 Obtenção e análise dos dados........................................................................... 23

3.3.1 Estado nutricional.................................................................................. 23

3.3.2 Consumo alimentar ............................................................................ 23

3.3.3 Análise do consumo alimentar ..................................................................... 25

3.3.4 Análises estatísticas.............................................................................. 26

4 RESULTADOS E DISCUSSÃO .................................................................... 27

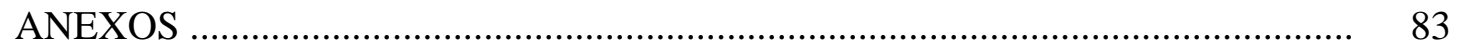

REFERÊNCIAS BIBLIOGRÁFICAS............................................................. 87 


\section{LISTA DE SIGLAS}

AHA - American Heart Association

CAAA - Centro de Atendimento e Apoio ao Adolescente

CARDIA - Coronary Artery Risk Development in Young Adults

CDCP - Center Disease Control and Prevention

DRIs - Dietary Reference Intakes

ENDEF - Estudo Nacional da Despesa Familiar

FAO - Food and Agriculture Organization of the United Nations

HDL - High Density Lipoprotein

IBGE - Instituto Brasileiro de Geografia e Estatística

ICS - Índice de Condições de Sobrevivência

IMC - Índice de Massa Corporal

LDL -Low Density Lipoprotein

NCEP - National Cholesterol Education Program

NCHS - National Center for Health Statistics

NHANES - National Health and Nutrition Examination Survey

NRC - National Research Council

OMS - Organizacion Mundial de la Salud

ONGs - Organizações Não-Governamentais

PNAE - Programa Nacional de Alimentação do Escolar

PNSN - Pesquisa Nacional sobre Saúde e Nutrição

POF - Pesquisa de Orçamentos Familiares

RDA - Recommended Dietary Allowances

SAS - Statistics Analysis System 
UNIFESP - Universidade Federal de São Paulo

VET - Valor Energético Total

WHO - World Health Organization 


\section{LISTA DE TABELAS}

Página

1 Características da distribuição do Valor Energético Total (VET) da dieta de escolares da rede pública de ensino, conforme Município de origem, 1997.

2 Valores médios e desvios-padrão do Valor Energético Total - VET da dieta de escolares da rede pública de ensino, de acordo com o gênero, faixa de idade e município de origem, 1997

3 Percentis da distribuição do Valor Energético Total (VET) da dieta de escolares da rede pública de ensino, conforme o município de origem, 1997

4 Participação dos macronutrientes no Valor Energético Total (VET) da dieta de escolares da rede pública de ensino, conforme o município de origem, 1997

5 Distribuição dos escolares da rede pública de ensino, de acordo com classificação da participação dos macronutrientes no Valor Energético Total (VET) da dieta, conforme município de origem, 1997

6 Distribuição dos escolares, menores de nove anos de idade, da rede pública de ensino, de acordo com o gênero e a participação dos macronutrientes no Valor Energético Total (VET) da dieta e conforme município de origem, 1997.

7 Distribuição dos escolares, com idade entre nove e treze anos, da rede pública de ensino, de acordo com o gênero e a participação dos macronutrientes no Valor Energético Total (VET) da dieta e conforme município de origem, 1997

8 Distribuição dos escolares da rede pública de ensino, de acordo com o estado nutricional (com base no Índice de Massa Corporal - IMC), gênero e município de origem, 1997. 
9 Distribuição dos escolares da rede pública de ensino, de acordo com a participação adequada dos macronutrientes no Valor Energético Total VET da dieta, estado nutricional (com base no IMC), faixa de idade e município de origem, 1997

10 Distribuição dos escolares da rede pública de ensino, com participação inadequada dos macronutrientes no Valor Energético Total - VET da dieta, de acordo com o estado nutricional (com base no IMC), idade e município de origem, 1997

11 Conteúdo médio de energia, lipídios, colesterol e fibras da dieta de escolares da rede pública de ensino, de acordo com o município de origem, 1997

12 Conteúdo médio de energia e minerais da dieta de escolares da rede pública de ensino, de acordo com o município de origem, 1997

13 Conteúdo médio de energia e vitaminas da dieta de escolares da rede pública de ensino, de acordo com o município de origem, 1997 


\section{LISTA DE QUADROS}

Página

1 Distribuição dos municípios integrantes da amostra, de acordo com algumas características socioeconômicas e demográficas, 1997 ........................ 18

2 Distribuição das unidades de ensino de acordo com o porte, número de alunos matriculados e alunos selecionados para a pesquisa, 1997 


\title{
ENERGIA E NUTRIENTES NA DIETA DE ESCOLARES: CONTRASTES ENTRE MUNICÍPIOS BRASILEIROS
}

\author{
Autor: ELOISE SANTUCCI RIBEIRO \\ Orientadora: Prof ${ }^{\mathrm{a}}$. Dr ${ }^{\mathrm{a}}$. MARINA VIEIRA DA SILVA
}

\section{RESUMO}

A infância e a adolescência são consideradas fases que envolvem uma série de transformações entre as quais merecem destaque o crescimento físico e desenvolvimento acelerados que são determinantes de uma maior demanda de energia e nutrientes. É fundamental que os indivíduos adotem alimentação balanceada no tocante à energia e nutrientes para que as mudanças na composição corporal e maturação sexual, entre outras demandas, sejam asseguradas. Entre os objetivos principais da pesquisa destacam-se a análise do estado nutricional, consumo de energia e nutrientes e a participação dos macronutrientes na dieta de amostra de 1325 escolares, matriculados em vinte unidades de ensino de dez municípios brasileiros. Os dados referentes ao consumo de alimentos foram obtidos por meio da adoção do método Recordatório 24horas. Para a elaboração das análises nutricionais foi utilizado o software Virtual Nutri (Philippi et al., 1996). Os resultados revelam ingestão média de energia (1503,4 kcal) que pode ser considerada menor que à recomendação definida para os alunos do grupo etário da amostra. Quando se analisou a situação dos escolares, de acordo com a participação dos macronutrientes no Valor Energético Total da Dieta - VET, observouse que, de forma geral, a maioria (55\%) adota dieta inadequada, sendo que as situações mais desfavoráveis atingem os estudantes dos municípios das Regiões Nordeste (Parnaíba e Brasileira) e Norte (Abaetetuba e Tailândia). Situação inversa foi identificada no tocante às dietas dos escolares de Joinville-SC $(71,3 \%$ do grupo adotavam dietas adequadas). A análise do estado nutricional revelou que é nula a prevalência de baixo peso entre os alunos da totalidade das vinte escolas integrantes da pesquisa. De foram geral a maioria (cerca de 92,6\%) foi classificada como eutrófica e proporção de escolares próxima à esperada identificada com sobrepeso. No entanto, nos municípios da Região Sul, os resultados distinguem-se pela superioridade da prevalência de sobrepeso em relação aos demais: proporções de escolares (14,7\%) de Joinville e $16,3 \%$, em Ponte Serrada foram diagnosticados com excesso de peso. Note-se que os referidos percentuais são praticamente três vezes maiores quando comparados à proporção observada (5\%) em populações considerado de referência. Quanto ao 
consumo de minerais, merece atenção a reduzida ingestão de cálcio (a maioria dos escolares não ingeriu $50 \%$ do valor preconizado). O consumo (médio) de praticamente a totalidade das vitaminas selecionadas pode ser considerado relativamente mais favorável, exceto quando se verifica, entre os alunos a baixa ingestão de folacina e ácido pantotênico. A reduzida presença de fibras da dieta da totalidade dos escolares causa preocupação, especialmente quando atenção é dirigida aos valores preconizados (25 a 38g/dia): o maior consumo foi observado entre os alunos de Parnaiba (14,3 g), enquanto em Joinville, a ingestão alcançou 7,9 g (menor quantidade média identificada). Não sobram dúvidas que o grupo formado por crianças e adolescentes, especialmente aqueles matriculados nas unidades da rede pública de ensino, merece a atenção dos órgãos de saúde e educação, principalmente no tocante ao monitoramento do consumo de alimentos. 


\section{NUTRIENT AND ENERGY INTAKES OF STUDENTS: CONTRASTS BETWEEN DIFFERENT BRAZILIAN MUNICIPALITIES}

Author: ELOISE SANTUCCI RIBEIRO

Adviser: Prof ${ }^{\mathrm{a}}$. Dr ${ }^{\mathrm{a}}$. MARINA VIEIRA DA SILVA

\section{SUMMARY}

Childhood and adolescence are considered periods that involve a series of changes in which some of them are worth enlightening: the physical growth and development that requires a higher intake of energy and nutrients. It is important that these subjects have a balanced food intake concerning energy and nutrients to reassure that the changes such as in body composition and sexual maturation are guaranteed. One of the most important goals of this work is the assessesment of the nutritional status, the energy and nutrients intake, and the macronutrients present in diets of a sample of 1325 students, enrolled in 20 public schools in 10 Brazilian states. The data on the students food intake were obtained using the 24-hour Recall Method. To the nutritional analyses the software Virtual Nutri was used. It was identified among the main findings an average of energy intake (1503.4 kcal) which was considered below the recommended allowance for the group. When the distribution of the students according to the participation of the macronutrients in the total energy value of the diet was analyzed, it was observed that most of them (55\%) has inadequate diets, being the worst situations among students of the Northeast Region (Parnaíba and Brasileira) and the North Region (Abaetetuba and Tailândia). The opposite was found among the students from JoinvilleSC (71,3\% of the group had diets classified as adequate). The analyses of the nutritional status found no prevalence of low weight among the students in the study. Most of them (around 92.6\%) were classified as eutrophic and an expected rate (5\%) was identified as overweight. Nonetheless among the students from Joinville (14.7\%) and Ponte Serrada (16.3\%) the results related to overweightness (percentages practically 3 times higher) distinguished by the superiority over the others. Regarding the consumption of minerals, it is surprisingly the low intake of calcium: most of them hadn't had 50\% of the recommended allowance. In relation to the average intake of vitamins the situation can be classified as more regular, except when the reduced intake of folacin and pantotenic 
acid is considered. The average content of fibers in the diets of all the students is cause of worries especially when the recommended daily allowance (25 to 38g): the highest intake was observed in students from Paraiba (14.3g) and the lowest was identified in students from Joinville. There are no doubts that the group of children and adolescents, especially the ones who attend public schools deserve close attention from the health and educational institutions concerning to food comsuption. 


\section{INTRODUÇÃO}

Merece destaque o reconhecimento que as análises envolvendo os determinantes do consumo de alimentos são complexas, especialmente quando se considera a situação da população (particularmente o grupamento jovem) de um país, que reúne características muito peculiares, como as observadas no Brasil.

De longa data também são conhecidos os danos para a saúde, entre os quais, podem ser destacados a desnutrição, decorrente do consumo insuficiente de nutrientes e a situação inversa, especialmente devido ao consumo excessivo de energia, a obesidade. Também, acumulam-se evidências quanto as características qualitativas da dieta que são igualmente importantes para o estado de saúde, especialmente no que se refere às doenças crônicas, que acometem os indivíduos, com maior frequência, na fase adulta.

Também cabe destacar que um consumo alimentar inadequado, por períodos prolongados, resulta em esgotamento das reservas orgânicas de micronutrientes, trazendo como consequência para crianças e adolescentes, retardo no desenvolvimento, redução na atividade física, diminuição da capacidade de aprendizagem, baixa resistência as infecções e maior suscetibilidade às doenças (Oliveira et al., 1998).

O período da infância e da adolescência é reconhecido pelo intenso desenvolvimento físico, intelectual e emocional. Nesse período é muito importante a ingestão adequada de energia e nutrientes. No entanto, diversas variáveis, nem sempre, com atuação favorável, exercem influência, sobre o estado nutricional e hábitos alimentares. São exemplos dessas variáveis a situação socioeconômica, os meios de comunicação, os grupos de amigos, consumo fora do domicílio, horários irregulares, entre outros.

Além do aumento do consumo de alimentos fora da moradia, são também identificadas, mudanças relativas à disponibilidade de alimentos nos domicílios brasileiros. Tem sido observada diminuição da participação dos gastos, das famílias 
brasileiras, com alimentação e, ainda, é notório que os dispêndios com alimentação são maiores para os grupos pertencentes aos estratos que envolvem rendimentos menores.

Em decorrência, por exemplo, da inadequação dos hábitos alimentares, constata-se o aumento da prevalência da obesidade entre crianças e adolescentes o que pode aumentar os riscos de doenças crônicas, tais como as cardiovasculares, hipertensão, diabetes, entre outras.

Vale ressaltar que o nível de colesterol na infância é um precursor do nível de colesterol na vida adulta e a sua identificação precoce pode auxiliar na prevenção da doença coronariana (Moura et al., 1997).

No que tange à situação alimentar da população brasileira, merecem destaque, as recentes análises elaboradas por Monteiro (2004), em parceria com o Ministério da Saúde e o Instituto Brasileiro de Geografia e Estatística - IBGE referente a segunda etapa da Pesquisa de Orçamentos Familiares - POF. As análises apontam para um crescimento, entre a população adulta brasileira, da prevalência da obesidade. Uma das razões para o aumento da obesidade pode ser o crescimento do teor de gordura na alimentação e a manutenção de um teor excessivo de açúcar na dieta. Os autores enfatizam quanto ao dispêndio de energia, que a tendência é de declínio, seja pela freqüência crescente de ocupações que não exigem esforço físico intenso, seja pelas formas sedentárias de lazer adotadas pela população, de forma geral.

Vale registrar também que foi identificado elevado "consumo de alimentos altamente calóricos”, entre adolescentes com idade entre 12 e 19 anos, com sobrepeso, no Rio de Janeiro. Os autores verificaram que os alimentos mais consumidos pelos adolescentes foram: sorvete, hamburguer, batata frita, biscoito, bolo, lingüiça, pizza, salgadinhos e chocolates. Ainda segundo os autores é necessário ressaltar que a carne bovina, biscoito, hamburguer, feijão, chocolates, salgadinhos, frutas e carne suína, representaram 70\% do valor energético total da dieta (Chiara et al., 2001).

Pesquisa tendo como foco as propagandas veiculadas por meio de comerciais das redes televisivas, especialmente quando são considerados os programas destinados ao público infantil e para adolescentes, revelaram que entre os alimentos que desfrutavam da preferência das crianças, predominaram aqueles presentes nas 
propagandas. Os autores identificaram que os estudantes de escolas das redes pública e privada optavam predominantemente por alimentos como hamburguer, nuggets, chocolate, sorvete e batata frita e que estes produtos eram comercializados pelas marcas líderes do mercado que destinavam elevados investimentos em marketing (Ferraz \& Rodrigues, 2001).

Outros resultados reforçaram essas características de hábitos alimentares inadequados, ao revelarem dados obtidos junto a amostra de adolescentes (estudantes de uma escola da rede municipal, do município de Serrana, região de Ribeirão Preto - SP). Os autores demonstraram que os hábitos alimentares são classificados como inadequados, devido ao predomínio de elevado consumo de lanches rápidos, refrigerantes, balas e doces, alimentos ricos em gordura e/ou carboidratos e pobres em fibras e oligoelementos. A pesquisa ainda mostrou que o sedentarismo deve ser considerado como fator agravante para a saúde dos adolescentes, assim como o hábito de se alimentarem enquanto assistem televisão (Nunes et al., 2001).

Tendo por base várias pesquisas acadêmicas reconhece-se como fundamental a implementação de programas no âmbito das unidades de ensino, com foco na Educação Nutricional. Considerando que substancial parte do tempo das crianças é dedicada as atividades escolares e, também, que expressiva proporção possui idade entre 7 e 14 anos e são atendidas diariamente nas escolas públicas, por meio do Programa Nacional de Alimentação Escolar - popularmente conhecido como “merenda escolar”, é lícito reconhecer que a unidade de ensino constitui-se num canal privilegiado para a promoção da formação de hábitos alimentares saudáveis (Oliveira, 1997).

É válido também considerar a importância assumida, para a população de 7 a 14 anos em todo o Brasil, do Programa Nacional de Alimentação Escolar, que visa fornecer refeições/alimentos durante o intervalo da jornada de aula, como recurso, a ser adotado para interferir de forma positiva, no sentido de incentivar o aumento do consumo de alimentos considerados saudáveis.

Cabe lembrar, por exemplo, que no planejamento dos cardápios do Programa Nacional de Alimentação Escolar, os alimentos selecionados para integrarem os 
cardápios devem possuir reconhecido valor nutritivo e ter boa aceitabilidade pelos escolares.

Dessa forma, a escola torna-se um espaço onde é possível, por meio de atividades incorporadas aos programas existentes, estimular o consumo de alimentos com atestada qualidade nutricional, uma vez que é na infância que podem ser consolidadas as práticas alimentares, frequentemente mais difíceis de serem modificadas na idade adulta (Gouveia, 1999).

Há reconhecimento por parte dos pesquisadores da área de saúde e nutrição que é na idade pré-escolar e escolar que se estabelecem os hábitos e, portanto, é necessário que a educação para a saúde tenha início neste período devido à sua maior aceitação e capacidade de assimilação de novos hábitos, por parte do grupamento jovem. Ilustra esse reconhecimento o trabalho de Carvalho et al. (2001) onde os autores enfatizam a importância da identificação precoce de práticas alimentares inadequadas. Desse modo medidas de intervenção, dirigidas especialmente aos escolares, podem ser implementadas, com vistas à adoção de dietas que atendam as necessidades nutricionais, favorecendo a prevenção de determinadas doenças.

Informe da Food and Agriculture Organization of the United Nations FAO/Organizacion Mundial de la Salud - OMS (2003) registra que é clara a importância do papel que os pais e o "meio escolar" desempenham na formação dos hábitos alimentares das crianças e na estimulação para a prática de atividades físicas. Alguns estudos, segundo o referido informe, tem mostrado que intervenções utilizando o ambiente escolar têm efeito na prevenção da obesidade.

Segundo Casotti et al. (1998), os adolescentes têm consciência dos alimentos que são adequados para a dieta, porém, na presença do grupo de amigos, optam pela chamada junk food (exemplos: batata-frita, hamburguer, pizza, sorvete) e na presença de autoridades, como professores e pais, procuram consumir alimentação balanceada, sem excesso de gordura ou açúcar.

Pereira et al. (2005), tendo por base dados de pesquisas recentes realizadas pelo The Coronary Artery Risk Development in Young Adults (CARDIA) e que tiveram início em 1985, envolvendo mais de 3000 pessoas (idade entre 18 e 30 anos), constataram 
diversos problemas, sendo que os mais graves são a obesidade e uma maior propensão de contrair diabetes. Ainda segundo os autores, aqueles indivíduos que possuíam o hábito de consumir alimentos em restaurante tipo fast-food (mais de duas vezes por semana), apresentaram um aumento de peso, em média, 4,5 quilos a mais, em comparação com aqueles que frequentavam esse tipo de estabelecimento uma vez por semana.

É importante considerar que as cantinas escolares e os vendedores ambulantes, que atuam no entorno da unidade de ensino, frequentemente comercializam alimentos com elevada densidade energética e que tradicionalmente são amplamente divulgados pela publicidade, tais como balas, lanches, salgados do tipo chips biscoito doce, hamburguer, maionese, pão doce, pipoca, pizza, refrigerantes, salgados tipo caseiro e doces. A comercialização desses alimentos no ambiente escolar, invariavelmente, representa um entrave para a educação nutricional e a formação de hábitos alimentares saudáveis (Danelon, 2004).

Ainda segundo o referido autor, há necessidade de orientação e treinamento a serem ministrados para os arrendatários das cantinas, visando o estímulo para a seleção de tipos de preparações mais saudáveis para os alunos, como exemplo a inclusão de alimentos com menor conteúdo de gorduras, aditivos, corantes e açúcares.

Concomitante à preocupação com a qualidade nutricional dos alimentos atenção especial deve ser dedicada à Segurança Alimentar (food safety), no que se refere à qualidade do alimento.

Face ao exposto não sobram dúvidas que o grupo formado por crianças e adolescentes merece atenção dos pesquisadores, técnicos e das autoridades das áreas de saúde pública, especialmente no que tange ao monitoramento do estado nutricional e consumo de alimentos.

Tendo em vista o crescente interesse pelas análises que envolvam a descrição pormenorizada do consumo alimentar de indivíduos com idade entre 7 e 13 anos, propôs-se a presente pesquisa com os objetivos de analisar o estado nutricional, o consumo de energia e nutrientes, com destaque para as análises relativas à participação dos macronutrientes no Valor Energético Total - VET da dieta dos escolares. 


\section{REVISÃO DA LITERATURA}

O ritmo cada vez mais acelerado da vida nas grandes cidades, a globalização e a influência da propaganda tem sido, entre outras variáveis, preponderantes para a mudança de hábitos alimentares da população.

Bleil (1998), registra que no Brasil existe uma tendência da população para a adoção de novos hábitos freqüentemente estimulados pela indústria alimentar, em detrimento do consumo de produtos regionais com forte tradição cultural. O referido autor relata que o feijão, a farinha de mandioca, o arroz e a farinha de milho que, durante décadas foram considerados alimentos tradicionais e presentes na dieta de parte substancial da população brasileira, passou por drástica redução de consumo.

Segundo Caroba et al. (2000), alguns dos motivos condicionantes das mudanças nos hábitos alimentares foram a crescente presença da mulher no mercado de trabalho e do aumento da oferta de alimentos industrializados e semi-preparados. Esses produtos são encontrados no mercado, devido a sua praticidade e por proporcionar rapidez de preparo para a sua utilização. Atendem, portanto, às demandas de ampla parcela da população, especialmente os grupos residentes nas áreas urbanas. Os alimentos com as referidas características vêm sendo incorporados cada vez mais aos hábitos alimentares, de forma predominante pelos adolescentes, invariavelmente com a justificativa de viabilizarem refeições rápidas e eventualmente mais econômicas, liberando assim as pessoas para se dedicarem a outras atividades de interesse (Vieira \& Priore, 2001).

Silva (1998), analisando as tendências do consumo alimentar, constatou que de forma muito rápida, estão ocorrendo mudanças decisivas no padrão de consumo de alimentos da população brasileira. Observou também que uma parcela substancial, representada pelos grupos considerados mais pobres, ampliou o consumo de alimentos protéicos (como carnes, leite e derivados). 
Galeazzi et al. (1997), analisaram o consumo alimentar de amostra populacional de cinco cidades do país (Campinas, Curitiba, Goiânia, Ouro Preto e Rio de Janeiro) durante os anos de 1996 e 1997 e ainda, estabeleceram comparações dos resultados obtidos com os dados registrados pelo Estudo Nacional da Despesa Familiar ENDEF - 1974/1975 e pela Pesquisa do Orçamento Familiar - POF - 1987/1988. Os autores identificaram uma redução no consumo de arroz, feijão e ovo. Por outro lado, observaram também que outros alimentos como queijo, carne de frango, farinha de trigo e fubá revelaram aumento de consumo. Um outro fator relevante que chamou a atenção dos autores foi a expressiva elevação do consumo de refrigerante e de embutidos, especialmente a salsicha.

Análises elaboradas por Monteiro et al. (2000), tendo por base dados das Pesquisas de Orçamentos Familiares - POFs, implementadas nos anos de 1987/88 e 1995/96, revelaram um aumento do consumo de lipídios, redução do consumo de carboidratos complexos, estagnação e até diminuição do consumo de leguminosas, verduras, legumes, frutas e sucos naturais e do aumento excessivo de açúcar refinado e refrigerantes.

Cabe lembrar também que os períodos da infância e da adolescência são caracterizados pelo intenso desenvolvimento físico e emocional. É muito importante nessas fases assegurar a ingestão adequada de nutrientes. No entanto, devido aos fatores como situação socioeconômica, influência da propaganda principalmente a veiculada pelas redes de televisão, motivações dos grupos de amigos, tendência típica da idade de negligenciar normas (como por exemplo, os horários das refeições), ocorrem interferências, invariavelmente indesejáveis, nos hábitos alimentares dos adolescentes.

Vale registrar que a adolescência, de acordo com Castro et al. (2002) é a fase da vida que, cronologicamente, envolve o período entre os 10 aos 20 anos de idade.

Especificamente no que se refere ao consumo de alimentos é interessante mencionar os resultados de pesquisa envolvendo adolescentes com idade entre 15 e 17 anos, matriculados em uma escola secundária estadual de Madri (Espanha). A pesquisa que teve como objetivo a análise da relação entre hábitos alimentares e ingestão de alimentos, conteúdo de energia e nutrientes nas dietas, revelaram que os adolescentes 
que assistiam à televisão por duas ou mais horas por dia consumiam menor quantidade de frutas, legumes, fibras e vitamina $\mathrm{C}$ em comparação ao grupo que permanecia menos tempo exposto à programação televisiva. A percentagem de adolescentes que revelou menor consumo de nutrientes em relação aos valores recomendados foi maior quando se considerou o grupo de escolares que assistiam televisão por mais de duas horas. Esse grupamento também revelou menor adequação no tocante à contribuição de macronutrientes para o Valor Energético Total - VET da dieta (Ortega et al., 1996).

Merece destaque a constatação que lanches e alimentos industrializados ocupam um espaço cada vez maior na pauta alimentar dos adolescentes. Bull \& Phil (1992); Silva (2000) relataram que um dos aspectos mais prejudicial deste hábito alimentar é o fato dos lanches, freqüentemente não apresentarem conteúdo nutricional balanceado, sendo, invariavelmente, rico em gorduras saturadas e carboidratos.

Um recurso de intervenção, visando a promoção da educação nutricional seria adotar o espaço escolar como local ideal para a implementação de programas voltados à educação para a saúde com ênfase nos aspectos alimentares e nutricionais. Merece destaque também o Programa Nacional de Alimentação Escolar, presente na totalidade das unidades de ensino do país como um serviço ao qual poderiam ser incorporadas estratégias, com vistas a promoção e consolidação de hábitos alimentares saudáveis.

Face ao exposto, enfatiza-se que é impossível ignorar a importância de fornecer orientações aos alunos sobre o conteúdo nutricional e ainda, sobre os custos dos alimentos que são comercializados pelas cantinas/lanchonetes escolares.

Atualmente, devido a disponibilidade de vários recursos que diminuem os esforços tanto no domicílio como no trabalho e as atividades recreativas que invariavelmente consolidam o sedentarismo há diminuição do gasto de energia, que reflete significativamente no modo vida das pessoas (Ziwian, 1999). Tudo isso associado a um aumento no consumo de alimentos gordurosos, com elevada densidade energética, e a diminuição na prática de exercícios físicos, colaboram para o aumento da obesidade (Albano \& Souza, 2001).

Vale ressaltar que, segundo Ziwian (1999) e Nunes et al. (1998), a propaganda causa um impacto decisivo na vida das pessoas, principalmente aquelas veiculadas por 
meio da televisão. A propaganda estimula as crianças e adolescentes a consumirem alimentos muito processados, contendo elevado conteúdo energético, expressiva quantidade de substâncias como a gordura, o açúcar, o colesterol e o sal (Ziwian, 1999).

Outro fator preponderante é a autonomia de substancial parcela de adolescentes na escolha dos alimentos. Os jovens acabam consumindo produtos alimentícios em função da saturação publicitária (Nunes et al., 1998; Ziwian, 1999). No entanto cabe salientar que o fato do adolescente escolher os alimentos não é um problema desde que seja previamente orientado para efetuar as melhores opções.

O comportamento relacionado à autonomia também é observado entre os alunos, quando se considera o ambiente escolar, em especial, quando cantinas funcionam nas unidades de ensino. Esses estabelecimentos contribuem para que os adolescentes (incluindo crianças com menor idade) também utilizem sua independência para a escolha dos alimentos. Não há dúvida que esses estabelecimentos interferem na prática alimentar, na medida que na maioria das vezes comercializam produtos que geralmente são veiculados pela mídia e que podem levar a consolidação de hábitos alimentares inadequados (Silva \& Pipitone, 1994).

De acordo com Figueiredo et al. (1994), os conhecimentos que são adquiridos na escola serão esquecidos e ignorados se os alimentos que são comercializados pelas cantinas ou similares como bares e lanchonetes não estiverem de acordo com os princípios de uma alimentação saudável. O mesmo acontecerá se a família não participar desse processo, reforçando as orientações quanto ao consumo ideal de alimentos.

Pesquisa, envolvendo 296 alunos, pertencentes às turmas de quarta a oitava série do primeiro grau (atualmente denominado Ensino Fundamental) da Rede Oficial de Ensino de Piracicaba, estado de São Paulo, visando conhecer as preferências dos escolares, revelou que os alimentos mais consumidos foram salgadinhos, lanches, refrigerantes, cachorro-quente e sorvete (Silva \& Pipitone, 1994).

Com a finalidade de avaliar o consumo alimentar de adolescentes, Abreu et al. (2004), realizaram estudo envolvendo 193 alunos, de ambos os gêneros, com idade entre 10 e 19 anos, matriculados em uma escola da rede privada de Cotia, estado de São Paulo. Os autores observaram que os alimentos (hot-dog, croissant, sorvete, coxinha e 
refrigerantes) mais consumidos continham elevada densidade energética, sendo que a procedência destes alimentos, era majoritariamente da cantina e dos vendedores ambulantes que atuavam no entorno da unidade de ensino. Os autores notaram também que os meninos menores de 15 anos apresentaram maior ingestão de energia, durante o intervalo (recreio), em relação as meninas da mesma faixa etária. Ainda segundo os autores, a maioria dos adolescentes (53\%) revelou que fazem uso da cantina, motivada pela praticidade.

Uma pesquisa tendo por base amostra de alunos, da rede municipal de ensino de Florianópolis (Santa Catarina), revelou elevada proporção de obesos. Dentre os alunos com idade entre 6 e 8 anos, 26\% apresentavam peso acima do esperado. Esses resultados motivaram a prefeitura para a adoção de medidas proibindo a venda de doces, refrigerantes, salgados industrializados, balas e confeitos nas cantinas das escolas públicas. Mereceu destaque o argumento que os estabelecimentos comercializavam alimentos que não atendiam as metas alimentares definidas pelo Conselho Municipal de Alimentação Escolar (Marques, 2001).

Nas análises envolvendo consumo alimentar de escolares é importante considerar a influência do gênero sobre o padrão alimentar. De acordo com dados registrados pela pesquisa coordenada pela Sodexho Research Institute (2000); Martins Filho (2001), existem diferenças no comportamento alimentar entre adolescentes, quando se considera o gênero. Especificamente com relação à referida pesquisa, realizada no Brasil e publicada em 2000, o conteúdo energético consumido pelos meninos (2850 kcal/dia) era 31,3\% superior ao consumido pelas meninas (2170 kcal/dia). A importância dos alimentos também é interpretada de maneira diferenciada pelos adolescentes. Para as meninas os alimentos além de prazerosos, devem trazer benefícios para a saúde, enquanto que, para os meninos além de promover o prazer, o alimento tem uma conotação social. Essa diferenciação é crescente, quando são analisados de forma comparativa, os tipos de alimentos consumidos diariamente, por indivíduos de ambos os gêneros. Os adolescentes do gênero feminino consomem proporcionalmente mais frutas $(81,6 \%)$, legumes $(76,3 \%)$, saladas $(56,4 \%)$, peixes $(44,7 \%)$ quando se compara esses dados do consumo com as informações obtidas junto 
aos adolescentes do gênero masculino. Os garotos consomem, em comparação com as meninas, maior quantidade de arroz $(84,5 \%)$, carne $(83,6 \%)$, ovos $(53,9 \%)$ e sopa $(29,7 \%)$.

Ainda tendo por base o gênero, estudo de Fisberg (2005a) registrou, entre os objetivos, a análise da prevalência da obesidade e identificou entre os resultados que o problema afeta cerca de 20,3\% das crianças do gênero masculino e 15,8 do gênero feminino.

De acordo com Dietz (1998), existe grande probabilidade das crianças e adolescentes obesos manterem essa condição, quando se tornarem adultos. Persistindo a referida situação nutricional pode ocorrer o surgimento de outras doenças como é o caso da hipertensão, dislipidemia e diabetes tipo II.

Fisberg (2005a) ressalta que a causa para o excesso de peso na infância é comportamental, ou seja, os "brasileiros incorporaram hábitos adotados por grupos populacionais de outros países como, por exemplo, o fast-food" e o costume de "comer qualquer coisa a qualquer hora”.

Estudo tendo por base amostra que reuniu 334 adolescentes com idade entre 10 e 19 anos, matriculados em um colégio particular de Teresina - PI, revelou hábitos alimentares inadequados. Apesar da expressiva diversificação na alimentação dos escolares, foi possível verificar a presença marcante de alimentos ricos em gordura, com elevado conteúdo de açúcares, reduzida quantidade de fibra e de precário valor nutricional. Os autores destacam, entre esses tipos de alimentos, os pães, doces, balas, gomas de mascar, bombons, sorvetes, refrigerantes e tabletes de chocolates. No que se refere ao estado nutricional dos adolescentes, os resultados revelaram prevalência (19,8\%) elevada de risco para o sobrepeso (Carvalho et al., 2001).

Pesquisa sobre obesidade infantil envolvendo 10.821 estudantes com idade entre 7 e 10 anos, matriculados em escolas públicas e privadas da cidade de Santos - SP revelou que, $15,74 \%$ das crianças apresentam sobrepeso e 17,97\% classificadas como obesas. O autor esclarece que a parcela de crianças com excesso de peso supera em muito a proporção de 5\% considerada aceitável para todas as faixas etárias (Fisberg, 2005a). 
Ainda segundo o referido autor, a incidência da obesidade é maior entre os alunos das escolas particulares (25,0\%), quando se compara com os dados obtidos junto aos estudantes das instituições de ensino público (15,5\%). Também foi possível identificar que o problema afeta cerca de 20,3\% das crianças do gênero masculino e 15,8\% do gênero feminino.

No Centro de Atendimento e Apoio ao Adolescente (CAAA) da Universidade Federal de São Paulo - UNIFESP, durante período de dois anos, foram observados 175 adolescentes obesos (Índice de Massa Corporal - IMC = 30). De acordo com os autores, foi possível verificar que os principais problemas identificados na alimentação dos adolescentes foram: a omissão de refeições, principalmente o café da manhã; ingestão elevada de refrigerantes (em torno de 1 litro/dia); lanches com expressiva densidade energética (normalmente salgadinhos fritos, chips, bolachas recheadas, chocolate e balas); baixa ingestão de frutas e hortaliças; substituições das principais refeições por lanches e compulsão alimentar (Cintra et al., 2001).

Pesquisa realizada por Monge-Rojas (2001), envolvendo 328 adolescentes, (167 meninos e 161 meninas), com idade entre 12 e 19 anos (52\% dos adolescentes da área urbana e 48\% da área rural), de San José (Costa Rica), visou a avaliação do consumo alimentar como fator de risco para doenças cardiovasculares. $\mathrm{O}$ autor verificou que cerca de $30 \%$ dos adolescentes possuíam consumo que excedia às recomendações preconizadas pela American Heart Association - AHA, especialmente quando se analisou o conteúdo de lipídio (total) e lipídio saturado presentes na dieta. Cerca de 50\% dos adolescentes apresentaram consumo de colesterol superior a 100 mg/1000 kcal. Em média, 45\% dos adolescentes não adotavam práticas alimentares que atendiam a recomendação (10 g/1000 kcal) de fibras na dieta. O autor também verificou que é maior a proporção de adolescentes da área urbana que não satisfaz a recomendação dietética preconizada para que a atuação seja mais efetiva no processo de prevenção de doenças cardiovasculares.

Sichieri et al. (1994), relatam que no Brasil as análises tendo por base os dados da Pesquisa Nacional sobre Saúde e Nutrição - PNSN (1990) mostraram que a prevalência de sobrepeso entre adolescentes, no início da década de 90 já merecia 
atenção, especialmente quando se considera as meninas moradoras da Região Sul do país e pertencentes às famílias com renda familiar per capita superior a 2,2 salários mínimos. Esse grupo revelou Índices de Massa Corporal - IMC maiores quando são comparados os resultados da pesquisa brasileira com os dados obtidos para o grupo (características como gênero, idade e renda familiar per capita similares) avaliado nos Estados Unidos, por meio da pesquisa intitulada Second National Health and Nutrition Examination Survey - NHANES durante o período de 1976 a 1980.

O estado nutricional da população, de acordo com dados divulgados pelo Ministério da Saúde (2002) é um excelente indicador de saúde e qualidade de vida, refletindo o modelo de desenvolvimento de uma determinada sociedade.

Pesquisa visando a avaliação do estado nutricional de 784 crianças e adolescentes (considerados sadios) institucionalizados, de ambos os gêneros, com idade entre 5 meses e 15 anos, mostrou que o grupo formado pelos pré-escolares e escolares reunia 14,76\% de indivíduos com sobrepeso, com diagnóstico de nanismo 4,58\%, 4,37\% com emaciação e 1,24\% sobrepeso e nanismo. Entre os adolescentes, foi verificado que $22,11 \%$ apresentam risco de sobrepeso e sobrepeso, 5,53\% magreza e baixo peso e 2,01\% identificados com nanismo (Ochsenhofer et al., 2004).

Ainda com relação ao estado nutricional de crianças e adolescentes, cabe lembrar que, trabalho de Silva et al. (2002), tendo como foco principal o estado nutricional, com prioridade para a identificação da prevalência de déficits de altura (adoção de escore $Z$ de altura para idade -ZAI < -2 como nível crítico para diagnóstico da proporção de alunos com baixa estatura para a idade) e tendo por base as informações da mesma amostra de alunos (cujos dados sobre consumo alimentar mereceram análises pormenorizadas na presente dissertação), pertencente as escolas públicas de dez municípios brasileiros revelou que, de forma geral, a proporção foi de 6,3. No entanto, a distribuição se revelou heterogênea sendo que, as maiores concentrações de déficits de altura foram observadas, conforme expectativa, nas cidades das Regiões Norte e Nordeste, consideradas as mais pobres do país. Nessas regiões os maiores percentuais (10,8\% e $27,1 \%$ observados entre os alunos das escolas central e periférica, respectivamente) foram identificados no município de Abaetetuba - Pará. No estado do 
Piauí, na cidade de Brasileira foi encontrada prevalência de 19,6\%, enquanto em Parnaíba, os valores observados foram de 16,0\% e 15,4\%, entre os alunos das escolas localizadas na região central e periférica, respectivamente. Ainda no que se refere aos déficits de altura, na cidade de Ponte Serrada (SC), 6,1\% de escolares, pertencentes a unidade de ensino da região central do município, apresentaram ZAI $<-2$, enquanto, na escola da periferia, apenas 1,3\% (proporção inferior à esperada) dos alunos foram classificados com baixa altura para a idade. Vale frisar que na época do levantamento dos dados, Ponte Serrada era considerado um dos municípios mais pobres do estado de Santa Catarina.

Sturion (2002) analisando a distribuição dos percentis do IMC obtidos tendo por base amostra de escolares observou 12,9\% de indivíduos classificados entre o $85^{\circ} \mathrm{P}$ e $95^{\circ} \mathrm{P}$ e, $6,3 \%$ com IMC pelo menos igual ao $95^{\circ} \mathrm{P}$. Vale lembrar que os valores esperados, quando se adota uma população de referência são, $10 \%$ e 5\%, respectivamente nos intervalos considerados pelo autor. Ainda de acordo com esse autor, quando se adotou o intervalo compreendido pelos valores do $85^{\circ} \mathrm{P}$ e $95^{\circ} \mathrm{P}$, foi observada proporção, acima da esperada, entre os escolares das unidades de ensino centrais de Abaetetuba (PA), Baldim (MG), Anápolis (GO) e Joinville (SC) e da unidade localizada na periferia de Contagem (MG). Na totalidade das escolas de Parnaíba (PI) e Ponte Serrada (SC), situação similar foi verificada.

A situação de substancial parcela da população de vários municípios nordestinos merece atenção particular e prioritária, tendo em vista que a Região Nordeste apresenta níveis de miséria e de pobreza substancialmente mais elevados, qualquer que seja a área analisada (rural, urbana, metropolitana) em relação à demais regiões do Brasil.

Dados apresentados por Hoffmann (1994) e Mello (1996) mostram que é também no nordeste do País onde foram identificadas as maiores proporções de desnutrição entre a população infantil. Da mesma maneira que o índice de pobreza, a situação nutricional revelou que, a prevalência de desnutrição no Nordeste era o dobro da proporção observada nas demais regiões (exceção do Norte que apresenta um perfil 
semelhante ao Nordeste). O Centro-Oeste exibe situação semelhante a Região Sudeste, enquanto as condições mais favoráveis são freqüentemente identificadas na Região Sul.

É importante ressaltar que invariavelmente a insuficiência de alimentos, associada ao baixíssimo poder aquisitivo de parte da população brasileira e ainda, o acesso, muitas vezes precário aos serviços de saúde, se manifesta em indicadores antropométricos de desnutrição (Hoffmann, 1994).

Cabe registrar que, embora tenham sido observadas mudanças positivas na maioria dos indicadores de saúde da população brasileira, quando se considera os últimos quinze anos, persistem inúmeros desafios, merecendo especial atenção os dados relativos à transição nutricional. 


\section{MATERIAL E MÉTODOS}

\subsection{Definição da amostra}

Inicialmente, realizou-se o sorteio de cinco estados que necessariamente deveriam pertencer a cada uma das grandes regiões geográficas do país. Dentre a totalidade dos estados brasileiros, obteve-se os estados do Pará (Região Norte), Piauí (Região Nordeste), Goiás (Região Centro-Oeste), Minas Gerais (Região Sudeste) e Santa Catarina (Região Sul). Em seguida, foram escolhidos dois municípios que representassem, na amostra $(n=10)$ cada um dos estados sorteados.

Na escolha dos municípios foi considerada a situação relativa a participação dos municípios no processo de municipalização do Programa de Alimentação Escolar, em fase de implantação, na época do início da pesquisa. Considerou-se também o fato de pelo menos um município (a ser incluído na pesquisa) manter um programa social, de preferência financiado e/ou coordenado pelo Governo Federal. No caso, optou-se por considerar o Programa Comunidade Solidária, que no período da realização da pesquisa, era implementado, majoritariamente nos municípios mais pobres, freqüentemente, em parceria com instituições, como exemplos Organizações Não-Governamentais (ONGs), empresas e sindicatos.

Devido à ampla diversidade do contingente populacional, presente nos municípios brasileiros, efetuou-se a classificação dos mesmos, de acordo com o número de habitantes.

É importante considerar que, a variável populacional, interfere, decisivamente, entre outros aspectos, na estrutura gerencial de programas e/ou serviços, especialmente aqueles que envolvem aquisição, preparo e distribuição de alimentos, como é o caso típico do Programa de Alimentação Escolar. 
Tendo por base a listagem disponível, em 1997, dos 4974 municípios brasileiros e sua respectiva população, publicada pelo Instituto Brasileiro de Geografia e Estatística - IBGE, elaborou-se um software específico, para ordenar os municípios, de cada um dos cinco estados, conforme o número de habitantes.

Na sequência, considerando a ordenação, em cada estado, foram selecionados dois municípios, sendo um de grande porte e o outro de pequeno porte. Esclarece-se que os municípios de grande porte, previstos para integrarem a amostra, foram selecionados entre os três mais populosos, excluindo-se a capital, em cada um dos cinco estados sorteados.

Para a realização da pesquisa buscou-se, o consentimento dos prefeitos que, previamente receberam documentos elaborados pelos responsáveis, contendo informações sobre os objetivos da pesquisa e esclarecimento sobre a utilização futura dos dados a serem obtidos.

A seguir apresenta-se o grupamento de municípios integrantes da amostra e algumas características demográficas e socioeconômicas selecionadas (Quadro 1). 


\begin{tabular}{|c|c|c|c|c|c|c|c|c|c|c|}
\hline \multirow[b]{2}{*}{ Características } & \multicolumn{10}{|c|}{ Municípios } \\
\hline & $\begin{array}{c}\text { Parnaíba } \\
\text { (PI) }\end{array}$ & \begin{tabular}{|c} 
Brasileira $^{(2)}$ \\
(PI)
\end{tabular} & $\begin{array}{c}\text { Abaetetuba } \\
\text { (PA) }\end{array}$ & $\begin{array}{l}\text { Tailândia } \\
\text { (PA) }\end{array}$ & $\begin{array}{l}\text { Contagem } \\
(\mathrm{MG})\end{array}$ & $\begin{array}{c}\text { Baldim } \\
\text { (MG) }\end{array}$ & $\begin{array}{l}\text { Anápolis } \\
\text { (GO) }\end{array}$ & $\begin{array}{c}\text { Itaguarú } \\
(\mathrm{GO})\end{array}$ & $\begin{array}{c}\text { Joinville } \\
\text { (SC) }\end{array}$ & $\begin{array}{l}\text { P.Serrada } \\
\text { (SC) }\end{array}$ \\
\hline População & 127929 & 8162 & 99989 & 17707 & 449588 & 8383 & 239378 & 6450 & 347151 & 12259 \\
\hline $\begin{array}{l}\text { População de } 7 \text { a } 14 \\
\text { anos }\end{array}$ & 27016 & --- & 23897 & 3888 & 82195 & 1532 & 42693 & 1271 & 61171 & 2356 \\
\hline $\begin{array}{l}\text { Taxa de analfabetismo } \\
\text { ( } 7 \text { a } 14 \text { anos) }\end{array}$ & 25,1 & --- & 29,1 & 46,7 & 3,7 & 5,4 & 4,8 & 8,9 & 1,5 & 5,1 \\
\hline $\begin{array}{l}\text { Índice de Condições } \\
\text { de Sobrevivência - } \\
\text { (ICS) }^{(3)} \\
\text { Número de Domicílios } \\
\text { Particulares: }\end{array}$ & 0,32 & --- & 0,46 & 0,46 & 0,11 & 0,38 & 0,2 & 0,37 & 0,1 & 0,51 \\
\hline Urbanos & 21313 & --- & 9550 & 1897 & 101052 & 1096 & 57244 & 982 & 83242 & 1387 \\
\hline $\begin{array}{l}\text { Rurais } \\
\text { Proporção de } \\
\text { Domićllios: }\end{array}$ & 4348 & --- & 6874 & 1580 & 6136 & 904 & 2949 & 614 & 2957 & 1569 \\
\hline $\begin{array}{l}\text { Com abastecimento de } \\
\text { água inadequado }\end{array}$ & 48,5 & --- & 60,5 & 93,8 & 8,0 & 34,3 & 15,9 & 41,5 & 4,2 & 22,3 \\
\hline $\begin{array}{l}\text { Com esgotamento } \\
\text { sanitário inadequado }\end{array}$ & 99,9 & --- & 99,9 & 95,3 & 38,4 & 63,1 & 60,1 & 100 & 17,6 & 99,1 \\
\hline
\end{tabular}

Quadro 1 - Distribuição dos municípios integrantes da amostra, de acordo com algumas características socioeconômicas e demográficas, $1997^{(1)}$ 


\begin{tabular}{|c|c|c|c|c|c|c|c|c|c|c|}
\hline \multirow[b]{2}{*}{ Características } & \multicolumn{10}{|c|}{ Municípios } \\
\hline & $\begin{array}{l}\text { Parnaíba } \\
(\mathrm{PI})\end{array}$ & $\begin{array}{c}\text { Brasileira }^{(2)} \\
(\mathrm{PI})\end{array}$ & $\begin{array}{c}\text { Abaetetuba } \\
\text { (PA) }\end{array}$ & $\begin{array}{l}\text { Tailândia } \\
\text { (PA) }\end{array}$ & $\begin{array}{l}\text { Contagem } \\
\text { (MG) }\end{array}$ & $\begin{array}{l}\text { Baldim } \\
\text { (MG) }\end{array}$ & $\begin{array}{l}\text { Anápolis } \\
\text { (GO) }\end{array}$ & $\begin{array}{c}\text { Itaguarú } \\
\text { (GO) }\end{array}$ & $\begin{array}{c}\text { Joinville } \\
\text { (SC) }\end{array}$ & $\begin{array}{l}\text { P.Serrada } \\
(\mathrm{SC})\end{array}$ \\
\hline \multicolumn{11}{|l|}{$\begin{array}{l}\text { Proporção de chefes } \\
\text { de família com renda } \\
\text { mensal: }\end{array}$} \\
\hline Até $1 / 2$ salário mínimo & 20,8 & --- & 15,4 & 5,1 & 8,4 & 27,0 & 11,9 & 18,7 & 6,7 & 2,1 \\
\hline & & --- & 43,6 & 25,5 & 25,5 & 66,0 & 33,7 & 43,9 & 14,0 & 47,0 \\
\hline $\begin{array}{l}\text { Mais de } 2 \text { salários } \\
\text { mínimos }\end{array}$ & 19,1 & --- & 24,0 & 31,5 & 48,4 & 17,4 & 39,4 & 24,3 & 65,1 & 21,1 \\
\hline $\begin{array}{l}\text { Proporção de chefes } \\
\text { de famílias: }\end{array}$ & & & & & & & & & & \\
\hline analfabetos & 41,3 & --- & 35,4 & 43,7 & 10,3 & 29,7 & 17,4 & 35,5 & 6,1 & 21,1 \\
\hline mulheres & 21,7 & --- & 11,8 & 6,6 & 18,1 & 24,2 & 20,5 & 15,9 & 12,9 & 10,4 \\
\hline
\end{tabular}

Quadro 1 - Distribuição dos municípios integrantes da amostra, de acordo com algumas características socioeconômicas e demográficas, $1997^{(1)}$

${ }^{(1)}$ Fonte: IBGE (1991) e IBGE (1997), citado por Silva et al. (2002)

(2) Município criado após o censo, realizado pelo IBGE, em 1991. No entanto, de acordo com o FNDE (2002), o município de Brasileira, possuía uma área de $910 \mathrm{~km}^{2}$, com população total de 7366 habitantes e densidade populacional de 8,10 habitantes por km². O município possuia 25 escolas (municipais) e duas de ensino fundamental. O número de alunos matriculados em 2002 alcançou o total de 1952 (197 pré-escolares e 1755 no ensino fundamental e outros)

${ }^{(3)}$ ICS = Índice de Condições de Sobrevivência (IBGE, 1994) - refere-se a hierarquização das Unidades da Federação e respectivos municípios com base num índice que incorpora variáveis que refletem, em grande medida, as condições de sobrevivência das crianças até 6 anos (Sturion, 2002). 
Na seqüência foi implementada a seleção das escolas. Para tanto, efetuou-se o sorteio de duas unidades de ensino, em cada um dos cinco municípios selecionados, pertencentes a rede oficial, com oferecimento de ensino gratuito e que atendessem alunos com idade entre 7 e 14 anos e cuja localização contemplasse a representação dos estabelecimentos situados na região central e periférica do município, respectivamente.

Vale ressaltar que nesta pesquisa não houve a participação de escolas situadas na zona rural.

Cabe mencionar que os conjuntos dos 10 municípios integram uma amostra de conveniência.

\subsection{População de estudo}

Em cada uma das vinte escolas foram sorteados 120 alunos, com idade entre 7 e 14 anos, por ser esse grupo formado pelos indivíduos considerados “público-alvo” pela legislação relativa ao Programa Nacional de Alimentação do Escolar - PNAE.

Em cada uma das unidades de ensino foram sorteados 80 alunos pertencentes as quatro primeiras séries (faixa de idade esperada 7 a 10 anos). Desse número ( $n=80)$, 20 são representantes de cada uma das quatro séries iniciais. O mesmo procedimento foi adotado para a identificação de 40 alunos com idade entre 11 e 14 anos, matriculados em cada uma das séries mais avançadas (quinta a oitavas séries) e que eram mantidas por parte das 20 escolas.

O fato do número de indivíduos, integrantes da amostra, com idade entre 11 e 14 anos ser menor é justificado por ser também reduzida a participação desses alunos na rede pública de ensino, situação decorrente da evasão escolar, ainda verificada no país, especialmente nas regiões mais pobres.

Buscou-se assegurar também, durante o processo de seleção dos alunos, a participação proporcional (50\%) de alunos de cada gênero. Os alunos foram sorteados em sala de aula, de maneira alternada, adotando-se como referência a lista de freqüência utilizada pelo professor. 
A seguir são apresentadas algumas informações que possibilitam caracterizar as unidades de ensino e o grupo de alunos que integram a pesquisa (Quadro 2). 


\begin{tabular}{|c|c|c|c|c|}
\hline \multirow{2}{*}{ Município/Estado } & \multirow{2}{*}{$\begin{array}{l}\text { Porte do } \\
\text { município }\end{array}$} & \multirow{2}{*}{$\begin{array}{c}\mathrm{N}^{\mathrm{o}} \mathrm{de} \\
\text { Matriculados }^{(*)}\end{array}$} & \multicolumn{2}{|c|}{$\begin{array}{c}\text { Alunos selecionados para a } \\
\text { pesquisa }\end{array}$} \\
\hline & & & $\mathrm{N}^{\mathrm{o}}$ & $\%$ \\
\hline $\begin{array}{l}\text { Anápolis (GO) } \\
\text { E.E. Virgínio Santillo }{ }^{(1,3)} \\
\text { E.E. Valdemar Cavalcanti } \\
(2,3)\end{array}$ & Grande & $\begin{array}{r}1251 \\
674\end{array}$ & $\begin{array}{l}79 \\
65\end{array}$ & $\begin{array}{l}5,6 \\
4,6\end{array}$ \\
\hline $\begin{array}{l}\text { Itaguaru (GO) } \\
\text { E.E Artur C. e Silva }{ }^{(1,3)} \\
\text { E.E. Dr. Ary R. V. Filho } \\
(2,3)\end{array}$ & Pequeno & $\begin{array}{l}507 \\
376\end{array}$ & $\begin{array}{l}71 \\
67\end{array}$ & $\begin{array}{l}5,0 \\
4,8\end{array}$ \\
\hline $\begin{array}{l}\text { Baldim (MG) } \\
\text { E.E. São Bernardo }{ }^{(1,3)} \\
\text { E.E. Oscar A. Guimarães }{ }^{(2,3)}\end{array}$ & Pequeno & $\begin{array}{l}317 \\
358\end{array}$ & $\begin{array}{l}70 \\
75\end{array}$ & $\begin{array}{l}5,0 \\
5,3\end{array}$ \\
\hline $\begin{array}{l}\text { Contagem (MG) } \\
\text { E.E Francisco F. Matos }{ }^{(1,3)} \\
\text { E.E. Elza M. Fouly }(2,3)\end{array}$ & Grande & $\begin{array}{r}1204 \\
567\end{array}$ & $\begin{array}{r}130 \\
80\end{array}$ & $\begin{array}{l}9,2 \\
5,7\end{array}$ \\
\hline $\begin{array}{l}\text { Abaetetuba (PA) } \\
\text { E.E. Basílio de Carvalho }{ }^{(1,3)} \\
\text { E.E. Esmeralda Cardoso } \\
(2,4)\end{array}$ & Grande & $\begin{array}{r}1105 \\
444\end{array}$ & $\begin{array}{l}83 \\
85\end{array}$ & $\begin{array}{l}5,9 \\
6,0\end{array}$ \\
\hline $\begin{array}{l}\text { Tailândia (PA) } \\
\text { E.E. Gabriel L. Silva }{ }^{(1,3)} \\
\text { E.E. J. Manoel de Araújo }{ }^{(2,3,5)}\end{array}$ & Pequeno & $\begin{array}{l}1242 \\
1685\end{array}$ & $\begin{array}{l}80 \\
42\end{array}$ & $\begin{array}{l}5,7 \\
3,0\end{array}$ \\
\hline $\begin{array}{l}\text { Brasileira (PI) } \\
\text { E.E. G.L.S.M. Carmosina }{ }^{(1,3)} \\
\text { E.E. Alberto T. Silva } \\
(2,6)\end{array}$ & Pequeno & $\begin{array}{l}304 \\
136\end{array}$ & $\begin{array}{r}76 \\
-\end{array}$ & $\begin{array}{l}5,4 \\
-\end{array}$ \\
\hline $\begin{array}{l}\text { Parnaíba (PI) } \\
\text { E.E. Conselheiro L. Couto }{ }^{(1,3)} \\
\text { E.E. Albertina F. C. Araújo } \\
(2,4)\end{array}$ & Grande & $\begin{array}{r}445 \\
1453\end{array}$ & $\begin{array}{l}50 \\
65\end{array}$ & $\begin{array}{l}3,5 \\
4,6\end{array}$ \\
\hline $\begin{array}{l}\text { Joinville (SC) } \\
\text { E.E. Conselheiro Mafra }{ }^{(1,3)} \\
\text { E.E. Plácido X. Vieira }{ }^{(2,3)}\end{array}$ & Grande & $\begin{array}{l}714 \\
572\end{array}$ & $\begin{array}{l}67 \\
62\end{array}$ & $\begin{array}{l}4,8 \\
4,4\end{array}$ \\
\hline $\begin{array}{l}\text { Ponte Serrada (SC) } \\
\text { E.E. Dom Vital } \\
\text { E.E. António Paglia }^{(2,3)}\end{array}$ & Pequeno & $\begin{array}{l}719 \\
571\end{array}$ & $\begin{array}{l}82 \\
80\end{array}$ & $\begin{array}{l}5,8 \\
5,7\end{array}$ \\
\hline Total & & 14.644 & $1409[9,6]$ & 100,0 \\
\hline
\end{tabular}

Quadro 2 - Distribuição das unidades de ensino de acordo com o porte, número de alunos matriculados e grupo selecionado para a pesquisa, 1997

OBS.: - os traços significam que os alunos da unidade de ensino não participaram da pesquisa, por terem sido dispensados das aulas (falta de água e gás) no dia programado para a coleta de dados.

- o número entre colchete significa o percentual em relação ao total $(n=14.644)$ de alunos matriculados nas escolas.

${ }^{(*)}$ Número de alunos matriculados fornecidos pela direção da escola.

${ }^{1}$ Escola situada na região central do município.

${ }^{2}$ Escola situada na periferia do município.

${ }^{3}$ Escolas que possuíam classes de $1^{\mathrm{a}}$ a $8^{\mathrm{a}}$ séries.

${ }^{4}$ Escolas que possuíam classes de $1^{\mathrm{a}}$ a $4^{\mathrm{a}}$ séries.

${ }^{5}$ Escola que possuía classe de $2^{\underline{a}}$ a $8^{\underline{a}}$ séries e também o ensino médio.

${ }^{6}$ Escola que possuía classes de $5^{\frac{a}{a}}$ a $8^{\mathrm{a}}$ séries. 


\subsection{Obtenção e análise dos dados}

\subsubsection{Estado nutricional}

Para avaliar o estado nutricional dos alunos, foram tomadas as medidas antropométricas de peso e altura, utilizando-se balança com capacidade máxima de 120 quilogramas e sensibilidade de um quilograma. Os escolares, pertencentes à amostra, foram pesados e medidos pelos integrantes da equipe, que receberam treinamento específico para as atividades de coleta da totalidade dos dados da pesquisa.

A altura foi obtida com os estudantes em posição ereta, pés (descalços) unidos e em paralelo. Utilizou-se uma fita métrica, afixada na parede, e esquadro, que foi firmemente apoiado sobre a cabeça, assegurando-se que o aluno encontrava-se na posição correta para proceder-se à leitura e registro da altura obtida.

Também foi analisada a distribuição dos percentis do Índice de Massa Corporal - IMC ou Índice de Quetelet, obtido por meio da expressão IMC = peso (kg) / [altura $\left.(\mathrm{m})^{2}\right]$.

De acordo com a recomendação da Organização Mundial da Saúde (WHO, 1995) adotou-se os seguintes níveis críticos: IMC $<5^{\circ}$ Percentil, $5^{\circ}$ Percentil $\leq$ IMC $<$ $95^{\circ}$ Percentil e IMC $\geq 95^{\circ}$ Percentil e o padrão de referência preconizado pelo Center Disease Control and Prevention - National Center for Health Statistics - NCHS (2002).

\subsubsection{Consumo alimentar}

Os dados referentes ao consumo alimentar foram obtidos por meio da aplicação de um formulário específico, onde foi registrada a quantidade de todos os alimentos consumidos, de acordo com a informação fornecida, pelos escolares (Anexo A).

As informações relativas ao consumo de alimentos foram coletadas durante o segundo semestre de 1997, por meio de entrevistas realizadas, no âmbito das unidades de ensino, por equipes formadas por nutricionistas e economistas domésticos, previamente treinados. Para a obtenção dos dados foi utilizado o método Recordatório 
24 horas (considerou-se todos os alimentos consumidos pelos alunos no ambiente familiar, como também em outros locais), que baseia-se na definição e quantificação da totalidade dos alimentos e bebidas consumidos no período anterior à entrevista (24 horas) ou geralmente, o dia anterior à obtenção dos dados.

Os alimentos foram registrados, em medidas caseiras, adotando-se formulário próprio, atentando-se para a discriminação das refeições (café da manhã, lanche da manhã, almoço, lanche da tarde ou merenda, jantar e lanche noturno), horário e local de consumo dos alimentos (Lerner, 1994; Mahan \& Arlin, 1994 e Silva, 1998). Com o objetivo de efetuar, de maneira apropriada o registro da quantidade dos alimentos consumidos foi utilizado um Modelo de Medidas de Utensílios Caseiros (Anexo B).

Tendo por base a metodologia adotada por pesquisadores nacionais e internacionais, pode se afirmar que o método Recordatório 24 horas tem sido o instrumento mais utilizado para a avaliação da ingestão de alimentos pelos indivíduos. Pesquisas, consideradas de grande porte, conduzida por Galeazzi et al. (1997), intitulada Estudo Multicêntrico e a pesquisa "Saúde e nutrição das crianças de São Paulo" (Monteiro, 1988) adotaram o Recordatório 24 horas para a obtenção das informações dietéticas (Villar, 2001).

Cabe registrar que, embora o referido método possibilite o envolvimento de erro, por não contemplar as variações diárias intra e inter indivíduos e ser dependente da memória do entrevistado, a opção pela adoção do método justifica-se pelo fato de ser um recurso útil para estimar a ingestão de alimentos ou nutrientes por grupos populacionais, uma vez que a quantidade média por eles ingerida não varia significativamente de um dia para o outro (Nelson, 1991).

O conteúdo de energia e nutrientes da dieta dos escolares foi calculado, adotando-se o software Virtual Nutri (Philippi et al., 1996).

É importante registrar que para a participação dos escolares na pesquisa foi solicitada prévia autorização dos pais/responsáveis por meio de correspondência contendo clara descrição dos objetivos e abrangência da pesquisa, acompanhada de um termo de consentimento livre e esclarecido. 


\subsubsection{Análise do consumo alimentar}

A pesquisa reserva destaque, entre os seus objetivos para a análise da dieta dos escolares por meio da identificação da participação dos macronutrientes (carboidratos, proteínas e lipídios) no Valor Energético Total - VET.

Tendo como referência a mais recente publicação Dietary Reference Intakes DRIs, elaborada pelo Institute of Medicine National Academy of Sciences (2000) é interessante descrever, de forma resumida, alguns dos argumentos que motivaram o referido órgão para a definição dos novos parâmetros, que foram adotados na presente pesquisa. A referida publicação registra que, “quando o consumo de gordura é baixo e a ingestão de carboidratos elevada, estudos intervencionais, tendo como apoio as pesquisas epidemiológicas, demonstraram uma redução na concentração plasmática de colesterol HDL, um aumento no plasma de colesterol total e da concentração de triacilgliceróis, condições que estão fortemente associados com a elevação do risco de doenças cardíacas coronarianas”. Também são apresentados resultados de estudos intervencionais que revelaram ingestão de gordura elevada, que freqüentemente estimula muitos indivíduos para o consumo de energia adicional e conseqüentemente, há ganho de peso. O ganho de peso condicionado pelas dietas ricas em gordura pode ser prejudicial para os indivíduos com predisposição à obesidade e, também, intensifica as conseqüências metabólicas da obesidade, particularmente, o risco de doenças coronarianas. Além disso, dietas ricas em gordura são geralmente acompanhadas por consumo aumentado de ácidos graxos saturados que podem elevar as concentrações plasmáticas do colesterol LDL e favorecer o aumento do risco de doenças coronarianas. Tendo por base o conjunto de evidências, foram propostos os novos parâmetros, no tocante a participação dos macronutrientes no Valor Energético Total da dieta. Para adultos foram preconizados os seguintes intervalos: 20\% - 35\% (lipídios); 45\% - 65\% (carboidratos) e 10\% - 35\% (proteínas).

Especialmente para o grupo de menor idade (infantil), há evidências que apontam para a maior taxa de oxidação de gordura, quando se compara com as situações observadas entre os adultos e que a ingestão reduzida de certos macronutrientes pode 
ocorrer com o consumo de dietas pobres em gordura, ao passo que há risco potencial de obesidade, com a expressiva ingestão de gordura (que pode ainda aumentar o risco de obesidade e doenças coronarianas).

Tendo por base a argumentação, foram registrados, na publicação intitulada Dietary Reference Intake - DRIs, para os indivíduos com idade entre 4 e 18 anos os seguintes intervalos (aceitáveis), para a participação dos macronutrientes na dieta: 25\% 35\% (lipídios); 45\% - 65\% (carboidratos) e 10\% - 30\% (proteínas).

Considerando que, os escolares que integram a amostra da pesquisa possuíam idade entre 6 e 13 anos, foram adotados os mesmos intervalos, descritos anteriormente.

Desse modo, na presente pesquisa, a dieta foi classificada como adequada ao revelar conformidade da participação concomitante dos três macronutrientes (lipídios, carboidratos e proteínas), com os intervalos preconizados para os estratos de idade dos alunos integrantes da pesquisa.

\subsubsection{Análises estatísticas}

Na pesquisa a totalidade dos cálculos, tendo em vista a elaboração das análises descritivas, da distribuição dos percentis de consumo energético, assim como também os cálculos das medidas, como médias, desvios-padrão, valores mínimos e máximos, foram efetuados, utilizando-se o software Statistics Analysis System - SAS (1998).

Para a análise da distribuição dos percentis do IMC adotou-se software específico, desenvolvido com exclusividade para viabilizar os cálculos necessários para a concretização da pesquisa. 


\section{RESULTADOS E DISCUSSÃO}

Antecedendo a apresentação dos resultados da pesquisa cabe lembrar que foram selecionados 1409 alunos para a composição da amostra, conforme anteriormente apresentado no quadro 2. Para a totalidade dos alunos foi possível a obtenção dos dados antropométricos (peso e altura) que integram diversas análises da dissertação.

No entanto ocorreram algumas perdas e invalidações de algumas observações, decorrentes do fato da não aquiescência dos pais e/ou estudantes para participarem das entrevistas que visavam a obtenção de dados relativos ao consumo alimentar e/ou pelo fato dos alunos não estarem presentes, na escola, no dia programado para a coleta de dados.

Desse modo a amostra para os quais dispõe-se da totalidade dos dados reúne 1325 alunos.

A seguir, apresenta a Tabela 1, contendo informações sobre o número de participantes da pesquisa e os resultados relativos as características da distribuição do Valor Energético Total - VET da dieta dos escolares. 
Tabela 1. Características da distribuição do Valor Energético Total (VET) da dieta de escolares da rede pública de ensino, conforme Município de origem, 1997

\begin{tabular}{l|r|r|c|c|c|c}
\hline \multirow{2}{*}{$\begin{array}{c}\text { Município/ } \\
\text { Estado }\end{array}$} & \multicolumn{2}{c|}{ Escolares } & \multicolumn{3}{c}{ Valor Energético Total - VET } \\
\cline { 2 - 7 } & $\mathrm{N}^{\mathrm{N}}$ & $\%$ & $\begin{array}{c}\text { Média de } \\
\text { Energia } \\
(\mathrm{kcal})\end{array}$ & $\begin{array}{c}\text { Desvio } \\
\text { Padrão }\end{array}$ & $\begin{array}{c}\text { Valor } \\
\text { Mínimo }\end{array}$ & $\begin{array}{c}\text { Valor } \\
\text { Máximo }\end{array}$ \\
\hline Parnaíba - PI & 110 & 8,3 & 1297,0 & 335,3 & 617,3 & 2326,8 \\
Brasileira - PI & 76 & 5,7 & 1236,3 & 335,2 & 601,1 & 2180,6 \\
Abaetetuba - PA & 147 & 11,1 & 1610,7 & 532,7 & 713,1 & 4327,7 \\
Tailândia - PA & 80 & 6,0 & 1780,2 & 615,1 & 673,1 & 3338,4 \\
Contagem - MG & 201 & 15,2 & 1519,2 & 370,4 & 813,8 & 2832,9 \\
Baldim - MG & 143 & 10,8 & 1454,6 & 400,7 & 790,3 & 3312,2 \\
Anápolis - GO & 144 & 10,9 & 1698,7 & 501,9 & 813,4 & 5196,3 \\
Itaguarú - GO & 135 & 10,2 & 1569,4 & 457,6 & 725,7 & 3375,0 \\
Joinville - SC & 129 & 9,7 & 1218,6 & 283,2 & 754,5 & 2220,8 \\
Ponte Serrada - SC & 160 & 12,1 & 1506,0 & 434,0 & 796,1 & 2857,3 \\
GERAL & 1325 & 100,0 & 1503,4 & 457,6 & 601,1 & 5196,3 \\
\hline
\end{tabular}


Ao examinar os dados da Tabela 1, observa-se que, de forma geral o consumo médio de energia (1503,4 kcal) dos escolares, se revela muito menor, quando são consideradas as recomendações definidas para o grupo, e tendo como referência os valores publicados pelo National Research Council - NRC (1989).

É importante destacar que, segundo Silva (2000), o valor energético sendo insuficiente, a proteína será, em parte, utilizada como fonte energética, comprometendo a sua participação na síntese orgânica.

Portanto é fundamental que as recomendações de energia estejam adequadas às necessidades estimadas, para se evitar o risco de desnutrição como também a ingestão excessiva que pode propiciar o sobrepeso e a obesidade (González, 2002).

É importante observar (Tabela 1) que ao estabelecer comparações entre os dados obtidos para os alunos do município de Joinville, que pertence a uma das regiões mais ricas do país - Região Sul, com as informações levantadas nos demais municípios, verificou-se que os escolares apresentaram um consumo energético menor (1218,6 kcal). Note-se que esse valor é inferior ao consumido pelos escolares das cidades de Brasileira, (1236,3 kcal) e Parnaíba (1297,0 kcal), ambas representantes, na presente pesquisa da Região Nordeste (considerada a mais pobre do país).

Examinando os valores mais elevados (valor máximo) de consumo energético se depara com um dado surpreendente obtido no município de Anápolis - GO. Nesse caso foi possível encontrar o valor de 5196,3 kcal (o maior observado), quando se compara com a totalidade dos valores verificados e ainda, muito superiores à média de consumo de energia identificado (1503,4 kcal).

Vale lembrar que, segundo Krause \& Mahan (1985); Gagliardi (2001), a excessiva ingestão de energia pode resultar em obesidade, em decorrência do desequilíbrio entre consumo e gasto energético, pressupondo maior ingestão do que demanda energética.

Ainda de acordo com a Tabela 1 vale notar que ao analisar os dados relativos ao consumo mínimo de energia pelos escolares fica evidente a diversidade entre os grupos pertencentes aos dez municípios. O consumo é claramente menor (não 
alcançando $620 \mathrm{kcal}$ ) quando se considera os dados obtidos junto aos alunos das escolas das cidades nordestinas de Parnaíba e Brasileira.

Situação bastante desfavorável no tocante aos valores mínimos de consumo energético, foi verificada também entre os escolares de Joinville (754,5 kcal) e Ponte Serrada (796,1 kcal), municípios localizados na Região Sul do Brasil. Ainda assim, vale notar que os alunos de Ponte Serrada (cidade com elevado contingente de pobres) apresentaram consumo médio de energia ligeiramente superior.

Quando se analisa os valores de desvios-padrão é possível confirmar a grande variabilidade revelada pelo consumo dos escolares, especificamente no que se refere o conteúdo energético, um dos principais objetivos da pesquisa. Merece destaque os dados obtidos entre os alunos do município de Tailândia (Pará), cujo valor do desvio-padrão alcançou 615,1 kcal e Anápolis (Goiás), onde o desvio-padrão do conteúdo de energia (501,9 kcal) também se revelou elevado.

Tendo em vista a importância de análises complementares envolvendo a discriminação dos escolares, de acordo com os estratos de idade e gênero, elaborou-se a Tabela 2, apresentada a seguir. 
Tabela 2. Valores médios e desvios-padrão do Valor Energético Total - VET da dieta de escolares da rede pública de ensino, de acordo com o gênero, faixa de idade e município de origem, 1997

\begin{tabular}{|c|c|c|c|c|c|c|c|c|}
\hline \multirow{4}{*}{ Município/Estado } & \multirow{3}{*}{\multicolumn{2}{|c|}{ Escolares }} & \multicolumn{6}{|c|}{ Valor Energético Total - VET } \\
\hline & & & \multirow{3}{*}{$\begin{array}{l}\text { Média de Energia } \\
\text { (Kcal) }\end{array}$} & \multicolumn{5}{|c|}{ Gênero/Idade (em anos) } \\
\hline & & & & \multicolumn{2}{|c|}{ Masculino } & \multicolumn{3}{|c|}{ Feminino } \\
\hline & № & $\%$ & & $<9$ & \begin{tabular}{l|l|l|}
9 & -13 \\
\end{tabular} & $<9$ & 9 & -13 \\
\hline \multirow[t]{2}{*}{ Parnaíba (PI) } & 110 & 8,3 & 1297,0 & 1268,0 & 1276,5 & 1385,9 & & 1294,1 \\
\hline & & & $(335,3)$ & $(316,6)$ & $(352,8)$ & $(378,9)$ & & $(313,5)$ \\
\hline \multirow[t]{2}{*}{ Brasileira (PI) } & 76 & 5,7 & 1236,3 & 1254,6 & 1246,0 & 1279,8 & & 1178,8 \\
\hline & & & $(335,2)$ & $(232,9)$ & $(492,5)$ & $(191,1)$ & & $(235,1)$ \\
\hline \multirow[t]{2}{*}{ Abaetetuba (PA) } & 147 & 11,1 & 1610,7 & 1803,2 & 1803,2 & 1754,3 & & 1522,2 \\
\hline & & & $(532,7)$ & $(655,2)$ & $(655,2)$ & $(842,7)$ & & $(443,0)$ \\
\hline \multirow[t]{2}{*}{ Tailândia (PA) } & 80 & 6,0 & 1780,2 & 1756,4 & 1822,3 & 1809,1 & & 1720,8 \\
\hline & & & $(615,1)$ & $(527,1)$ & $(540,2)$ & $(665,5)$ & & $(733,1)$ \\
\hline \multirow[t]{2}{*}{ Contagem (MG) } & 201 & 15,2 & 1519,2 & 1588,9 & 1583,9 & 1439,2 & & 1392,9 \\
\hline & & & $(370,4)$ & $(325,1)$ & $(398,7)$ & $(312,1)$ & & $(317,3)$ \\
\hline \multirow[t]{2}{*}{ Baldim (MG) } & 143 & 10,8 & 1454,6 & 1712,1 & 1460,0 & 1270,9 & & 1447,3 \\
\hline & & & $(400,7)$ & $(344,3)$ & $(379,1)$ & $(321,4)$ & & $(456,2)$ \\
\hline \multirow[t]{2}{*}{ Anápolis (GO) } & 144 & 10,9 & 1698,7 & 1856,7 & 1620,1 & 1737,3 & & 1695,9 \\
\hline & & & $(501,9)$ & $(448,4)$ & $(412,6)$ & $(785,9)$ & & $(328,1)$ \\
\hline \multirow[t]{2}{*}{ Itaguarú (GO) } & 135 & 10,2 & 1569,4 & 1621,7 & 1649,9 & 1350,1 & & 1551,2 \\
\hline & & & $(457,6)$ & $(412,1)$ & $(479,2)$ & $(350,0)$ & & $(475,6)$ \\
\hline \multirow[t]{2}{*}{ Joinville (SC) } & 129 & 9,7 & 1218,6 & 1360,7 & 1287,5 & 1186,6 & & 1280,7 \\
\hline & & & $(283,2)$ & $(308,5)$ & $(283,5)$ & $(186,9)$ & & $(308,1)$ \\
\hline \multirow[t]{2}{*}{ Ponte Serrada (SC) } & 160 & 12,1 & 1506,0 & 1363,3 & 1607,1 & 1427,6 & & 1507,3 \\
\hline & & & $(434,0)$ & $(351,9)$ & $(491,2)$ & $(418,4)$ & & $(381,6)$ \\
\hline
\end{tabular}

Nota: os números entre parênteses são os valores dos desvios-padrão. 
Ao examinar os dados reunidos na Tabela 2 é importante lembrar que, independentemente do gênero é recomendado para as crianças com idade entre 7 e 10 anos, dieta contendo $2000 \mathrm{kcal} / \mathrm{dia}$. Quando se considera o grupo com idade entre $11 \mathrm{e}$ 14 anos há distinção entre os gêneros, no tocante à recomendação: 2200 kcal para as meninas e 2500 kcal para os meninos (NRC, 1989).

Examinando os dados médios registrados na Tabela 2 é possível verificar que em nenhum município integrante da amostra, os escolares (de ambos grupos etários) adotavam dieta que atingisse a recomendação.

No entanto cabe destacar que os valores dos desvios-padrão são elevados (indicativo de acentuada variabilidade), especialmente quando se analisa os valores obtidos para o grupamento feminino dos municípios do estado do Pará. Os valores de desvio-padrão que acompanham os valores médios de consumo obtidos para as meninas mais jovens (< 9 anos) alcançam 842,7 kcal e 665,5 kcal, quando se considera a população escolar de Abaetetuba e Tailândia, respectivamente. Entre as garotas mais velhas (9 - 13 anos), merece destaque o consumo médio das alunas de Tailândia (1720,8 $\mathrm{kcal}-\mathrm{DP}=733,1)$.

Pesquisa que reuniu objetivos similares aos definidos para a presente pesquisa, implementada por Kazapi et al. (2001) mostrou que mais da metade dos adolescentes apresentaram reduzido consumo energético.

Garcia et al. (2003), analisando dados de amostra formada por 153 adolescentes, com idade de 11,90 anos ( $\mathrm{DP}=1,26)$, de ambos os gêneros, também revelaram valor médio de consumo alimentar (1953 kcal), portanto, inferior ao recomendado.

Em relação ao gênero e idade nota-se na cidade de Joinville - SC, um consumo energético que pode ser considerado inferior à recomendação, quando comparado aos dados coletados junto aos alunos dos demais municípios. Conforme citado, vale lembrar que Joinville - SC pertence a uma das regiões geográficas mais ricas do país. Registra-se que o menor valor $(1186,6 \mathrm{kcal}$ - DP $=186,9)$ encontrado foi observado entre as meninas com idade inferior a 9 anos. Para o grupo de escolares com idade entre 9 a 13 anos, o consumo médio foi de 1280,7 kcal ( $\mathrm{DP}=308,1)$. Percebe-se, portanto, que os 
valores identificados não atingem sequer as recomendações, preconizadas para os escolares mais jovens (7 a 10 anos).

$\mathrm{Na}$ presente pesquisa foi verificado maior consumo (médio) para os meninos com menor idade, quando se compara os resultados com os dados obtidos para as garotas.

Ao examinar os resultados relativos aos alunos com maior idade, os valores não são muito distintos, portanto, não possibilita a afirmação que os garotos desfrutam, de forma geral, de consumo energético superior, quando comparado à situação verificada entre as meninas.

Albano (2000) observou elevado consumo de energia entre os adolescentes, 2733,87 kcal (DP = 891,52) para o gênero masculino e 2197,23 kcal (DP = 825,68) para o gênero feminino (valores que atenderam 136,3\% e 123,3\% da recomendação preconizada).

Estudos envolvendo amostra de adolescentes, do gênero feminino, com idade entre 14 e 17 anos, matriculados em uma escola técnica estadual de São Paulo, revelaram que, $80 \%$ das alunas não consumiam o conteúdo de energia recomendado (Braggíon, et al, 2000).

Garcia et al. (2003), identificaram, para o sexo masculino, consumo energético (2020,1 kcal) que supera o conteúdo (1842,7 kcal) identificado na dieta das meninas.

Albuquerque \& Monteiro (2002), que analisaram grupo de 247 escolares (150 meninas e 97 meninos) com idade entre nove e dez anos, matriculados em escolas públicas de Maceió (Alagoas), revelaram que independente do gênero, a ingestão de energia não atingiu a recomendação preconizada pela Recommended Dietary Allowances - RDA. O déficit energético observado entre os escolares de ambos os gêneros, alcançou $35 \%$.

Na Tabela 3, apresentada a seguir, são mostrados os resultados relativos aos percentis da distribuição do Valor Energético Total - VET da dieta dos escolares. 
Tabela 3. Percentis da distribuição do Valor Energético Total (VET) da dieta de escolares da rede pública de ensino, conforme o município de origem, 1997

\begin{tabular}{l|rr|r|c|c|c|c}
\hline \multicolumn{1}{c}{ Município/ } & \multicolumn{2}{c|}{ Escolares } & \multicolumn{5}{c}{ Percentis } \\
\cline { 2 - 8 } \multicolumn{1}{c}{ Estado } & \multicolumn{1}{c}{$\mathrm{N}^{\mathrm{o}}$} & $\%$ & $10^{\circ} \mathrm{P}$ & $25^{\circ} \mathrm{P}$ & $50^{\circ} \mathrm{P}$ & $75^{\circ} \mathrm{P}$ & $90^{\circ} \mathrm{P}$ \\
\hline Parnaíba - PI & 110 & 8,3 & 844,0 & 1084,2 & 1264,1 & 1765,1 & 1765,1 \\
Brasileira - PI & 76 & 5,7 & 925,4 & 1028,4 & 1201,3 & 1371,3 & 1624,3 \\
Abaetetuba - PA & 147 & 11,1 & 990,4 & 1212,6 & 1569,0 & 1935,3 & 2263,8 \\
Tailândia - PA & 80 & 6,0 & 1023,0 & 1364,6 & 1673,7 & 2234,0 & 2605,5 \\
Contagem - MG & 201 & 15,2 & 1114,6 & 1252,5 & 1454,3 & 1782,1 & 2023,4 \\
Baldim - MG & 143 & 10,8 & 1067,9 & 1189,7 & 1407,2 & 1631,9 & 1873,7 \\
Anápolis - GO & 144 & 10,9 & 1196,8 & 1369,1 & 1629,5 & 1973,2 & 2162,8 \\
Itaguarú - GO & 135 & 10,2 & 1049,3 & 1216,6 & 1507,7 & 1857,6 & 2144,9 \\
Joinville - SC & 129 & 9,7 & 970,1 & 1063,6 & 1242,9 & 1451,6 & 1585,5 \\
Ponte Serrada - SC & 160 & 12,1 & 1081,7 & 1230,8 & 1399,0 & 1713,9 & 2169,8 \\
\hline GERAL & 1325 & 100,0 & 1006,0 & 1192,0 & 1427,3 & 1730,9 & 2115,4 \\
\hline
\end{tabular}


Da análise geral dos resultados reunidos na Tabela 3, depreende-se que 50\% dos escolares (considerando a totalidade dos dados obtidos nos municípios que integram a amostra) consumiram em média (1427,3 kcal) conteúdo de energia menor, quando se considera média preconizada (2200 kcal) para o grupamento (NRC, 1989).

Atentando-se, especificamente, para os dados obtidos no município de Parnaíba - PI, verifica-se que 10\% dos escolares apresentaram consumo inferior a 844,0 kcal. Valores de energia ligeiramente superiores a $1000 \mathrm{kcal}$, somente foram observados, na dieta de 10\% dos escolares dos municípios de Tailândia (1023,0 kcal), Contagem (1114,6 kcal), Baldim (1067,9 kcal), Anápolis (1196,8 kcal), Itaguarú (1049,3 kcal) e Ponte Serrada (1081,7 kcal). Vale frisar também que, de forma geral 10\% dos escolares consumiram no máximo, média de 1006,0 kcal.

De forma geral, quando se analisa os valores referentes ao consumo mínimo de energia dos $10 \%$ dos escolares, discriminados pelo nível crítico do $90^{\circ}$ Percentil, nota-se que, em quatro municípios (Parnaíba, Brasileira, Baldim, Joinville), os valores encontrados são inferiores a $2000 \mathrm{kcal} / \mathrm{dia}$. No entanto, entre esses, somente Parnaíba e Brasileira, localizados na Região Nordeste do país são classificados como municípios que possuem substancial proporção de famílias pobres.

Cabe destacar que tendo por base os dados obtidos nas escolas do município de Tailândia (Pará) 10\% dos alunos, consumiram dietas cujo conteúdo energético foi no mínimo 2605,5 kcal. Note-se que se trata do valor referente ao $90^{\circ}$ Percentil.

$\mathrm{Na}$ presente pesquisa, com o envolvimento de amostra de alunos de 10 municípios brasileiros, somente em Tailândia (Pará) foi possível verificar que 75\% dos escolares consumiram no máximo 2234 kcal. Para todos os demais municípios, o consumo de parcela de alunos (ou seja, 75\% da amostra) foi inferior a $1973 \mathrm{kcal}$ (conteúdo energético observado em Anápolis, estado de Goiás).

Enfatiza-se, também que, 75\% dos alunos da cidade de Brasileira (Piauí), apresentaram consumo máximo de 1371 kcal. Note-se que o referido município é o mais pobre, entre os integrantes da amostra da pesquisa. 
Caroba (2002), em pesquisa envolvendo amostra de 578 adolescentes da cidade de Piracicaba - SP, também encontrou que 10\% dos indivíduos consumiu no máximo 991,7 kcal.

Sanches (2002), analisando dados relativos ao consumo de 210 alunos, com idade entre 7 e 14 anos, da rede pública de Piracicaba - SP, verificou que 75\% da amostra, consumiam no máximo cerca de 2500 kcal.

Cabe citar também os resultados obtidos por Maestro (2002), por meio de pesquisa envolvendo alunos do município de Piedade - SP, que revelaram situação diferenciada daquela encontrada por Sanches (2002). Em Piedade, 75\% dos alunos, adotavam dietas, cujo conteúdo energético não ultrapassava 2003 kcal.

É pertinente registrar que município de Piedade se distingue de substancial parcela de municípios paulistas, por possuir a maioria (60\%) da população vivendo na zona rural.

Comparando os resultados obtidos para os escolares paulistas e os dados da presente pesquisa, parece evidente (e esperado) o maior consumo energético (médio) identificado entre os alunos dos municípios paulistas (Região Sudeste).

É importante frisar que o elevado consumo de energia para os alunos diagnosticados com sobrepeso/obesidade poderá causar uma série de distúrbios, a curto prazo, como a obesidade e, possivelmente na vida adulta, a hipertensão, o aumento de risco para as doenças crônicas, entre outros.

A Tabela 4, apresentada a seguir, reúne os dados relativos a participação dos macronutrientes no Valor Energético Total - VET da dieta dos escolares. 
Tabela 4. Participação dos macronutrientes no Valor Energético Total (VET) da dieta de escolares da rede pública de ensino, conforme o município de origem, 1997

\begin{tabular}{|c|c|c|c|c|c|c|c|c|c|c|c|c|c|c|}
\hline \multirow{3}{*}{$\begin{array}{c}\text { Município/ } \\
\text { Estado }\end{array}$} & \multicolumn{2}{|c|}{ Escolares } & \multicolumn{12}{|c|}{ Participação percentual dos macronutrientes no VET } \\
\hline & \multirow[b]{2}{*}{$\mathrm{N}^{\mathrm{o}}$} & \multirow[b]{2}{*}{$\%$} & \multicolumn{4}{|c|}{ Proteína } & \multicolumn{4}{|c|}{ Carboidrato } & \multicolumn{4}{|c|}{ Lipídio } \\
\hline & & & A & $\mathrm{B}$ & $\mathrm{C}$ & $\mathrm{D}$ & A & $\mathrm{B}$ & $\mathrm{C}$ & $\mathrm{D}$ & A & B & $\mathrm{C}$ & $\mathrm{D}$ \\
\hline Parnaíba - PI & 110 & 8,3 & 17,9 & 3,9 & 9,8 & 30,7 & 53,5 & 9,9 & 26,8 & 82,0 & 29,1 & 9,0 & 6,0 & 51,0 \\
\hline Brasileira - PI & 76 & 5,7 & 17,0 & 4,0 & 6,5 & 28,1 & 47,1 & 8,2 & 32,8 & 80,0 & 35,9 & 8,6 & 5,9 & 57,4 \\
\hline Abaetetuba-PA & 147 & 11,1 & 19,7 & 6,5 & 6,0 & 42,2 & 47,2 & 8,9 & 24,8 & 67,1 & 33,1 & 8,4 & 12,7 & 58,2 \\
\hline Tailândia - PA & 80 & 6,0 & 19,9 & 5,4 & 8,4 & 36,6 & 51,3 & 10,7 & 27,9 & 79,5 & 28,8 & 7,6 & 12,2 & 53,7 \\
\hline Contagem-MG & 201 & 15,2 & 16,8 & 4,5 & 6,9 & 34,5 & 53,3 & 9,0 & 26,2 & 73,6 & 29,9 & 6,7 & 14,9 & 46,5 \\
\hline Baldim - MG & 143 & 10,8 & 16,5 & 4,4 & 8,4 & 28,5 & 54,3 & 8,7 & 33,6 & 76,8 & 29,2 & 6,2 & 13,8 & 46,2 \\
\hline Anapolis - GO & 144 & 10,9 & 20,1 & 4,3 & 10,7 & 31,8 & 49,7 & 8,2 & 25,8 & 71,1 & 30,2 & 6,3 & 16,0 & 45,7 \\
\hline Itaguarú - GO & 135 & 10,2 & 17,0 & 3,7 & 7,5 & 27,1 & 52,8 & 9,6 & 28,1 & 73,8 & 30,2 & 8,7 & 14,8 & 64,4 \\
\hline Joinville - SC & 129 & 9,7 & 20,5 & 3,6 & 11,8 & 30,6 & 50,0 & 6,2 & 29,8 & 64,1 & 29,6 & 4,9 & 21,5 & 46,1 \\
\hline P.Serrada - SC & 160 & 12,1 & 16,7 & 3,6 & 8,0 & 24,7 & 55,2 & 7,9 & 35,8 & 71,7 & 28,1 & 6,0 & 16,5 & 44,1 \\
\hline GERAL & 1325 & 100,0 & 18,0 & 4,7 & 6,0 & 42,2 & 51,7 & 9,1 & 24,8 & 82,0 & 30,3 & 7,4 & 5,9 & 64,4 \\
\hline
\end{tabular}

Nota : A = percentual de participação do macronutriente no VET

$$
\begin{aligned}
& \mathrm{B}=\text { desvio padrão. } \\
& \mathrm{C}=\text { valor mínimo observado. } \\
& \mathrm{D}=\text { valor máximo observado. }
\end{aligned}
$$


Tendo por base os dados da tabela 4, verifica-se que para os alunos dos municípios de Anápolis (Goiás) e Joinville (Santa Catarina) a participação da proteína no Valor Energético Total - VET supera 20\%, enquanto os menores valores foram encontrados quando se examinou a dieta dos escolares de Contagem (16,8\%) e Baldim (16,5\%), ambos municípios pertencentes ao estado de Minas Gerais.

Quanto aos carboidratos, observa-se maior participação (55,2\%) no VET das dietas dos alunos da rede pública de Ponte Serrada (SC). No entanto, deve ser enfatizado que a proporção é inferior à preconizada (DRIs, 2000).

O exame, de forma geral dos dados relativos ao lipídio, verifica-se média de 30,3\%. A participação do referido macronutriente supera a proporção (30\%) de participação na dieta dos escolares de cinco municípios, representantes das Regiões Norte, Nordeste e Centro-Oeste. A menor proporção de lipídio (28,1\%) foi identificada quando se analisou o Valor Energético Total - VET da dieta dos escolares de Ponte Serrada, município de Santa Catarina.

Monteiro et al. (2000), revelam a ocorrência de modificações na composição da disponibilidade alimentar com relação a macronutrientes na dieta dos brasileiros. Os referidos autores descrevem que houve um declínio na participação de carboidratos nas dietas da população das áreas metropolitanas do Norte-Nordeste, sendo a diminuição compensada, pelo aumento na oferta de proteínas e de lipídios. Ao analisar os resultados obtidos para o Centro-Sul do país, os referidos autores destacam a participação dos carboidratos na dieta e a substituição, pela população, dos lipídios por proteínas na dieta. A participação de lipídios no consumo da população das Regiões Norte e Nordeste, demonstra que houve um pequeno acréscimo, mas considerado inferior, quando comparado à situação verificada na Região Centro-Sul.

A seguir, apresenta-se a Tabela 5, onde é possível observar a distribuição dos escolares de acordo com a classificação (adequada/inadequada) das dietas dos escolares no tocante à participação dos macronutrientes no VET. 
Tabela 5. Distribuição dos escolares da rede pública de ensino de acordo com classificação da participação dos macronutrientes no Valor Energético Total (VET) da dieta, conforme município de origem, 1997

\begin{tabular}{|c|c|c|c|c|c|c|}
\hline \multirow{4}{*}{$\begin{array}{l}\text { Município/ } \\
\text { Estado }\end{array}$} & \multirow{2}{*}{\multicolumn{2}{|c|}{ Escolares }} & \multicolumn{4}{|c|}{ Escolares com Participação dos macronutrientes no VET } \\
\hline & & & \multicolumn{2}{|c|}{ Adequada } & \multicolumn{2}{|c|}{ Inadequada } \\
\hline & $\mathrm{N}^{0}$ & $\%$ & $\mathrm{~N}^{\mathrm{o}}$ & $\%$ & $\mathrm{~N}^{\mathrm{o}}$ & $\%$ \\
\hline & (a) & & (b) & (b)(a) & (c) & (c)/(a) \\
\hline Parnaíba - PI & 110 & 8,3 & 43 & 39,1 & 67 & 60,9 \\
\hline Brasileira - PI & 76 & 5,7 & 30 & 39,5 & 46 & 60,5 \\
\hline Abaetetuba - PA & 147 & 11,1 & 46 & 31,3 & 101 & 68,7 \\
\hline Tailândia - PA & 80 & 6,0 & 29 & 36,3 & 51 & 63,8 \\
\hline Contagem - MG & 201 & 15,2 & 97 & 48,3 & 104 & 51,7 \\
\hline Baldim - MG & 143 & 10,8 & 73 & 51,0 & 70 & 49,0 \\
\hline Anápolis - GO & 144 & 10,9 & 68 & 47,2 & 76 & 52,8 \\
\hline Itaguarú - GO & 135 & 10,2 & 50 & 37,0 & 85 & 63,0 \\
\hline Joinville - SC & 129 & 9,7 & 92 & 71,3 & 37 & 28,7 \\
\hline Ponte Serrada - SC & 160 & 12,1 & 74 & 46,3 & 86 & 53,8 \\
\hline GERAL & 1325 & 100,0 & 602 & 45,4 & 723 & 54,6 \\
\hline
\end{tabular}


Ao analisar os dados reunidos na Tabela 5 é possível observar que, de forma geral, a maioria das dietas $(54,6 \%)$ se revelaram inadequadas, quando se considera, concomitantemente a proporção de participação dos três macronutrientes (critério adotado para a classificação).

Note-se que a pior situação foi observada, entre os alunos dos municípios das Regiões Norte e Nordeste. Nessas localidades mais de 60\% dos escolares adotavam dietas inadequadas. É interessante destacar que no município de Abaetetuba (Pará), praticamente $70 \%$ dos alunos, tiveram as dietas consideradas inadequadas. Também chama a atenção a situação de Anápolis (Goiás) onde a maioria (52,8\%) dos escolares adotavam dietas classificadas como inadequadas.

Inversamente, a situação menos comprometedora, foi verificada, quando se analisou a dieta dos escolares de Joinville (SC). Nesse município, o percentual das dietas inadequadas não alcançou 30\%, ocorrendo, portanto predomínio (cerca de $70 \%$ ) de dietas adequadas.

Vale lembrar que as conseqüências a longo prazo de uma alimentação inadequada podem ser decorrentes tanto da quantidade como da qualidade dos alimentos ingeridos (González, 2002).

Kazapi et al. (2001), também revelaram participação inadequada dos macronutrientes da dieta da maioria dos escolares avaliados. Os referidos autores, observaram que a proporção de lipídios e proteínas no VET da dieta dos alunos superavam às recomendações definidas para o grupo.

Visando a elaboração de análises complementares, no que se refere à adequação das dietas, considerou-se pertinente, a discriminação dos escolares, de acordo com a faixa etária. Para tanto, foram elaboradas as Tabelas 6 e 7, que possibilitam o exame dos dados obtidos para os alunos com idade inferior a nove anos e os resultados, referentes aos alunos mais velhos (idade entre 9 e 13 anos), respectivamente. 
Tabela 6. Distribuição dos escolares, menores de nove anos de idade, da rede pública de ensino, de acordo com o gênero e a participação dos macronutrientes no Valor Energético Total - VET da dieta e conforme município de origem, 1997

\begin{tabular}{|c|c|c|c|c|c|c|c|c|c|c|c|c|c|c|}
\hline \multirow{4}{*}{ Município/Estado } & \multirow{3}{*}{\multicolumn{2}{|c|}{ Escolares }} & \multicolumn{12}{|c|}{ Participação dos macronutrientes no VET da dieta dos escolares } \\
\hline & & & \multicolumn{6}{|c|}{ Adequada } & \multicolumn{6}{|c|}{ Inadequada } \\
\hline & & & \multicolumn{2}{|c|}{ Masculino } & \multicolumn{2}{|c|}{ Feminino } & \multicolumn{2}{|c|}{ Total } & \multicolumn{2}{|c|}{ Masculino } & \multicolumn{2}{|c|}{ Feminino } & \multicolumn{2}{|c|}{ Total } \\
\hline & $\mathrm{N}^{0}$ & $\%$ & № & $\%$ & No & $\%$ & $\mathrm{~N}^{\mathrm{o}}$ & $\%$ & № & $\%$ & $\mathrm{~N}^{\mathrm{o}}$ & $\%$ & $\mathrm{~N}^{\mathrm{o}}$ & $\%$ \\
\hline Parnaíba (PI) & 22 & 5,8 & 4 & 18,1 & 6 & 27,3 & 10 & 45,5 & 4 & 18,2 & 8 & 36,4 & 12 & 54,5 \\
\hline Brasileira (PI) & 32 & 8,5 & 2 & 6,3 & 5 & 15,6 & 7 & 21,9 & 9 & 28,1 & 16 & 50,0 & 25 & 78,1 \\
\hline Abaetetuba (PA) & 31 & 8,2 & 3 & 9,7 & 8 & 25,8 & 11 & 35,5 & 7 & 22,6 & 13 & 41,9 & 20 & 64,5 \\
\hline Tailândia (PA) & 20 & 5,3 & 3 & 15,0 & 3 & 15,0 & 6 & 30,0 & 6 & 30,0 & 8 & 40,0 & 14 & 70,0 \\
\hline Contagem (MG) & 44 & 11,6 & 13 & 29,5 & 12 & 27,3 & 25 & 56,8 & 9 & 20,5 & 10 & 22,7 & 19 & 43,2 \\
\hline Baldim (MG) & 39 & 10,3 & 9 & 23,1 & 14 & 28,2 & 23 & 59,0 & 7 & 18,0 & 9 & 23,1 & 16 & 41,0 \\
\hline Anápolis (GO) & 53 & 14,0 & 13 & 24,5 & 14 & 26,4 & 27 & 50,9 & 12 & 22,6 & 14 & 26,4 & 26 & 49,0 \\
\hline Itaguarú (GO) & 43 & 11,4 & 5 & 11,6 & 11 & 25,6 & 16 & 37,2 & 13 & 30,2 & 14 & 32,6 & 27 & 62,8 \\
\hline Joinville (SC) & 38 & 10,1 & 12 & 31,6 & 12 & 31,6 & 24 & 63,2 & 7 & 18,4 & 7 & 18,4 & 14 & 36,8 \\
\hline Ponte Serrada (SC) & 56 & 14,8 & 16 & 28,6 & 13 & 23,2 & 29 & 51,8 & 11 & 19,6 & 16 & 28,6 & 27 & 48,2 \\
\hline Total & 378 & 100,0 & 80 & {$[21,2]$} & 98 & {$[25,9]$} & 178 & {$[47,1]$} & 85 & {$[22,5]$} & 115 & {$[30,4]$} & 200 & {$[52,9]$} \\
\hline
\end{tabular}


De forma geral, 52,9\% (maioria) dos escolares mais jovens revelaram dietas classificadas como inadequadas.

Chama à atenção o resultado observado entre as crianças de Brasileira - PI. Neste município, 78,1\% das dietas foram classificadas como inadequadas no tocante à participação dos macronutrientes no VET. A menor proporção (36,8\%) de crianças que adotam dietas inadequadas foi identificada no município de Joinville - SC.

Examinando os resultados, tendo por base a discriminação dos escolares de acordo com o gênero verifica-se que a maior proporção de crianças com menor idade, que desfrutavam de dietas inadequadas foi observada entre as meninas (30,4\%). Note-se que quando se considera a situação dos garotos, a proporção identificada é menor $(22,5)$.

Quando se analisa os alunos com dietas classificadas como adequadas verificase que $25,9 \%$ são meninas, enquanto uma proporção ligeiramente menor $(21,2 \%)$ dos meninos desfrutam de dietas adequadas.

Cabe lembrar também que em Joinville foi observado o menor valor (médio) de consumo de energia $(1218,6 \mathrm{kcal}$ - DP = 283,2), quando se considera o conjunto dos municípios. No entanto é entre os alunos mais jovens desse município que a maior proporção $(63,2 \%)$ de escolares desfruta de dietas adequadas no tocante à participação dos macronutrientes no VET.

Ainda quando se refere ao consumo energético, também discriminando os escolares de acordo com o gênero, Kazapi et al. (2001), identificaram consumo energético acima do preconizado entre os adolescentes, do sexo masculino (32,58\%), quando comparado com a situação das adolescentes (23,15\%). Os autores observaram também que, no tocante ao consumo insuficiente de energia, a pior situação prevaleceu entre as adolescentes (57,88\%), enquanto 47,37\%, dos garotos exibiram consumo inferior ao recomendado.

No entanto, Maestro (2002), registrou relativa homogeneidade ao analisar os dados obtidos junto aos escolares de ambos os gêneros. Aproximadamente $35 \%$ dos meninos e 34\% das meninas consumiam dietas classificadas como adequadas.

Albuquerque \& Monteiro (2002), também observaram que a ingestão total de energia mostrou-se similar quando se considerou escolares de ambos os gêneros. O valor 
médio encontrado foi $1297 \mathrm{kcal}(\mathrm{DP}=378)$ para os meninos e $1300 \mathrm{kcal}(\mathrm{DP}=458)$ para as garotas. Os autores destacam que os referidos valores correspondem ao atendimento de 64,8\% e 65,0\% dos valores preconizados para o grupo do gênero masculino e feminino, respectivamente.

Na seqüência, a Tabela 7 reúne dados relativos aos resultados obtidos para os alunos mais velhos (idade entre 9 e 13 anos), no tocante à participação dos macronutrientes no VET da dieta. 
Tabela 7. Distribuição dos escolares, com idade entre nove e treze anos, da rede pública de ensino, de acordo com o gênero e a participação dos macronutrientes no Valor Energético Total - VET da dieta e conforme município de origem, 1997

\begin{tabular}{|c|c|c|c|c|c|c|c|c|c|c|c|c|c|c|}
\hline \multirow{4}{*}{ Município/Estado } & \multirow{3}{*}{\multicolumn{2}{|c|}{ Escolares }} & \multicolumn{12}{|c|}{ Participação dos macronutrientes no VET da dieta dos escolares } \\
\hline & & & \multicolumn{6}{|c|}{ Adequada } & \multicolumn{6}{|c|}{ Inadequada } \\
\hline & & & \multicolumn{2}{|c|}{ Masculino } & \multicolumn{2}{|c|}{ Feminino } & \multicolumn{2}{|c|}{ Total } & \multicolumn{2}{|c|}{ Masculino } & \multicolumn{2}{|c|}{ Feminino } & \multicolumn{2}{|c|}{ Total } \\
\hline & № & $\%$ & № & $\%$ & No & $\%$ & No & $\%$ & $\mathrm{~N}^{0}$ & $\%$ & No & $\%$ & $\mathrm{~N}^{0}$ & $\%$ \\
\hline Parnaíba (PI) & 88 & 9,3 & 18 & 20,5 & 15 & 17,0 & 33 & 37,5 & 25 & 28,4 & 30 & 34,1 & 55 & 62,5 \\
\hline Brasileira (PI) & 44 & 4,7 & 12 & 27,3 & 11 & 25,0 & 23 & 52,3 & 9 & 20,5 & 12 & 27,3 & 21 & 47,7 \\
\hline Abaetetuba (PA) & 116 & 12,2 & 20 & 17,2 & 15 & 12,9 & 35 & 30,2 & 46 & 39,7 & 35 & 30,2 & 81 & 69,8 \\
\hline Tailândia (PA) & 60 & 6,3 & 13 & 21,7 & 10 & 16,7 & 23 & 38,4 & 21 & 35,0 & 16 & 27,7 & 37 & 61,7 \\
\hline Contagem (MG) & 157 & 16,6 & 53 & 33,8 & 19 & 12,1 & 72 & 45,9 & 52 & 33,1 & 33 & 21,0 & 85 & 54,1 \\
\hline Baldim (MG) & 104 & 11,0 & 36 & 34,6 & 14 & 13,5 & 50 & 48,1 & 32 & 30,8 & 22 & 21,2 & 54 & 51,9 \\
\hline Anápolis (GO) & 981 & 9,6 & 26 & 28,6 & 15 & 16,5 & 41 & 45,1 & 37 & 40,7 & 13 & 14,3 & 50 & 54,9 \\
\hline Itaguarú (GO) & 92 & 9,7 & 24 & 26,1 & 10 & 10,9 & 34 & 37,0 & 39 & 42,4 & 19 & 20,7 & 58 & 63,0 \\
\hline Joinville (SC) & 91 & 9,6 & 42 & 46,2 & 26 & 28,6 & 68 & 74,8 & 15 & 16,5 & 8 & 8,8 & 23 & 25,2 \\
\hline Ponte Serrada (SC) & 104 & 11,0 & 24 & 23,1 & 21 & 20,2 & 45 & 43,3 & 36 & 34,6 & 23 & 22,1 & 59 & 56,7 \\
\hline Total & 947 & 100,0 & 268 & {$[28,3]$} & 156 & {$[16,5]$} & 424 & {$[44,8]$} & 312 & {$[32,9]$} & 211 & {$[22,3]$} & 523 & {$[55,2]$} \\
\hline
\end{tabular}


Ao analisar os dados da Tabela 7, observa-se que praticamente a metade $(44,8 \%)$ dos escolares desfrutam de dietas classificadas como adequadas. No entanto, chama atenção a proporção muito baixa $(16,5 \%)$ verificada quando se considera o grupo do gênero feminino.

Merece atenção também a situação vivenciada pelos escolares do município de Abaetetuba, onde apenas 30,2\% das dietas, são adequadas no tocante à participação relativa dos macronutrientes no VET.

A presente pesquisa inclui entre seus objetivos a análise do estado nutricional (atual) dos escolares $(n=1325)$ integrantes da amostra. Embora seja indiscutível a importância de análises pormenorizadas, optou-se nesta seção, pela inclusão da avaliação da situação por meio da elaboração de análises concomitantes, envolvendo o estado nutricional (avaliado por meio da análise da distribuição de percentis do Índice de Massa Corporal - IMC), gênero, idade, classificação da dieta de acordo com a participação dos macronutrientes no VET e município de origem. Os resultados foram reunidos nas Tabelas 8, 9 e 10, apresentadas a seguir.

A Tabela 8 mostra os resultados relativos ao estado nutricional dos escolares ( $n=1325)$, de acordo com o gênero e município de origem. 
Tabela 8. Distribuição dos escolares da rede pública de ensino, de acordo com o estado nutricional (com base no Índice de Massa Corporal - IMC), gênero e município de origem, 1997

\begin{tabular}{|c|c|c|c|c|c|c|c|c|c|c|c|c|c|c|}
\hline \multirow{4}{*}{ Município/Estado } & \multirow{3}{*}{\multicolumn{2}{|c|}{ Escolares }} & \multicolumn{12}{|c|}{ Estado Nutricional/Gênero } \\
\hline & & & \multicolumn{4}{|c|}{$\mathrm{IMC}<5^{\circ} \mathrm{P}$} & \multicolumn{4}{|c|}{$5^{\circ} \mathrm{P} \leq \mathrm{IMC}<95^{\circ} \mathrm{P}$} & \multicolumn{4}{|c|}{$\mathrm{IMC} \geq 95^{\circ} \mathrm{P}$} \\
\hline & & & \multicolumn{2}{|c|}{ Masculino } & \multicolumn{2}{|c|}{ Feminino } & \multicolumn{2}{|c|}{ Masculino } & \multicolumn{2}{|c|}{ Feminino } & \multicolumn{2}{|c|}{ Masculino } & \multicolumn{2}{|c|}{ Feminino } \\
\hline & № & $\%$ & $\mathrm{~N}^{\mathrm{o}}$ & $\%$ & $\mathrm{~N}^{0}$ & $\%$ & $\mathrm{~N}^{0}$ & $\%$ & No & $\%$ & $\mathrm{~N}^{0}$ & $\%$ & $\mathrm{~N}^{\mathrm{o}}$ & $\%$ \\
\hline Parnaíba (PI) & 110 & 8,3 & - & - & - & - & 47 & 42,7 & 57 & 51,8 & 4 & 3,6 & 2 & 1,9 \\
\hline Brasileira (PI) & 76 & 5,7 & - & - & - & - & 43 & 56,6 & 32 & 42,1 & 0 & 0,0 & 1 & 1,3 \\
\hline Abaetetuba (PA) & 147 & 11,1 & - & - & - & - & 71 & 48,3 & 70 & 47,6 & 5 & 3,4 & 1 & 0,7 \\
\hline Tailândia (PA) & 80 & 6,0 & - & - & - & - & 36 & 45,0 & 37 & 46,3 & 7 & 8,7 & 0 & 0,0 \\
\hline Contagem (MG) & 201 & 15,2 & - & - & - & - & 119 & 59,2 & 67 & 33,4 & 8 & 4,0 & 7 & 3,4 \\
\hline Baldim (MG) & 143 & 10,8 & - & - & - & - & 83 & 58,0 & 55 & 38,5 & 4 & 2,8 & 1 & 0,7 \\
\hline Anápolis (GO) & 144 & 10,9 & - & - & - & - & 84 & 58,3 & 54 & 37,5 & 4 & 2,8 & 2 & 1,4 \\
\hline Itaguarú (GO) & 135 & 10,2 & - & - & - & - & 76 & 56,3 & 52 & 38,5 & 5 & 3,7 & 2 & 1,5 \\
\hline Joinville (SC) & 129 & 9,7 & - & - & - & - & 61 & 47,3 & 49 & 38,0 & 15 & 11,6 & 4 & 3,1 \\
\hline Ponte Serrada (SC) & 160 & 12,1 & - & - & - & - & 73 & 45,6 & 61 & 38,1 & 14 & 8,8 & 12 & 7,5 \\
\hline Total & 1325 & 100,0 & - & - & - & - & 683 & {$[52,3]$} & 534 & {$[40,3]$} & 66 & {$[5,0]$} & 32 & {$[2,4]$} \\
\hline
\end{tabular}

Notas: - os números entre colchetes são os percentuais em relação ao total de escolares $(n=1325)$ para os quais se dispõe do conjunto de informações completas (medidas antropométricas e consumo alimentar).

- os traços significam que não foram identificados escolares com IMC $<5^{\circ} \mathrm{P}$. 
Examinando os dados da Tabela 8 chama a atenção à inexistência, nesta amostra de escolares, indivíduos classificados abaixo do $5^{\circ}$ Percentil. Trata-se de um resultado interessante, tendo em vista que o valor do referido percentil discrimina o grupamento de alunos considerados magros/baixo peso.

Mesmo nas regiões geográficas consideradas mais pobres (Regiões Norte e Nordeste) que são representadas na amostra pelos municípios de Brasileira (Piauí) e Abaetetuba (Pará), não foram encontrados, nas escolas da rede pública de ensino, alunos classificados com déficits de peso.

Vale lembrar que no tocante à situação econômica da amostra considerada nesta pesquisa, Silva et al. (2002) observaram que 13,5\% dos escolares pertenciam a famílias com rendimento mensal per capita inferior a R \$ 25,00. Proporção maior $(20,6)$ dos escolares viviam em domicílios cuja renda per capita variava de $\mathrm{R} \$ 25,00$ a $\mathrm{R} \$$ 49,00. O grupamento (24,3\%), relativamente mais rico, revelou que os rendimentos eram pelo menos igual a $\mathrm{R} \$ 150,00$.

No intervalo que abrange o $5^{\circ} \mathrm{P} \leq \mathrm{IMC}<95^{\circ} \mathrm{P}$ foi identificada proporção de 92,6 (52,3\% e 40,3\%, meninos e meninas, respectivamente).

Cabe lembrar que é esperado encontrar, em população de referência, 90\% de indivíduos que integram o referido intervalo.

No intervalo IMC $\geq 95^{\circ} \mathrm{P}$, onde se espera encontrar 5\% de indivíduos, a presente pesquisa de modo geral, identificou $7,4 \%(5,0 \%$ e $2,4 \%$ entre meninos e garotas, respectivamente), ou seja, 2,4\% acima do esperado.

No entanto, merece destaque a situação das crianças do estado de Santa Catarina. Note-se que em Joinville, 14,7\% (11,6\% meninos e 3,1\% de meninas) foram classificados com sobrepeso e em Ponte Serrada - SC considerado um município muito pobre, os dados revelam 7,5\% de alunas com IMC $\geq 95^{\circ} \mathrm{P}$ e $8,8 \%$ de meninos, na mesma condição. A situação se distingue da realidade observada nos demais municípios, especialmente Tailândia - PA, onde nenhum escolar integrou o intervalo discriminado pelo $95^{\circ}$ Percentil.

Tendo por base dados relativos à população brasileira, com menos de 25 anos, Anjos et al. (1998), revelaram que as meninas, a partir dos 12 anos de idade, 
apresentavam valores maiores de IMC, quando se comparava os resultados obtidos para os meninos.

Embora mereçam atenção os valores de IMC identificados entre os 1325 escolares da presente pesquisa, cabe salientar que a prevalência de sobrepeso/obesidade é menor, quando comparada à parcela de análises registradas pela literatura especializada. Entre esses trabalhos, cabe citar a pesquisa implementada por Gama (1997). Esse autor, por meio de estudo envolvendo 316 adolescentes, de ambos os gêneros e classificados de acordo com três intervalos de idade (10 a 12, 13 a 15 e 16 a 19 anos) revelou que entre os meninos a prevalência de sobrepeso e obesidade era de $18 \%$ e $32 \%$, respectivamente e entre as meninas, $6,0 \%$ e $16 \%$.

Garcia et al. (2003), observaram entre adolescentes de ambos os gêneros, prevalência de sobrepeso de 19,6\%. Os autores identificaram no grupo formado pelos meninos que 10,8\% e 9,8\% apresentavam risco de sobrepeso e obesidade, respectivamente, enquanto entre as garotas as proporções observadas foram de 11,8\% e $5,0 \%$, para sobrepeso e obesidade, respectivamente.

Albano (2000), observou que 10,9\% e 18,5\% dos escolares exibiam sobrepeso e risco de sobrepeso. Para o gênero masculino, o autor observou 4,6\% de indivíduos com sobrepeso e 27,9\% com risco de sobrepeso (prevalência do distúrbio que totaliza 32,5\%) e para o gênero feminino, foi identificado $26,5 \%$, sendo $16,3 \%$ com sobrepeso e 10,2\% com risco de sobrepeso.

Carvalho et al. (2001) avaliaram o estado nutricional de 360 estudantes, adotando o Índice de Massa Corporal (IMC) e o nível crítico de IMC $\geq 85^{\circ} \mathrm{P}$, para discriminação do sobrepeso. Os autores encontraram proporção elevada (19,8\%) de adolescentes com risco de sobrepeso. Cabe lembrar que é esperado, em grupos adotados como referência, proporção de 15\% de indivíduos nessa condição.

Na seqüência as Tabelas 9 e 10, visam apresentar os resultados relativos às análises envolvendo o estado nutricional, a idade e à participação dos macronutrientes no Valor Energético Total - VET da dieta dos escolares, de acordo com a sua classificação como adequada (Tabela 9) e inadequada (Tabela 10). 
Tabela 9. Distribuição dos escolares da rede pública de ensino, de acordo com a participação adequada dos macronutrientes no Valor Energético Total - VET da dieta, estado nutricional (com base no IMC), faixa de idade e município de origem, 1997

\begin{tabular}{|c|c|c|c|c|c|c|c|c|c|c|c|c|c|c|}
\hline \multirow{4}{*}{ Município/Estado } & \multirow{3}{*}{\multicolumn{2}{|c|}{ Escolares }} & \multicolumn{12}{|c|}{ Participação adequada dos macronutrientes no VET/Estado Nutricional/Idade } \\
\hline & & & \multicolumn{4}{|c|}{$\mathrm{IMC}<5^{\circ} \mathrm{P}$} & \multicolumn{4}{|c|}{$5^{\circ} \mathrm{P} \leq \mathrm{IMC}<95^{\circ} \mathrm{P}$} & \multicolumn{4}{|c|}{ IMC $\geq 95^{\circ} \mathrm{P}$} \\
\hline & & & \multicolumn{2}{|c|}{$<9$} & \multicolumn{2}{|c|}{$9 \mid-13$} & \multicolumn{2}{|c|}{$<9$} & \multicolumn{2}{|c|}{$9 \mid-13$} & \multicolumn{2}{|c|}{$<9$} & \multicolumn{2}{|c|}{$9 \longmapsto 13$} \\
\hline & $\mathrm{N}^{\mathrm{o}}$ & $\%$ & $\mathrm{~N}^{\mathrm{o}}$ & $\%$ & No & $\%$ & No & $\%$ & No & $\%$ & № & $\%$ & $\mathrm{~N}^{0}$ & $\%$ \\
\hline Parnaíba (PI) & 43 & 7,1 & - & - & - & - & 10 & 23,3 & 32 & 74,4 & 0 & 0,0 & 1 & 2,3 \\
\hline Brasileira (PI) & 30 & 5,0 & - & - & - & - & 7 & 23,3 & 22 & 73,4 & 0 & 0,0 & 1 & 3,3 \\
\hline Abaetetuba (PA) & 46 & 7,6 & - & - & - & - & 11 & 23,9 & 34 & 73,9 & 0 & 0,0 & 1 & 2,2 \\
\hline Tailândia (PA) & 29 & 4,8 & - & - & - & - & 5 & 17,2 & 21 & 72,4 & 1 & 3,4 & 2 & 6,9 \\
\hline Contagem (MG) & 97 & 16,2 & - & - & - & - & 24 & 24,7 & 66 & 68,0 & 1 & 1,0 & 6 & 6,3 \\
\hline Baldim (MG) & 73 & 12,1 & - & - & - & - & 21 & 28,8 & 48 & 65,8 & 2 & 2,7 & 2 & 2,7 \\
\hline Anápolis (GO) & 68 & 11,3 & - & - & - & - & 26 & 38,2 & 41 & 60,3 & 1 & 1,5 & 0 & 0,0 \\
\hline Itaguarú (GO) & 50 & 8,3 & - & - & - & - & 15 & 30,0 & 31 & 62,0 & 1 & 2,0 & 3 & 6,0 \\
\hline Joinville (SC) & 92 & 15,3 & - & - & - & - & 22 & 23,9 & 56 & 60,9 & 2 & 2,2 & 12 & 13,0 \\
\hline Ponte Serrada (SC) & 74 & 12,3 & - & - & - & - & 22 & 29,7 & 42 & 56,8 & 7 & 9,5 & 3 & 4,0 \\
\hline Total & 602 & 100,0 & - & - & - & - & 163 & {$[27,1]$} & 393 & {$[65,3]$} & 15 & {$[2,5]$} & 31 & {$[5,1]$} \\
\hline
\end{tabular}


É possível observar que $602(45,4 \%)$ do total de escolares $(n=1325)$ - menos da metade da amostra da pesquisa - tiveram suas dietas classificadas como adequadas no tocante à participação dos macronutrientes no VET. Entre esses, 92,4\% $(n=556)$ foram identificados como eutróficos $\left(5^{\circ} \mathrm{P} \leq \mathrm{IMC}<95^{\circ} \mathrm{P}\right)$ e menos de $10 \%(7,6 \%)$ com IMC $\geq$ $95^{\circ} \mathrm{P}$ (condição indicativa de obesidade).

Prevalece também, de forma geral, maior proporção de alunos eutróficos, entre os mais velhos (9 a 13 anos).

Ainda de acordo com a Tabela 9, atentando para os resultados de acordo com o município de origem dos alunos, observa-se que as maiores proporções de indivíduos com dietas adequadas são do estado de Minas Gerais (Contagem 16,2\% e Baldim 12,1\%) e Santa Catarina (Joinville 15,3\% e Ponte Serrada 12,3\%).

Em situação menos privilegiada, ou seja, menores proporções de alunos (com dieta adequada) foram identificadas no estado de Piauí (7,1\% em Parnaíba e 5,0\% em Brasileira). Note-se também que, nos referidos municípios foram observadas as menores proporções de escolares com IMC $\geq 95^{\circ} \mathrm{P}$.

Ao examinar os dados dos escolares $(n=166)$ do estado de Santa Catarina observa-se que mesmo desfrutando de dietas classificadas como adequadas no que diz respeito à participação dos macronutrientes no VET, foi identificado contingente (28,7\%, sendo 15,2\% em Joinville e 13,5\% em Ponte Serrada) de escolares com IMC $\geq$ $95^{\circ} \mathrm{P}$.

Ainda tendo por base os dados desse grupo de escolares catarinenses destaca-se que, em Joinville a maior proporção de obesos é observada entre os alunos com maior idade e em Ponte Serrada, condição inversa (9,5\% entre os mais jovens - proporção praticamente 2,4 vezes superior à identificada em Ponte Serrada - 4,0\%, entre os mais velhos).

Na Tabela 10, mostrada a seguir, será possível examinar o conjunto de dados relativos ao grupo ( $n=723-54,6 \%$ do total da amostra) de escolares com dietas inadequadas, discriminados por idade, estado nutricional atual e município de origem. 
Tabela 10. Distribuição dos escolares da rede pública de ensino, com participação inadequada dos macronutrientes no Valor Energético Total - VET da dieta, de acordo com o estado nutricional (com base no IMC), idade e município de origem, 1997

\begin{tabular}{|c|c|c|c|c|c|c|c|c|c|c|c|c|c|c|}
\hline \multirow{4}{*}{ Município/Estado } & \multirow{3}{*}{\multicolumn{2}{|c|}{ Escolares }} & \multicolumn{12}{|c|}{ Participação inadequada dos macronutrientes no VET/Estado Nutricional/Idade } \\
\hline & & & \multicolumn{4}{|c|}{$\mathrm{IMC}<5^{\circ} \mathrm{P}$} & \multicolumn{4}{|c|}{$5^{\circ} \mathrm{P} \leq \mathrm{IMC}<95^{\circ} \mathrm{P}$} & \multicolumn{4}{|c|}{$\mathrm{IMC} \geq 95^{\circ} \mathrm{P}$} \\
\hline & & & \multicolumn{2}{|c|}{$<9$} & \multicolumn{2}{|c|}{$9 \mid-13$} & \multicolumn{2}{|c|}{$<9$} & \multicolumn{2}{|c|}{$9 \mid-13$} & \multicolumn{2}{|c|}{$<9$} & \multicolumn{2}{|c|}{$9 \mid-13$} \\
\hline & $\mathrm{N}^{\mathrm{o}}$ & $\%$ & № & $\%$ & № & $\%$ & № & $\%$ & $\mathrm{~N}^{\mathrm{0}}$ & $\%$ & $\mathrm{~N}^{\mathrm{o}}$ & $\%$ & № & $\%$ \\
\hline Parnaíba (PI) & 67 & 9,3 & - & - & - & - & 9 & 13,9 & 53 & 79,1 & 3 & 4,5 & 2 & 3,0 \\
\hline Brasileira (PI) & 46 & 6,4 & - & - & - & - & 25 & 54,3 & 21 & 45,7 & 0 & 0,0 & 0 & 0,0 \\
\hline Abaetetuba (PA) & 101 & 13,9 & - & - & - & - & 19 & 18,8 & 77 & 76,2 & 1 & 1,0 & 4 & 4,0 \\
\hline Tailândia (PA) & 51 & 7,1 & - & - & - & - & 13 & 25,5 & 34 & 66,7 & 1 & 0,9 & 3 & 5,9 \\
\hline Contagem (MG) & 104 & 14,4 & - & - & - & - & 17 & 16,3 & 79 & 76,0 & 2 & 1,9 & 6 & 5,8 \\
\hline Baldim (MG) & 70 & 9,6 & - & - & - & - & 15 & 21,4 & 54 & 77,1 & 1 & 1,4 & 0 & 0,0 \\
\hline Anápolis (GO) & 76 & 10,5 & - & - & - & - & 24 & 31,6 & 47 & 61,8 & 2 & 2,6 & 3 & 3,9 \\
\hline Itaguarú (GO) & 85 & 11,8 & - & - & - & - & 27 & 31,8 & 55 & 64,7 & 0 & 0,0 & 3 & 3,5 \\
\hline Joinville (SC) & 37 & 5,1 & - & - & - & - & 12 & 32,5 & 20 & 54,1 & 2 & 5,4 & 3 & 8,1 \\
\hline Ponte Serrada (SC) & 86 & 11,9 & - & - & - & - & 21 & 24,4 & 49 & 57,0 & 6 & 7,0 & 10 & 11,6 \\
\hline Total & 723 & 100,0 & - & - & - & - & 182 & {$[25,2]$} & 489 & {$[67,6]$} & 18 & {$[2,5]$} & 34 & {$[4,7]$} \\
\hline
\end{tabular}


Ao analisar a Tabela 10 observa-se que o grupo formado por 723 (54,6\%) do total de escolares $(n=1325)$ - mais da metade da amostra da pesquisa - desfrutavam de dietas classificadas como inadequadas. No entanto, 671 (92,8\%) foram identificados como eutróficos $\left(5^{\circ} \mathrm{P} \leq \mathrm{IMC}<95^{\circ} \mathrm{P}\right)$ e $7,2 \%$ com IMC $\geq 95^{\circ} \mathrm{P}$ (condição indicativa de obesidade). Vale frisar que é esperado 5\% de indivíduos nesta condição e, portanto, a proporção $(7,2 \%)$ supera à esperada.

Ainda de acordo com a tabela 10 é possível observar que, de forma geral, as maiores proporções de dietas inadequadas são verificadas entre os alunos com maior idade (9 a 13 anos), exceto quando se considera o valor (45,7\%) - considerado o menor - observado entre os alunos de Brasileira - PI. Nesse município, são majoritariamente os mais jovens (<9 anos) que adotam dietas inadequadas (54,3\%).

Merece atenção quando se analisa os resultados no tocante ao município de origem dos alunos, as maiores proporções de indivíduos que desfrutam dietas inadequadas observadas nos estados de Minas Gerais (Contagem, 14,4\%), Pará (Abaetetuba, 13,9\%), Santa Catarina (11,9\%) e Goiás (Itaguarú, 11,8\%).

Entre os escolares $(n=123)$ do estado de Santa Catarina foi identificada a maior prevalência (19,7\%, ou seja, 8,1,\% em Joinville e 11,6\% em Ponte Serrada) de escolares com IMC $\geq 95^{\circ} \mathrm{P}$. Curiosamente, entre os escolares do município de Joinville, foi observado o menor percentual de escolares $(5,1 \%)$ com adoção de dietas inadequadas.

Para atender os objetivos desta pesquisa também serão apresentados, a seguir, os resultados e análises relativos ao conteúdo médio de nutrientes da dieta dos escolares integrantes da amostra. Vale esclarecer que, embora as tabelas específicas que reúnem dados sobre o consumo (médio) de nutrientes registrem também dados sobre o Valor (médio) Energético Total - VET (kcal) da dieta dos alunos, a manutenção dessas informações visaram facilitar as análises, uma vez que o leitor poderá examinar os resultados específicos, no tocante aos nutrientes, tendo comodidade para estabelecer comparações tendo como parâmetro o conteúdo médio de energia da dieta dos escolares registrado na totalidade das tabelas. 
A Tabela 11, apresentada a seguir, reúne os resultados referentes ao conteúdo médio dos nutrientes lipídios totais, lipídios insaturados, colesterol e fibra presentes na dieta dos escolares. 
Tabela 11. Conteúdo médio de energia, lipídios, colesterol e fibras da dieta de escolares da rede pública de ensino, de acordo com o município de origem, 1997

\begin{tabular}{|c|c|c|c|c|c|c|c|}
\hline \multirow{3}{*}{ Município/Estado } & \multirow{2}{*}{\multicolumn{2}{|c|}{ Escolares }} & \multicolumn{5}{|c|}{ Conteúdo de energia e nutrientes selecionados } \\
\hline & & & \multirow{2}{*}{$\begin{array}{l}\text { Média de Energia } \\
\text { (Kcal) }\end{array}$} & \multirow{2}{*}{$\begin{array}{l}\text { Lipídios totais } \\
\text { (g) }\end{array}$} & \multirow{2}{*}{$\begin{array}{c}\text { Lipídios } \\
\text { Insaturados } \\
\text { (g) }\end{array}$} & \multirow{2}{*}{$\begin{array}{l}\text { Colesterol } \\
\text { (mg) }\end{array}$} & \multirow{2}{*}{$\begin{array}{l}\text { Fibra } \\
\text { (g) }\end{array}$} \\
\hline & № & $\%$ & & & & & \\
\hline Parnaíba (PI) & 110 & 8,3 & $\begin{array}{l}1297,0 \\
(335,3)\end{array}$ & $\begin{array}{c}43,0 \\
(19,0)\end{array}$ & $\begin{array}{c}26,8 \\
(12,9)\end{array}$ & $\begin{array}{c}196,1 \\
(127,1)\end{array}$ & $\begin{array}{l}14,3 \\
(7,0)\end{array}$ \\
\hline Brasileira (PI) & 76 & 5,7 & $\begin{array}{l}1236,3 \\
(335,2)\end{array}$ & $\begin{array}{c}50,0 \\
(18,4)\end{array}$ & $\begin{array}{c}32,4 \\
(11,7)\end{array}$ & $\begin{array}{c}237,6 \\
(149,4)\end{array}$ & $\begin{array}{l}13,8 \\
(5,0)\end{array}$ \\
\hline Abaetetuba (PA) & 147 & 11,1 & $\begin{array}{l}1610,7 \\
(532,7)\end{array}$ & $\begin{array}{c}50,4 \\
(18,0)\end{array}$ & $\begin{array}{c}32,5 \\
(11,5)\end{array}$ & $\begin{array}{c}240,1 \\
(146,7)\end{array}$ & $\begin{array}{l}13,6 \\
(5,1)\end{array}$ \\
\hline Tailândia (PA) & 80 & 6,0 & $\begin{array}{l}1780,2 \\
(615,1)\end{array}$ & $\begin{array}{c}55,0 \\
(27,3)\end{array}$ & $\begin{array}{c}24,9 \\
(14,6)\end{array}$ & $\begin{array}{c}283,6 \\
(592,1)\end{array}$ & $\begin{array}{l}14,2 \\
(8,4)\end{array}$ \\
\hline Contagem (MG) & 201 & 15,2 & $\begin{array}{l}1519,2 \\
(370,4)\end{array}$ & $\begin{array}{c}52,0 \\
(17,9)\end{array}$ & $\begin{array}{c}26,3 \\
(10,9)\end{array}$ & $\begin{array}{c}261,4 \\
(157,3)\end{array}$ & $\begin{array}{l}13,4 \\
(5,4)\end{array}$ \\
\hline Baldim (MG) & 143 & 10,8 & $\begin{array}{l}1454,6 \\
(400,7)\end{array}$ & $\begin{array}{c}47,9 \\
(18,6)\end{array}$ & $\begin{array}{c}24,7 \\
(10,2)\end{array}$ & $\begin{array}{c}276,1 \\
(809,6)\end{array}$ & $\begin{array}{l}13,4 \\
(7,9)\end{array}$ \\
\hline Anápolis (GO) & 144 & 10,9 & $\begin{array}{l}1698,7 \\
(501,9)\end{array}$ & $\begin{array}{c}57,1 \\
(22,4)\end{array}$ & $\begin{array}{c}28,6 \\
(13,2)\end{array}$ & $\begin{array}{c}281,6 \\
(408,1)\end{array}$ & $\begin{array}{l}12,4 \\
(4,0)\end{array}$ \\
\hline Itaguarú (GO) & 135 & 10,2 & $\begin{array}{l}1569,4 \\
(457,6)\end{array}$ & $\begin{array}{c}54,9 \\
(29,2)\end{array}$ & $\begin{array}{c}31,4 \\
(19,5)\end{array}$ & $\begin{array}{c}225,7 \\
(148,2)\end{array}$ & $\begin{array}{l}12,7 \\
(5,3)\end{array}$ \\
\hline Joinville (SC) & 129 & 9,7 & $\begin{array}{l}1218,6 \\
(283,2)\end{array}$ & $\begin{array}{c}42,1 \\
(11,3)\end{array}$ & $\begin{array}{l}18,8 \\
(6,2)\end{array}$ & $\begin{array}{l}171,0 \\
(77,1)\end{array}$ & $\begin{array}{r}7,9 \\
(2,7)\end{array}$ \\
\hline Ponte Serrada (SC) & 160 & 12,1 & $\begin{array}{l}1506,0 \\
(434,0)\end{array}$ & $\begin{array}{c}47,2 \\
(17,5)\end{array}$ & $\begin{array}{c}23,0 \\
(10,1)\end{array}$ & $\begin{array}{c}189,8 \\
(107,1)\end{array}$ & $\begin{array}{l}12,2 \\
(5,2)\end{array}$ \\
\hline
\end{tabular}

Notas: - os números entre parênteses são os valores dos desvios-padrão. 
No tocante aos lipídios totais, presente na dieta, nota-se que os escolares de todos os municípios, revelam consumo médio que pode ser classificado como abaixo do recomendado. Vale destacar que o consumo diário de lipídios de acordo com a National Research Council - NRC (1989) deve atender os valores correspondentes aos intervalos 61 a 85g, para as meninas e 69 a 97g, para os meninos.

Ao examinar os dados da tabela 11 verifica-se o maior $(57,1 \mathrm{~g}-\mathrm{DP}=22,4)$ consumo de lipídios observado entre os escolares de Anápolis, que no entanto, não alcança o valor preconizado.

A situação relativa ao consumo das crianças do município de Parnaíba - PI chama a atenção por não atingir o valor médio (50g) considerado recomendado para ingestão diária. Note-se que em Brasileira - PI o consumo (médio) dos escolares identificado é $50 \mathrm{~g}(\mathrm{DP}=18,4)$.

Merece atenção os dados obtidos junto aos escolares dos municípios de Santa Catarina, cujo consumo médio de lipídios se revelou o menor (Joinville, 42,1g e Ponte Serrada, 47,2g), dentre os membros da amostra. No entanto, tal situação pode ser considerada satisfatória, se for considerado os valores divulgados pelo National Academy of Sciences (2002).

Maestro (2002), analisando dados obtidos junto aos alunos da rede pública de ensino de município paulista, verificou que o consumo mínimo $(98,25 g)$ entre as meninas era menor, quando comparado ao conteúdo $(101,93 \mathrm{~g})$ ingerido pelos rapazes.

Sanches (2002), avaliando a situação nutricional de escolares de Piracicaba SP identificou que $10 \%$ da amostra consumiu quantidade de lipídios no mínimo igual a 130,25g. O autor enfatiza que essa proporção (10\%) de alunos adota dietas, cujo conteúdo de lipídios é praticamente o dobro do valor preconizado pela National Academy of Sciences (2002). Cabe registrar também que a quantidade (130,85g) identificada refere-se ao $90^{\circ} \mathrm{P}$ da distribuição do consumo de lipídios.

Segundo González (2002), os cuidados no que diz respeito às recomendações nutricionais dos lipídios têm como objetivo evitar as deficiências de ácidos graxos essenciais e os riscos de doenças não transmissíveis como obesidade, aterosclerose e câncer entre outras. 
De acordo com Vannuchi et al. (1990), as gorduras constituem uma fonte concentrada de energia, extremamente útil para aumentar a densidade energética da dieta, especialmente quando se considera as demandas o grupo dos pré-escolares.

Examinando os dados relativos ao consumo de lipídios insaturados observa-se que a maioria dos escolares adota dietas cujo conteúdo do nutriente é substancial. O maior conteúdo $(32,5 \mathrm{~g}$ - DP $=11,5)$ foi identificado na dieta dos escolares de Abaetetuba - PA. Menor quantidade foi identificada quando se analisou o consumo dos alunos de Joinville (18,8 g - DP = 6,2) e Ponte Serrada (23,0 - DP = 10,1).

Vannucchi et al. (1990), recomendam, para a população brasileira, que a ingestão de ácidos graxos poliinsaturados dos indivíduos não exceda 10\% do total da energia, sendo que valor em torno de $7 \%$ da energia total alimentar foi considerado pelos autores como sendo o mais adequado.

De acordo com Juzwiak (2002) a ingestão adequada (AI) de ácido linoleico (Ômega 6) varia de 10 - 16 g/dia e a de $\alpha$ - linolênico (Ômega 3) de 0,9 - 1,6 g/dia para crianças de 3 - 18 anos.

González (2002) registra que ao considerar a ingestão de lipídios é fundamental proporcionar quantidade adequada de ácidos graxos essenciais, especialmente da série do ácido linoleico (Ômega-6) e do ácido $\alpha$ linolênico (Ômega-3).

As melhores fontes de ácido linoleico (Ômega 6), são encontradas nos óleos de milho, girassol e açafrão. $\mathrm{O} \alpha$ - linolênico (Ômega 3) está presente na cavalinha, salmão e demais peixes de águas salgadas frias, como também nos óleos de soja e canola. O Ômega 6 contribui para a redução das concentrações de LDL quando substitui os ácidos graxos saturados e o Ômega 3 tem efeito semelhante, porém, é mais efetivo na diminuição dos níveis de triglicérides sanguíneos (Angelis \& Ctenas,1992).

De acordo com Ettinger (2002), os ácidos graxos saturados aumentam os níveis de lipídios plasmáticos e os ácidos graxos poliinsaturados (PUFA) os diminuem. Entretanto, concentrações elevadas de PUFA podem ser consideradas perigosas. Ligações duplas são altamente reativas e se unem ao oxigênio para formar peróxidos quando expostas ao ar ou calor, produzindo aromas e odores desagradáveis (rancidez). Ainda segundo o autor, os óleos ricos em PUFA também são reativos durante o 
cozimento, podendo gerar elevadas concentrações tóxicas de produtos de aldeído que podem promover as doenças cardiovasculares.

Pesquisas indicam que o consumo excessivo dos ácidos graxos poliinsaturados talvez favoreça o "aparecimento de câncer nas pessoas com predisposição genética ao distúrbio”, tendo em vista as comprovações obtidas por meio de pesquisas envolvendo animais que receberam elevadas doses de ácidos graxos poliinsaturados (Angelis \& Ctenas, 1992).

Ainda de acordo com as informações da Tabela 11 verifica-se atentando-se especificamente para os valores de desvios-padrão que há expressiva diversidade no tocante a presença de colesterol na dieta dos escolares, como ilustra o valor (DP $=809,6$ ) obtido para a média de consumo dos alunos do município de Baldim - MG.

Valores inferiores a $200 \mathrm{mg} /$ dia foram identificados apenas nas dietas dos escolares dos municípios de Parnaíba (196,1 g - DP = 127,1), Ponte Serrada (189,8 - DP $=107,1)$ e Joinville $(171,0 \mathrm{mg}-\mathrm{DP}=77,1)$. De forma geral os dados obtidos nessa pesquisa são concordantes com os registros do National Cholesterol Education Program - NCEP (1991) quanto ao colesterol dietético que deve ser abaixo de $300 \mathrm{mg} / \mathrm{dia}$ (Krummel, 2002; Forti et al., 1998; Consenso Brasileiro sobre Dislipidemias, 1996).

Situação inversa foi encontrada por Garcia et al. (2003), que identificaram cerca de 50\% de adolescentes, de ambos os sexos, com ingestão elevada de colesterol (329,7 mg).

Moura \& Sonati (1998), desenvolveram, durante 1994 e 1995, pesquisa envolvendo amostra de 194 escolares, de ambos os gêneros, matriculados na primeira série de uma escola estadual do ensino fundamental, em Campinas - SP. A pesquisa visou identificar o perfil lipídico da dieta dos alunos, relacionando-o com o colesterol plasmático. Os resultados revelaram quantidade média ingerida de colesterol para ambos os gêneros (176 mg/dL) que atendia aos padrões de recomendações internacionais, porém, 9,9\% dos escolares consumiam quantidade acima de $250 \mathrm{mg}$ de colesterol e 28\%, ingeriram no mínimo 300 mg.

De acordo com Elias et al. (2001), evidências provenientes por meio de estudos envolvendo animais relacionaram um maior consumo dietético a elevados níveis de 
colesterol sérico. Ainda segundo os autores, foi verificado em primatas que o maior efeito da dieta rica em colesterol é o aumento das concentrações e alterações no tamanho e na composição das partículas de lipoproteínas de baixa densidade (LDL).

Vale ressaltar que o colesterol é parte importante das membranas celulares e precursor de vários hormônios, sendo que o próprio organismo pode sintetizá-lo visando atender às demandas (Vannuchi, 1990).

No tocante ao colesterol sérico, os níveis aceitáveis de colesterol total para crianças e adolescentes de acordo com o National Cholesterol Education Program NCEP (1991) devem ser inferiores a 170 mg/dL (Krummel, 2002; Forti et al.,1998; Consenso Brasileiro sobre Dislipidemias, 1996).

Gerber \& Zielinsky (1997), tendo por base amostra de 1.501 escolares, com idade entre 6 e 16 anos, residentes no município de Bento Gonçalves - RS (região sul do Brasil), verificaram que 420 (27,98\%) apresentavam hipercolesterolemia (> $180 \mathrm{mg} / \mathrm{dL})$, sendo que 189 (12,6\%) o conteúdo de colesterol era superior a $200 \mathrm{mg} / \mathrm{dL}, 72$ (4,8\%) apresentavam a colesterolemia acima de $220 \mathrm{mg} / \mathrm{dL}$ e 24 (1,6\%) conteúdo que superava $240 \mathrm{mg}$.

Coronelli \& Moura (2003), avaliaram o perfil lipídico de 172 escolares, com idade entre 7 e 10 anos, residentes em Campinas - SP (região sudeste do Brasil). Na pesquisa foi considerado "caso" a hipercolesterolemia, diagnosticada quando a criança apresentava colesterol pelo menos igual a $200 \mathrm{mg} / \mathrm{dL}$ e "controle" quando o valor observado, situava-se entre 140 e $170 \mathrm{mg} / \mathrm{dL}$. Entre o grupo de crianças consideradas “caso” o valor observado foi $215 \mathrm{mg} / \mathrm{dL}$ e entre os demais (“controle”), $154 \mathrm{mg} / \mathrm{dL}$.

Moura \& Sonati (1998), identificaram uma concentração de colesterol sérico para as meninas de $156 \mathrm{mg} / \mathrm{dL}(\mathrm{DP}=27)$ e $145 \mathrm{mg} / \mathrm{dL}(\mathrm{DP}=27)$, para os meninos. Nota-se que esses valores são menores quando comparados aos dados encontrados também entre os escolares de Campinas - SP, por Coronelli \& Moura (2003).

Ainda de acordo com a Tabela 11, merece destaque os dados relativos ao conteúdo de fibras presentes na dieta dos escolares, especialmente quando se considera os valores recomendados (DRIs, 2002) para os grupos com idade entre 8 (25 g/dia) e 14 anos (38 g/dia). Note-se também que Vanucchi et al. (1990) preconizam para a 
população brasileira (adultos jovens) pelo menos 20 g/dia, o que corresponde à ingestão de 8 a 10 g/1000 kcal da dieta.

De forma geral os resultados no tocante ao consumo de fibras pelos escolares merecem especial atenção tendo em vista que as dietas praticamente não alcançam $50 \%$ do valor recomendado.

Os dados mostram que o consumo dos escolares de Joinville $(7,9 \mathrm{~g}-\mathrm{DP}=2,7)$ e Ponte Serrada $(12,2 \mathrm{~g}$ - DP = 5,2) é muito baixo e, portanto, merece intervenção para que a situação possa ser revertida com êxito.

A redução no consumo de fibras pode ser explicado devido as alterações de hábitos alimentares que contribuiram para a diminuição do consumo de folhosos. Leão et al. (2003), por meio de pesquisa envolvendo amostra de 387 alunos, com idade entre 5 e 10 anos, matriculados em escolas da rede pública e particular da cidade de Salvador (Bahia) e mediante adoção de questionário de freqüência alimentar, verificaram elevado consumo de leite, carnes, pão e margarina e baixo consumo de folhosos, entre os estudantes de ambas as redes de ensino que integraram a pesquisa.

Reduzido consumo de hortaliças folhosas entre os adolescentes também foi identificado por Carvalho et al. (2001). Os autores destacam a necessidade de valorização desses vegetais como componentes alimentares reconhecidos como fontes valiosas de fibras, minerais e vitaminas.

Court (1988), analisa o reduzido consumo de fibras, tendo por base descrição das preferências dos adolescentes por grupo de alimentos específicos. De acordo com o autor, os adolescentes não apreciam vegetais, legumes e peixe, dando preferência para os alimentos com elevado conteúdo energético, ricos em gorduras e carboidratos.

Monje-Rojas (2001), também verificou reduzido consumo de fibras (aproximadamente $12 \mathrm{~g} / 1000 \mathrm{kcal}$ - DP = 6) entre os adolescentes da área urbana e rural de San Jose, Costa Rica.

Maestro (2002) registrou preocupação com consumo de fibras inadequado pelos escolares (moradores de um município paulista), decorrente da reduzida presença de frutas e hortaliças na dieta. 
De acordo com Angelis \& Ctenas (1993), a importância do consumo de fibras na alimentação decorre do papel que as mesmas exercem ao prevenir o câncer de cólon e diminuir a absorção do colesterol e também aumentar a saciedade, contribuindo assim para a diminuição da ingestão de alimentos. Face a essas características, as fibras são indicadas para o tratamento da obesidade. Ainda segundo os referidos autores, as melhores fontes de fibras solúveis são aveia, pêssego, mamão, parte branca da laranja e maçã. São consideradas melhores fontes de fibras insolúveis os cereais integrais, farelos de trigos e aveia, frutas, vegetais folhosos e grãos.

De acordo com Velásquez-Meléndez et al. (1997), o consumo adequado de vitaminas e minerais é importante para a manutenção das diversas funções metabólicas. Ainda segundo os autores, a ingestão inadequada desses nutrientes pode potencialmente levar a estados de carência nutricional, sendo conhecidas diversas manifestações patológicas produzidas pelas deficiências.

As vitaminas e os minerais são fundamentais para o crescimento e saúde dos adolescentes. Nesse estágio da vida há uma demanda exarcebada dos referidos nutrientes.

Nesta fase de crescimento acelerado é recomendável atentar para o atendimento das necessidades de energia e nutrientes como proteína, ferro, cálcio, zinco e vitaminas (Oliveira et al., 2005; Spear, 2002).

A tabela 12 reúne os resultados relativos ao consumo médio de minerais selecionados, obtidos junto à amsotra de alunos $(n=1325)$. 
Tabela 12. Conteúdo médio de energia e minerais da dieta de escolares da rede pública de ensino, de acordo com o município de origem, 1997

\begin{tabular}{|c|c|c|c|c|c|c|c|}
\hline \multirow{3}{*}{ Município/Estado } & \multirow{2}{*}{\multicolumn{2}{|c|}{ Escolares }} & \multicolumn{5}{|c|}{ Conteúdo de minerais } \\
\hline & & & \multirow{2}{*}{$\begin{array}{l}\text { Média de Energia } \\
\text { (Kcal) }\end{array}$} & \multirow{2}{*}{$\begin{array}{l}\text { Selênio } \\
(\mu \mathrm{g})\end{array}$} & \multirow{2}{*}{$\begin{array}{l}\text { Cobre } \\
\text { (mg) }\end{array}$} & \multirow{2}{*}{$\begin{array}{l}\text { Magnésio } \\
\text { (mg) }\end{array}$} & \multirow{2}{*}{$\begin{array}{c}\text { Manganês } \\
\text { (mg) }\end{array}$} \\
\hline & No & $\%$ & & & & & \\
\hline \multirow[t]{2}{*}{ Parnaíba (PI) } & 110 & 8,3 & 1297,0 & 61,0 & 1,3 & 197,8 & 26,2 \\
\hline & & & $(335,3)$ & $(24,8)$ & $(0,5)$ & $(57,5)$ & $(36,3)$ \\
\hline \multirow[t]{2}{*}{ Brasileira (PI) } & 76 & 5,7 & 1236,3 & 56,3 & 1,7 & 174,1 & 21,1 \\
\hline & & & $(335,2)$ & $(16,9)$ & $(1,8)$ & $(48,2)$ & $(16,7)$ \\
\hline \multirow[t]{2}{*}{ Abaetetuba (PA) } & 147 & 11,1 & 1610,7 & 56,1 & 1,1 & 171,3 & 21,0 \\
\hline & & & $(532,7)$ & $(17,5)$ & $(0,4)$ & $(48,9)$ & $(16,8)$ \\
\hline \multirow[t]{2}{*}{ Tailândia (PA) } & 80 & 6,0 & 1780,2 & 85,2 & 1,2 & 199,2 & 36,1 \\
\hline & & & $(615,1)$ & $(35,2)$ & $(0,8)$ & $(77,2)$ & $(38,1)$ \\
\hline \multirow[t]{2}{*}{ Contagem (MG) } & 201 & 15,2 & 1519,2 & 77,2 & 1,3 & 186,2 & 34,0 \\
\hline & & & $(370,4)$ & $(3,1)$ & $(3,2)$ & $(50,1)$ & $(32,7)$ \\
\hline \multirow[t]{2}{*}{ Baldim (MG) } & 143 & 10,8 & 1454,6 & 71,4 & 1,5 & 187,1 & 33,1 \\
\hline & & & $(400,7)$ & $(25,0)$ & $(1,0)$ & $(49,7)$ & $(35,6)$ \\
\hline \multirow[t]{2}{*}{ Anápolis (GO) } & 144 & 10,9 & 1698,7 & 89,1 & 1,4 & 186,7 & 33,9 \\
\hline & & & $(501,9)$ & $(42,5)$ & $(0,7)$ & $(62,7)$ & $(32,7)$ \\
\hline \multirow[t]{2}{*}{ Itaguarú (GO) } & 135 & 10,2 & 1569,4 & 79,1 & 1,4 & 180,4 & 38,6 \\
\hline & & & $(457,6)$ & $(26,7)$ & $(0,7)$ & $(54,4)$ & $(32,2)$ \\
\hline \multirow[t]{2}{*}{ Joinville (SC) } & 129 & 9,7 & 1218,6 & 73,8 & 1,0 & 154,9 & 16,8 \\
\hline & & & $(283,2)$ & $(22,3)$ & $(0,4)$ & $(31,7)$ & $(16,4)$ \\
\hline \multirow[t]{2}{*}{ Ponte Serrada (SC) } & 160 & 12,1 & 1506,0 & 73,6 & 1,3 & 108,9 & 26,0 \\
\hline & & & $(434,0)$ & $(20,3)$ & $(0,6)$ & $(30,5)$ & $(22,8)$ \\
\hline
\end{tabular}

Nota: os números entre parênteses são os valores dos desvios-padrão. 
Tabela 12. Conteúdo médio de energia e minerais da dieta de escolares da rede pública de ensino, de acordo com o município de origem, 1997

\begin{tabular}{|c|c|c|c|c|c|c|c|}
\hline \multirow{3}{*}{ Município/Estado } & \multirow{2}{*}{\multicolumn{2}{|c|}{ Escolares }} & \multicolumn{5}{|c|}{ Conteúdo de minerais } \\
\hline & & & \multirow{2}{*}{$\begin{array}{l}\text { Média de Energia } \\
\text { (Kcal) }\end{array}$} & \multirow{2}{*}{$\begin{array}{l}\text { Cálcio } \\
\text { (mg) }\end{array}$} & \multirow{2}{*}{$\begin{array}{l}\text { Fósforo } \\
\text { (mg) }\end{array}$} & \multirow{2}{*}{$\begin{array}{l}\text { Ferro } \\
\text { (mg) }\end{array}$} & \multirow{2}{*}{$\begin{array}{l}\text { Zinco } \\
\text { (mg) }\end{array}$} \\
\hline & $\mathrm{N}^{\mathrm{o}}$ & $\%$ & & & & & \\
\hline \multirow[t]{2}{*}{ Parnaíba (PI) } & 110 & 8,3 & 1297,0 & 330,0 & 797,2 & 12,8 & 9,2 \\
\hline & & & $(335,3)$ & $(32,4)$ & $(217,4)$ & $(3,8)$ & $(3,7)$ \\
\hline \multirow[t]{2}{*}{ Brasileira (PI) } & 76 & 5,7 & 1236,3 & 258,7 & 750,5 & 4,2 & 9,4 \\
\hline & & & $(335,2)$ & $(105,3)$ & $(211,9)$ & $(3,0)$ & $(3,6)$ \\
\hline \multirow[t]{2}{*}{ Abaetetuba (PA) } & 147 & 11,1 & 1610,7 & 257,2 & 744,0 & 11,0 & 21,0 \\
\hline & & & $(532,7)$ & $(107,8)$ & $(216,2)$ & $(3,1)$ & $(16,8)$ \\
\hline \multirow[t]{2}{*}{ Tailândia (PA) } & 80 & 6,0 & 1780,2 & 544,2 & 921,1 & 15,0 & 36,1 \\
\hline & & & $(615,1)$ & $(276,4)$ & $(348,0)$ & $(7,0)$ & $(38,1)$ \\
\hline \multirow[t]{2}{*}{ Contagem (MG) } & 201 & 15,2 & 1519,2 & 466,6 & 873,3 & 12,1 & 34,0 \\
\hline & & & $(370,4)$ & $(212,7)$ & $(224,2)$ & $(3,1)$ & $(32,7)$ \\
\hline \multirow[t]{2}{*}{ Baldim (MG) } & 143 & 10,8 & 1454,6 & 439,7 & 823,6 & 11,7 & 33,1 \\
\hline & & & $(400,7)$ & $(182,4)$ & $(229,6)$ & $(3,7)$ & $(35,6)$ \\
\hline \multirow[t]{2}{*}{ Anápolis (GO) } & 144 & 10,9 & 1698,7 & 398,9 & 1025,7 & 13,9 & 33,9 \\
\hline & & & $(501,9)$ & $(196,6)$ & $(372,9)$ & $(5,1)$ & $(32,7)$ \\
\hline \multirow[t]{2}{*}{ Itaguarú (GO) } & 135 & 10,2 & 1569,4 & 490,6 & 899,8 & 12,6 & 38,6 \\
\hline & & & $(457,6)$ & $(218,2)$ & $(897,0)$ & $(3,8)$ & $(32,2)$ \\
\hline \multirow[t]{2}{*}{ Joinville (SC) } & 129 & 9,7 & 1218,6 & 370,0 & 744,1 & 11,1 & 16,8 \\
\hline & & & $(283,2)$ & $(221,0)$ & $(190,5)$ & $(2,8)$ & $(16,4)$ \\
\hline \multirow[t]{2}{*}{ Ponte Serrada (SC) } & 160 & 12,1 & 1506,0 & 453,6 & 780,0 & 12,0 & 26,0 \\
\hline & & & $(434,0)$ & $(201,4)$ & $(221,9)$ & $(3,9)$ & $(22,8)$ \\
\hline
\end{tabular}

Nota: os números entre parênteses são os valores dos desvios-padrão. 
Ao examinar os resultados relativos ao consumo de selênio é importante considerar o valor médio preconizado (40 $\mu \mathrm{g} / \mathrm{dia})$, para o grupo etário avaliado nessa pesquisa (National Academy of Sciences, 2002).

Os dados obtidos (Tabela 12) revelam expressivo consumo (médio) de selênio, especialmente quando se considera a condição dos escolares dos municípios de Anápolis - GO e Tailândia - PA. Nesses municípios os alunos ingeriram quantidade de selênio acima de $80 \mu \mathrm{g}$ (praticamente o dobro do valor recomendado). Em situação oposta, ou seja, o menor consumo foi identificado entre os alunos de Abaetetuba - PA e Brasileira - PI. Mesmo em situação de relativa inferioridade aos demais escolares integrantes da amostra, o consumo identificado nos referidos municípios pode ser considerado satisfatório, tendo em vista que supera o valor médio preconizado.

Maestro (2002), também encontrou um expressivo consumo de selênio, revelando que 50\% da população analisada apresentou consumo médio que supera 68,36 $\mu g$. No entanto é importante esclarecer que os escolares da amostra eram moradores de um município do interior paulista (Região Sudeste do Brasil).

De acordo com Mahan \& Escott-Stump (2002), o selênio e a vitamina E atuam como antioxidantes, podendo participar de diversas atividades cooperativas que também visam manter as células saudáveis.

De acordo com a National Academy of Sciences (2002), o grupamento de idade considerado na presente pesquisa deve ingerir $700 \mu \mathrm{g} / \mathrm{dia}$ de cobre.

Examinando os dados da Tabela 12 é possível observar que a totalidade dos alunos revelaram consumo no mínimo igual a 1,0 mg (1000 $\mu \mathrm{g})$. Entre os escolares do município de Joinville - SC, a ingestão foi a menor verificada (1,0 mg). Em situação mais favorável, foi identificada entre os alunos de Brasileira (PI), cujo consumo de cobre foi o maior (1,8 mg ou $1800 \mu \mathrm{g})$.

Urbano et al. (2002), analisando dados de amostra de adolescentes, com idade entre 11 e 16 anos, de ambos os gêneros, identificaram ingestão diária de cobre de 1,71 $\mathrm{mg}(\mathrm{DP}=0,63)$ para o sexo masculino e $1,77 \mathrm{mg}(\mathrm{DP}=0,89)$ para o sexo feminino. De acordo com os autores os valores obtidos atendiam à recomendação (valores entre 1,5 e 
2,5 mg/d) preconizada no final da década de 80 por meio da publicação Recommended Dietary Allowances - (RDA, 1989).

O cobre integra a composição de muitas enzimas e, assim como o selênio e vitamina E, também atua no sentido de proteger o organismo contra a ação de oxidantes e radicais livres (Mahan \& Escott-Stump, 2002).

Tendo como referência o valor de $240 \mathrm{mg} /$ dia de magnésio preconizado para o grupo pela National Academy Sciences (2002) é possível concluir que o consumo da maioria dos escolares se revelou inferior à recomendação. A melhor situação parece ser vivenciada pelos escolares de Tailândia - PA, que ingeriram quantidade (média) de 199,2 mg (DP = 77,2) do referido mineral.

Em situação oposta, ainda no que tange ao magnésio, encontra-se o consumo dos escolares da Região Sul (Joinville - 154,9 mg e Ponte Serrada, 108,9 mg) - os maiores valores identificados.

Sanches (2002), também identificou consumo reduzido de magnésio entre os escolares da rede pública de ensino (50\% da amostra consumiu no máximo 180,23 mg).

Apesar de ser rara, cabe registrar que a deficiência grave de magnésio se manifesta clinicamente por sinais como tremor, espasmo muscular, mudanças de personalidade, anorexia, náusea e vômito (Mahan \& Escott-Stump, 2002).

Merece atenção o substancial consumo médio de manganês pelos escolares da totalidade dos municípios da amostra. Note-se a situação dos escolares de Joinville - SC, cujo consumo médio de 16,8 mg, supera expressivamente os valores preconizados (1,6 mg para meninas e $1,9 \mathrm{mg}$ para os meninos).

Cabe registrar que os valores adotados como referência foram estabelecidos pela National Academy Sciences (2002).

Merece destaque, também, os valores de desvios-padrão que acompanham as médias de consumo de manganês, que revelam a grande dispersão dos valores identificados no que tange o consumo dos escolares.

É importante destacar que o manganês é componente de diversas enzimas e está associado à formação dos tecidos conjuntivo e esquelético e atua de forma decisiva 
no crescimento, na reprodução e no metabolismo de carboidratos e lipídios (Mahan \& Escott-Stump, 2002).

Análise atenta dos dados reunidos na Tabela 12, revela o reduzido consumo de cálcio observado entre os escolares da totalidade dos municípios.

Tendo como recomendação 1300 mg/dia (National Academy of Sciences, 2002), verifica-se que do ponto de vista regional a pior situação é vivenciada pelas crianças do Nordeste (ingestão de 330,0 mg/dia observada entre os alunos de Parnaíba e 258,7 mg/dia - quantidade média consumida pelos alunos de Brasileira).

Quando são considerados os escolares da Região Sul, pode ser classificado como crítico o consumo médio dos escolares de Joinville (370,0 mg) e Ponte Serrada (453,6 mg). Merece atenção a situação das crianças de Joinville, cujo consumo praticamente não alcança 30\% do valor preconizado.

Na seqüência, analisa-se a situação dos escolares dos municípios de Abaetetuba e Tailândia, ambos localizados na Região Norte. Em Abaetetuba foi identificado o menor consumo médio (257,2 mg/dia). No entanto, localizado na mesma região geográfica, o município de Tailândia revelou que seus escolares, ingeriram em média 544,2 mg/dia ( $\mathrm{DP}=276,4)$ que supera em muito a quantidade presente na dieta dos alunos de Abaetetuba. Contudo, cabe a ressalva que o valor observado é muito menor (menos da metade) da quantidade preconizada.

Devido ao desenvolvimento muscular, esquelético e endócrino acelerados, as necessidades de cálcio são maiores durante a puberdade e adolescência, quando comparadas com as demandas impostas durante a infância ou a fase adulta (Spear, 2002). Oliveira et al. (2005) relatam que na adolescência a ingestão de cálcio é necessária motivada pelo aumento da retenção, visando a formação óssea. Esse é um período crítico de mineralização do osso, pois até os trinta anos de idade será incorporada ao organismo a massa óssea total, sendo que 90\% dessa massa é agregada na adolescência.

Vale enfatizar que na adolescência é necessário que exista um balanço positivo do cálcio para atingir o pico máximo de massa óssea, até a finalização do crescimento. O processo de mineralização pode durar três ou quatro anos adicionais (González, 2002). 
Maestro (2002) identificou ao analisar dados escolares, que 50\% da população observada consumiu quantidade muito pequena (383,72 mg pelos meninos e 397,56 mg, pelas meninas). Quando se considerou os $10 \%$ da população com maior consumo de cálcio, observou-se conteúdo, entre os meninos de 761,88 mg e 806,9 mg, a ingestão média das meninas.

A reduzida ingestão de cálcio e possíveis deficiências freqüentemente observadas entre os escolares podem ser decorrentes da pouca freqüência de consumo de leite e seus derivados. Vale ressaltar que esses alimentos são considerados fontes de substancial quantidade de cálcio.

Carvalho et al. (2001), observaram que há tendência entre os adolescentes de não consumirem o leite diariamente. Aproximadamente 25,68\% e 24,57\% de meninos e meninas, respectivamente, não ingeriam com regularidade mínima necessária o alimento.

Albuquerque \& Monteiro (2002), encontraram entre os escolares matriculados em escolas públicas municipais de Maceió, consumo abaixo do recomendado: 339 mg $\mathrm{DP}=229$, que corresponde a $42 \%$ de atendimento das necessidades dos meninos e 351 $\mathrm{mg}-\mathrm{DP}=494$, ou seja, 44\% (menos da metade do valor preconizado) para as meninas.

Garcia et al. (2003), também identificaram consumo insuficiente de cálcio entre os escolares: $580 \mathrm{mg}$ para os meninos e $421 \mathrm{mg}$ para as meninas, indicando que 90,2\% e 98,4\% das dietas são inadequadas no que se refere ao consumo de cálcio de garotos e garotas, respectivamente. Ainda segundo os autores, esse déficit é explicado pela reduzida quantidade ingerida de leite e derivados e ainda, especialmente pela substituição, freqüente no desjejum, do leite por sucos industrializados e refrigerantes nos lanches da manhã e tarde comumente realizados fora do ambiente escolar.

Sanches (2002), ao examinar os dados da ingestão de cálcio, tendo por base amostra de alunos de escolas públicas verificou que ampla maioria (90\%) consumia quantidade (média) inferior a 902,15 mg.

Albano (2000), identificou, adotando como padrão de recomendação os valores preconizados pelo NRC (1989), baixo consumo de cálcio entre os escolares (gênero masculino $819 \mathrm{mg}$ - DP = 397,87 e entre as meninas, 579,86 mg - DP = 378,59, ou seja, 
68,31\% e 48,32\% do valor preconizado, respectivamente). Ainda segundo o autor, se for considerado, nas análises a quantidade de cálcio recomendada mais recentemente (1300 mg), a proporção de indivíduos, cujo consumo seria classificado como adequado diminuíria para 63,1 \% entre os garotos e 44,6\%, entre as alunas. Cabe lembrar que o valor, considerado mais recente foi estabelecido pela National Academy of Sciences (2002).

Situação similar à identificada no tocante ao consumo de cálcio é observada quando se considera o consumo (médio) de fósforo pelos escolares.

Tendo em vista que é preconizado 1250 mg/dia, pela National Academy of Sciences (2002), para o atendimento das demandas de crianças e adolescentes, verificase que a totalidade dos escolares revelam consumo inadequado.

Chega a ser curiosa a condição dos alunos de Parnaíba (797,2 mg), Brasileira (750,5 mg), Joinville (744,1 mg) e Ponte Serrada (780,0 mg), esses dois últimos municípios, pertencentes ao estado de Santa Catarina (Região Sul). Os referidos dados são reveladores de reduzido consumo de fósforo.

Melhor condição relativa, no tocante ao consumo de fósforo, foi identificada entre os alunos de Anápolis (1025,7 mg) e Itaguarú (899,8 mg), municípios situados na Região Centro-Oeste do Brasil.

O mineral fósforo merece atenção, tendo em vista que ocupa o segundo lugar após o cálcio, em abundância nos tecidos humanos. Cerca de $80 \%$ integra o esqueleto e dentes como cristais de fosfato de cálcio e os $20 \%$ restantes constituem um pool metabolicamente ativo em cada célula do corpo e no compartimento de fluido extracelular (Anderson, 2002).

Albuquerque \& Monteiro (2002), identificaram reduzido consumo de fósforo entre os escolares (569 mg - DP = 294 entre os alunos do gênero masculino e 551 mg $\mathrm{DP}=257$, entre as meninas, ou seja, $71 \%$ e $69 \%$ de atendimento das recomendações, respectivamente).

Como o fósforo atua em todas as funções corpóreas, a sua deficiência pode acarretar sérios prejuízos, como por exemplos a redução de ATP e de outras moléculas 
orgânicas de fosfato, como também anormalidades neuromusculares, esqueléticas, hematológicas e renais (Mahan \& Escott-Stump, 2002).

Antecedendo a análise relativa à ingestão de ferro pelos escolares, cabe lembrar que Nascimento et al. (2004) destacam a preocupação com a prevalência de anemia ferropriva identificada nos grupos populacionais da totalidade das regiões brasileiras. Os autores classificam a situação como um grande problema de saúde pública.

Examinando os dados da Tabela 12, verifica-se que o consumo dos escolares supera, na maioria dos municípios, o valor médio do mineral preconizado (8mg), pela National Academy of Sciences (2002). Merece atenção os dados relativos aos escolares do município de Brasileira - PI, cujo consumo médio (4,2 mg) do ferro é praticamente a metade do valor recomendado para atendimento das demandas do estágio de vida.

Tendo em vista o resultado observado é possível que os escolares do município de Brasileira (PI) - um dos mais pobres do país - sejam vitimados pela anemia ferropriva e, portanto, intervenções devem ser adotadas de forma sistemática, com o objetivo de reverter a situação de precariedade, no que diz respeito ao consumo de ferro, vivenciadas pelas crianças.

Cabe lembrar que o ferro atua como elemento estrutural do grupo heme na hemoglobina, proteína responsável pelo transporte do oxigênio e do gás carbônico no sangue e também como co-fator em diversas enzimas não heme, necessárias para o funcionamento adequado das células. Esse mineral assume papel importante em processos metabólicos como na síntese das purinas, entre outros (Oliveira \& Marchini, 1998).

Garcia et al. (2003) identificaram entre escolares que 83,6\% das meninas ingeriam baixa quantidade de alimentos considerados fontes expressivas de ferro.

Nascimento et al. (2004), analisando dados obtidos junto a adolescentes “infanto-juvenis, com idade entre 9,5 (meninas) e 10 anos (meninos)”, revelaram prevalência de anemia ferropriva nas crianças e adolescentes, de $22 \%$ e 31\%, respectivamente.

Matos et al. (2003), analisaram dados de 327 adolescentes, matriculados ( $5^{\mathrm{a}}$ a $8^{\text {a }}$ série) no ensino municipal de Balneário Camboríu - SC e identificaram incidência de 
anemia de 33\%. Segundo os autores foi possível constatar entre as meninas maior proporção de anêmicas (35\%), em relação aos meninos (29\%).

A Agência Nacional de Vigilância Sanitária - ANVISA considerando que a anemia ferropriva representa um problema nutricional importante no Brasil e com severas conseqüências econômicas e sociais, por meio da Resolução n 344 , de 13 de dezembro de 2002, publicado no Diário Oficial de 18/12/2002, tornou obrigatória a fortificação da farinha de trigo e de milho com ferro e ácido fólico com vistas ao combate a anemia e outras deficiências.

Fisberg et al. (2003); Vellozo et al. (2003), tendo por base amostra de crianças (1 a 6 anos) e análises envolvendo alimentos fortificados (feijão e pão enriquecido com ferro), concluíram que a utilização desses alimentos pode ser efetiva na prevenção de anemia ferropriva.

Por outro lado, Urbano et al. (2002), revelaram adequação do consumo de ferro, sendo que dos 47 adolescentes em estirão pubertário, 18 meninos e 10 meninas revelaram 95\% e 36\% de atendimento à recomendação, respectivamente.

Albano (2000) observou consumo médio do ferro de 13,37 mg - DP = 5,95 para o grupamento dos meninos e para as meninas, ingestão de 12,13 mg - DP = 5,70, com alcance de $111,31 \%$ e $80,89 \%$ das recomendações preconizadas pelo National Research Council - NRC (1989).

Outro aspecto que deve ser considerado é a biodisponibilidade do ferro na dieta e a absorção intestinal do mesmo, que varia com o estado nutricional relativo ao referido nutriente. Vale frisar que a absorção do ferro não-heme aumenta em presença de carnes e ácido ascórbico. Por outro lado, algumas substâncias como taninos, fitatos, certas proteínas (presentes na gema do ovo) e algumas fibras reduzem sua absorção (Vannucchi et al., 1990).

Ainda tendo por base os resultados registrados na Tabela 12 é possível observar a ingestão de zinco pelos escolares.

Cabe lembrar que, de acordo com a National Academy of Sciences (2002), é preconizado para o zinco $8 \mathrm{mg} /$ dia, para atendimento das demandas do grupo que integra a pesquisa. 
Examinando os dados obtidos, verifica-se que os escolares de Parnaíba - PI e Brasileira - PI revelaram ingestão média mais próxima ao valor preconizado, revelando inclusive ligeira superioridade.

Excetos para os escolares dos dois municípios nordestinos, o consumo (médio) dos demais, supera em muito, à recomendação. Trata-se obviamente de situação que merece atenção tendo em vista que mesmo sendo considerado nutriente de fundamental importância, especialmente para as crianças e adolescentes, a ingestão excessiva pode causar prejuízos para a saúde.

Urbano et al. (2002), revelaram situação inversa, ao verificarem que 79\% dos integrantes da amostra apresentaram ingestão inadequada de zinco. No entanto, os níveis séricos desse mineral foram classificados como normais.

É importante registrar que o zinco é essencial para o crescimento e para o desenvolvimento adequado do adolescente. A deficiência do mineral acarreta retardo na maturação sexual e no crescimento, além de provocar alterações do paladar (Oliveira et al., 2005).

Os resultados obtidos relativos ao consumo das vitaminas foram reunidos na Tabela 13, apresentada a seguir. 
Tabela 13. Conteúdo médio de energia e vitaminas da dieta de escolares da rede pública de ensino, de acordo com o município de origem, 1997

\begin{tabular}{|c|c|c|c|c|c|c|c|c|}
\hline \multirow{3}{*}{ Município/Estado } & \multirow{2}{*}{\multicolumn{2}{|c|}{ Escolares }} & \multicolumn{6}{|c|}{ Conteúdo de vitaminas } \\
\hline & & & \multirow{2}{*}{$\begin{array}{c}\text { Média de } \\
\text { Energia (Kcal) }\end{array}$} & \multirow{2}{*}{$\begin{array}{l}\text { Vitamina C } \\
\text { (mg) }\end{array}$} & \multirow{2}{*}{$\begin{array}{l}\text { Tiamina } \\
\text { (mg) }\end{array}$} & \multirow{2}{*}{$\begin{array}{l}\text { Riboflavina } \\
\text { (mg) }\end{array}$} & \multirow{2}{*}{$\begin{array}{l}\text { Vitamina } \mathrm{B}_{6} \\
\text { (mg) }\end{array}$} & \multirow{2}{*}{$\begin{array}{c}\text { Vitamina } \mathrm{B}_{12} \\
(\mu \mathrm{g})\end{array}$} \\
\hline & № & $\%$ & & & & & & \\
\hline \multirow[t]{2}{*}{ Parnaíba (PI) } & 110 & 8,3 & 1297,0 & 78,2 & 1,0 & 0,9 & 1,4 & 3,4 \\
\hline & & & $(335,3)$ & $(62,8)$ & $(0,3)$ & $(0,4)$ & $(0,4)$ & $(1,8)$ \\
\hline \multirow[t]{2}{*}{ Brasileira (PI) } & 76 & 5,7 & 1236,3 & 55,1 & 0,9 & 0,8 & 1,3 & 3,9 \\
\hline & & & $(335,2)$ & $(51,8)$ & $(0,3)$ & $(0,4)$ & $(0,4)$ & $(1,7)$ \\
\hline \multirow[t]{2}{*}{ Abaetetuba (PA) } & 147 & 11,1 & 1610,7 & 53,8 & 0,9 & 0,8 & 1,3 & 3,9 \\
\hline & & & $(532,7)$ & $(46,5)$ & $(0,3)$ & $(0,4)$ & $(0,4)$ & $(1,6)$ \\
\hline \multirow[t]{2}{*}{ Tailândia (PA) } & 80 & 6,0 & 1780,2 & 40,5 & 1,3 & 1,5 & 1,3 & 5,3 \\
\hline & & & $(615,1)$ & $(102,2)$ & $(0,5)$ & $(0,9)$ & $(0,6)$ & $(13,6)$ \\
\hline \multirow[t]{2}{*}{ Contagem (MG) } & 201 & 15,2 & 1519,2 & 103,8 & 1,2 & 1,2 & 1,4 & 3,8 \\
\hline & & & $(370,4)$ & $(291,5)$ & $(0,4)$ & $(0,4)$ & $(0,4)$ & $(2,3)$ \\
\hline \multirow[t]{2}{*}{ Baldim (MG) } & 143 & 10,8 & 1454,6 & 275,0 & 1,2 & 1,1 & 1,4 & 4,7 \\
\hline & & & $(400,7)$ & $(724,9)$ & $(0,4)$ & $(0,9)$ & $(0,6)$ & $(18,7)$ \\
\hline \multirow[t]{2}{*}{ Anápolis (GO) } & 144 & 10,9 & 1698,7 & 77,6 & 0,9 & 1,2 & 1,6 & 7,3 \\
\hline & & & $(501,9)$ & $(132,5)$ & $(0,7)$ & $(0,6)$ & $(0,6)$ & $(2,8)$ \\
\hline \multirow[t]{2}{*}{ Itaguarú (GO) } & 135 & 10,2 & 1569,4 & 152,9 & 1,3 & 1,1 & 1,5 & 4,2 \\
\hline & & & $(457,6)$ & $(289,7)$ & $(0,4)$ & $(0,4)$ & $(0,5)$ & $(2,2)$ \\
\hline \multirow[t]{2}{*}{ Joinville (SC) } & 129 & 9,7 & 1218,6 & 63,7 & 1,0 & 1,0 & 1,2 & 4,3 \\
\hline & & & $(283,2)$ & $(41,6)$ & $(0,2)$ & $(0,3)$ & $(1,2)$ & $(1,7)$ \\
\hline \multirow[t]{2}{*}{ Ponte Serrada (SC) } & 160 & 12,1 & 1506,0 & 66,5 & 1,3 & 1,1 & 1,3 & 3,2 \\
\hline & & & $(434,0)$ & $(63,6)$ & $(0,5)$ & $(0,5)$ & $(0,5)$ & $(1,7)$ \\
\hline
\end{tabular}

Nota: os números entre parênteses são os valores dos desvios-padrão. 
Tabela 13. Conteúdo médio de energia e vitaminas da dieta de escolares da rede pública de ensino, de acordo com o município de origem, 1997

\begin{tabular}{|c|c|c|c|c|c|c|c|c|}
\hline \multirow{3}{*}{ Município/Estado } & \multirow{2}{*}{\multicolumn{2}{|c|}{ Escolares }} & \multicolumn{6}{|c|}{ Conteúdo de vitaminas } \\
\hline & & & \multirow{2}{*}{$\begin{array}{c}\text { Média de } \\
\text { Energia (Kcal) }\end{array}$} & \multirow{2}{*}{$\begin{array}{l}\text { Niacina } \\
\text { (mg) }\end{array}$} & \multirow{2}{*}{$\begin{array}{l}\text { Folacina } \\
\text { ( } \mu \mathrm{g})\end{array}$} & \multirow{2}{*}{$\begin{array}{c}\text { Ácido } \\
\text { Pantotênico } \\
\text { (mg) }\end{array}$} & \multirow{2}{*}{$\begin{array}{c}\text { Vitamina A } \\
(\mu \mathrm{g})\end{array}$} & \multirow{2}{*}{$\begin{array}{c}\text { Vitamina E } \\
\text { (mg) }\end{array}$} \\
\hline & № & $\%$ & & & & & & \\
\hline Parnaíba (PI) & 110 & 8,3 & $\begin{array}{l}1297,0 \\
(335,3)\end{array}$ & $\begin{array}{l}14,7 \\
(5,4)\end{array}$ & $\begin{array}{l}164,8 \\
(60,9)\end{array}$ & $\begin{array}{c}2,7 \\
(1,0)\end{array}$ & $\begin{array}{l}1118,3 \\
(799,4)\end{array}$ & $\begin{array}{l}13,4 \\
(6,8)\end{array}$ \\
\hline Brasileira (PI) & 76 & 5,7 & $\begin{array}{l}1236,3 \\
(335,2)\end{array}$ & $\begin{array}{l}12,1 \\
(4,7)\end{array}$ & $\begin{array}{l}161,9 \\
(62,5)\end{array}$ & $\begin{array}{l}2,4 \\
(0,8)\end{array}$ & $\begin{array}{l}1149,0 \\
(605,9)\end{array}$ & $\begin{array}{l}15,2 \\
(7,4)\end{array}$ \\
\hline Abaetetuba (PA) & 147 & 11,1 & $\begin{array}{l}1610,7 \\
(532,7)\end{array}$ & $\begin{array}{l}12,0 \\
(4,7)\end{array}$ & $\begin{array}{l}158,9 \\
(59,7)\end{array}$ & $\begin{array}{l}2,4 \\
(0,9)\end{array}$ & $\begin{array}{l}1156,9 \\
(581,7)\end{array}$ & $\begin{array}{l}15,4 \\
(7,4)\end{array}$ \\
\hline Tailândia (PA) & 80 & 6,0 & $\begin{array}{l}1780,2 \\
(615,1)\end{array}$ & $\begin{array}{l}15,0 \\
(7,2)\end{array}$ & $\begin{array}{l}78,7 \\
(3,7)\end{array}$ & $\begin{array}{c}9,5 \\
(1,7)\end{array}$ & $\begin{array}{c}677,3 \\
(112,5)\end{array}$ & $\begin{array}{c}7,1 \\
(4,9)\end{array}$ \\
\hline Contagem (MG) & 201 & 15,2 & $\begin{array}{l}1519,2 \\
(370,4)\end{array}$ & $\begin{array}{l}14,5 \\
(5,7)\end{array}$ & $\begin{array}{l}166,2 \\
(88,2)\end{array}$ & $\begin{array}{c}3,5 \\
(1,5)\end{array}$ & $\begin{array}{c}653,1 \\
(577,0)\end{array}$ & $\begin{array}{l}12,7 \\
(5,9)\end{array}$ \\
\hline Baldim (MG) & 143 & 10,8 & $\begin{array}{l}1454,6 \\
(400,7)\end{array}$ & $\begin{array}{l}14,5 \\
(4,5)\end{array}$ & $\begin{array}{c}159,2 \\
(163,5)\end{array}$ & $\begin{array}{c}3,5 \\
(1,2)\end{array}$ & $\begin{array}{r}981,8 \\
1883,0\end{array}$ & $\begin{array}{l}11,5 \\
(5,4)\end{array}$ \\
\hline Anápolis (GO) & 144 & 10,9 & $\begin{array}{l}1698,7 \\
(501,9)\end{array}$ & $\begin{array}{l}17,2 \\
(6,4)\end{array}$ & $\begin{array}{l}166,4 \\
(63,1)\end{array}$ & $\begin{array}{c}3,6 \\
(1,5)\end{array}$ & $\begin{array}{l}4819,5 \\
(474,4)\end{array}$ & $\begin{array}{l}12,2 \\
(5,0)\end{array}$ \\
\hline Itaguarú (GO) & 135 & 10,2 & $\begin{array}{l}1569,4 \\
(457,6)\end{array}$ & $\begin{array}{l}14,7 \\
(4,4)\end{array}$ & $\begin{array}{l}170,0 \\
(73,9)\end{array}$ & $\begin{array}{c}3,3 \\
(1,1)\end{array}$ & $\begin{array}{c}515,3 \\
(567,3)\end{array}$ & $\begin{array}{c}13,7 \\
(11,2)\end{array}$ \\
\hline Joinville (SC) & 129 & 9,7 & $\begin{array}{l}1218,6 \\
(283,2)\end{array}$ & $\begin{array}{l}15,4 \\
(4,6)\end{array}$ & $\begin{array}{l}126,6 \\
(44,1)\end{array}$ & $\begin{array}{l}2,9 \\
(0,9)\end{array}$ & $\begin{array}{c}974,2 \\
(751,4)\end{array}$ & $\begin{array}{c}8,4 \\
(2,5)\end{array}$ \\
\hline Ponte Serrada (SC) & 160 & 12,1 & $\begin{array}{l}1506,0 \\
(434,0)\end{array}$ & $\begin{array}{l}16,5 \\
(5,1)\end{array}$ & $\begin{array}{l}140,0 \\
(50,3)\end{array}$ & $\begin{array}{c}3,2 \\
(0,9)\end{array}$ & $\begin{array}{c}708,8 \\
(612,4)\end{array}$ & $\begin{array}{l}12,0 \\
(5,0)\end{array}$ \\
\hline
\end{tabular}

Nota: os números entre parênteses são os valores dos desvios-padrão. 
Quando se analisa os dados (conteúdo médio da dieta) relativos à vitamina C (Tabela 13), nota-se que são os alunos de Tailândia - PA que apresentam o menor consumo (40,5 mg). Esse valor não atinge à recomendação de $45 \mathrm{mg}$ definida para o grupo (National Academy of Sciences, 2002). Cabe ainda salientar que o valor médio do nutriente é acompanhado de desvio-padrão $(102,2)$ que revela a existência de substancial variabilidade no consumo de vitamina C, entre os alunos integrantes da amostra.

Chama a atenção também o resultado do consumo $(275,0 \mathrm{mg}-\mathrm{DP}=724,9)$ identificado entre os estudantes de Baldim - MG. Trata-se obviamente de observação discrepante (praticamente 6,7 vezes maior que o valor recomendado). Vale salientar também que os dados da pesquisa foram obtidos por meio da adoção do questionário Recordatório 24 horas e, portanto, pode ter sido captada uma situação não trivial do consumo alimentar dos alunos das escolas públicas do referido município mineiro.

Albano (2000), identificou no tocante à vitamina C, consumo médio para os meninos de $120,59 \mathrm{mg}-\mathrm{DP}=128,89$ e $161,59 \mathrm{mg}-\mathrm{DP}=199,14$, para as garotas Esses valores respresentam 237,39\% e 318,47\% do atendimento da recomendação, respectivamente. $\mathrm{O}$ autor ressalta que o expressivo consumo deve-se ao fato de alguns adolescentes, integrantes da amostra analisada, ingerirem alimentos considerados expressivas fontes de vitamina $\mathrm{C}$, entre eles sucos e frutas.

No entanto, Maestro (2002), identificou que $75 \%$ dos escolares consumiram quantidade menor que 51,28 mg/dia de vitamina C. Note-se que substancial parcela da amostra analisada pelo autor residia na zona rural, situação que pode contribuir, tendo em vista a disponibilidde de espaço, por exemplo, para produção de frutas tais como a laranja, acerola, entre outras consideradas expressivas fontes de vitamina C.

Outro aspecto que deve ser considerado é a ocorrência de perdas de vitamina C durante a cocção dos alimentos. No caso das refeições servidas, por exemplo, no âmbito das unidades de ensino (que foram incluídas nos cálculos nutricionais envolvendo os alimentos consumidos pelos alunos, integrantes da amostra, que informaram ser beneficiários do programa), esse fato pode ocorrer, tendo em vista que a maioria das hortaliças (consideradas fontes de vitamina C) quando servidas aos escolares são, frequentemente submetidas a processos de cocção durante períodos prolongados. 
Destaca-se também que a vitamina C é essencial para potencializar a absorção do ferro não-heme e exerce, também, papel fundamental no metabolismo do ácido fólico. Acredita-se que expressivas concentrações de vitamina C auxiliam o organismo ampliando a resistência a infecções, prevenindo o câncer, diminuindo o risco de desenvolver doenças cardiovasculares e auxiliando no tratamento da hipertensão e de cataratas (Bricarello \& Goulart, 1999).

Gama (1997) por meio de pesquisa, envolvendo amostra de 316 adolescentes, agrupados de acordo com o gênero e três estratos de idade (10 a 12, 13 a 15 e 16 a 19 anos), registrou que $78,6 \%$ das meninas e $75,3 \%$, do grupo do gênero masculino revelaram ingestão considerada adequada de vitamina C.

É importante ressaltar que a adoção de uma dieta rica em frutas e hortaliças, contendo quantidades de vitamina C, E e carotenóides, pode contribuir para a defesa antioxidante do organismo, inibindo danos oxidativos em macromoléculas, podendo retardar ou prevenir o aparecimento de diversos tipos de câncer (Silva \& Naves, 2001).

Estudos envolvendo grupamentos populacionais revelaram que a deficiência de vitaminas identificadas como integrantes do “Complexo B” é um dos problemas nutricionais com maior incidência na população mundial, afligindo principalmente os indivíduos em fase de crescimento (Fisberg, 2005b).

Ao examinar a Tabela 13 no que tange à ingestão de tiamina (vitamina $\mathrm{B}_{1}$ ) pelos escolares, observa-se quantidade ligeiramente elevada, se for considerado o valor (0,9 mg), preconizado pela National Academy of Sciences, (2002). Exceção é verificada, quando se analisa a situação dos alunos dos municípios de Brasileira e Abaetetuba onde os valores relativos ao consumo são idênticos, exceto a variabilidade captada pelo desvio padrão $(0,9 \mathrm{mg}-\mathrm{DP}=0,3)$ e Anápolis $(0,9 \mathrm{mg}-\mathrm{DP}=0,7)$. Note-se que esses três valores são iguais à recomendação.

No que diz respeito ao consumo de riboflavina (vitamina $\mathrm{B}_{2}$ ), e tendo como padrão de referência o valor 0,9 mg, preconizado pela National Academy of Sciences (2002), observa-se que a maioria dos escolares desfrutam de consumo médio pelo menos igual a 1,0 mg/dia. Exceção é observada quando se verifica a ingestão dos alunos dos 
municípios do Piauí (Parnaíba - 0,9 mg/dia; Brasileira - 0,8 mg/dia) e Abaetetuba (0,8 mg/dia). No entanto os valores são praticamente coincidentes com à recomendação.

Cabe lembrar que, de acordo com Fisberg (2005b), o consumo de tiamina e riboflavina é essencial para o metabolismo de carboidratos, proteínas e gorduras e para a formação do sangue, estando relacionados, estreitamente, com o desenvolvimento e a manutenção do bom funcionamento do organismo humano.

É importante lembrar que a National Academy of Sciences (2002) preconiza para as crianças em idade escolar os valores médios diários de 1,0 mg de vitamina $\mathrm{B}_{6}$, $1,8 \mu$ g de vitamina $\mathrm{B}_{12}$ e $12 \mathrm{mg}$ de niacina.

Ainda de acordo com a Tabela 13 cabe observar que a totalidade dos escolares desfruta de dietas cujo conteúdo supera a recomendação de vitamina $\mathrm{B}_{6}$. No município de Anápolis, por exemplo, foi verificado a maior ingestão da referida vitamina (1,6 mg $\mathrm{DP}=0,6)$, que difere ligeiramente da menor quantidade (1,2 mg - DP = 1,2) identificada na dieta dos alunos de Joinville.

No que se refere ao consumo da vitamina $B_{12}$, verifica-se que os escolares da totalidade dos municípios desfrutam de consumo (médio) que supera à recomendação (1,8 $\mu \mathrm{g} / \mathrm{dia})$. Entre os alunos do município de Anápolis - GO se destaca a ingestão de 7,3 $\mu \mathrm{g}(\mathrm{DP}=2,8)$ da referida vitamina.

Considerando os dados mostrados na Tabela 13 e lembrando que o valor de niacina recomendado (12 mg/dia), pode se afirmar que a ingestão do nutriente da totalidade dos escolares atende à recomendação preconizada. Note-se que o menor consumo (12,1 mg/dia), observado entre os escolares de Brasileira - PI, seguido da ingestão média de 12,1 mg, verificada entre os alunos de Abaetetuba - PA são praticamente iguais ao valor recomendado para o grupamento da pesquisa.

De acordo com a National Academy of Sciences (2002) é recomendado para as crianças com idade entre 9 e 13 anos valor de $300 \mu \mathrm{g} /$ dia de folacina.

Ao examinar os dados reunidos na Tabela 13 verifica-se que o menor consumo $(78,7 \mu \mathrm{g})$ foi identificado entre os alunos da rede pública de ensino de Tailândia - PA e o maior, $170 \mu \mathrm{g}(\mathrm{DP}=73,9)$ em Itaguarú - GO 
A principal função da folacina é observada na síntese do DNA e RNA, afetando, também, a síntese protéica (Anderson et al. 1988). A folacina também é essencial para a formação e maturação de células sanguíneas vermelhas e brancas na medula óssea (Combs Jr., 2002).

Maestro (2002), tendo por base dados de 508 alunos, com idade entre 6 e 18 anos, matriculados na rede pública, de Piedade - SP, município onde a maioria da população reside na zona rural, verificou-se que $90 \%$ dos escolares ingeriam quantidade de folacina $(185,78 \mu \mathrm{g} / \mathrm{dia})$ menor que à recomendada.

Monje-Rojas (2001), analisando o consumo alimentar de amostra de escolares residentes na zona rural e urbana identificou consumo médio de $137 \mathrm{mg}$ de folacina/1000 kcal (DP = 53). O autor ressalta que a situação dos alunos da zona urbana era relativamente melhor, quando comparada à realidade da zona rural. A maioria (55\%) dos escolares da zona urbana ingeriram em quantidade que atendeu à recomendação do nutriente, enquanto o grupo da zona rural, consumiu conteúdo que alcançou 47\%.

De acordo com Anderson et al. (1988), as manifestações de deficiência de folacina são mais acentuadas nos tecidos de rápido crescimento ou naqueles com ágil renovação celular. A deficiência da referida vitamina em seres humanos produz anemia megaloblástica, glossite e distúrbios gastrintestinais. É importante frisar que as melhores fontes de folacina (folium = folha) são as folhas verdes, fígado, em carnes e peixes, nozes, leguminosas e cereais integrais.

Cabe tecer algumas considerações também sobre a biodisponibilidade, destacando que, de acordo com Combs Jr. (2002), deficiências de ferro e vitamina C podem prejudicar a utilização do folato pelo organismo.

Ortega et al. (1996), também observaram dados preocupantes quanto ao consumo de folacina entre escolares adolescentes $(181,3 \mu \mathrm{g} /$ dia entre os indivíduos que permaneciam até duas horas assistindo à televisão e 161,8 $\mu \mathrm{g}$ /dia entre aqueles com permanência diária acima de duas horas).

Vale registrar que é definida pela National Academy of Sciences (2002) recomendação de $4 \mathrm{mg} /$ dia de ácido pantotênico para indivíduos com idade entre 9 e 13 anos. 
Ao analisar (Tabela 13) o consumo de ácido pantotênico dos alunos, nota-se que o grupo de Tailândia - PA desfruta de dietas, cujo conteúdo (9,5 mg/dia - DP = 1,7) é praticamente o dobro da recomendação. Cabe registrar que a referida ingestão foi a maior observada.

Em situação oposta, ou seja, menor consumo (2,4 mg) foram identificados os alunos dos municípios de Brasileira - PI e Abaetetuba - PA.

Cabe destacar que os escolares residentes nos demais municípios revelaram ingestão que não atingiu o valor preconizado.

Vale ressaltar que o ácido pantotênico é essencial para o metabolismo de ácidos graxos, aminoácidos e carboidratos e assume papéis importantes na acilação de proteínas (Combs Jr., 2002). Ainda segundo o autor, o ácido pantotênico por ser amplamente distribuído nos alimentos, fato que, provavelmente contribui para que as deficiências sejam raramente observadas.

Sabe-se que a vitamina A assume papéis essenciais na visão, no crescimento, desenvolvimento e manutenção do tecido epitelial, nas funções imunológicas e reprodução. Um dos principais sinais de deficiência de vitamina A é a visão prejudicada pela perda de pigmentos visuais (Combs Jr., 2002).

Face a importância da vitamina A, especialmente para o crescimento e desenvolvimento de crianças e adolescentes, julgou-se pertinente analisar o consumo dos escolares, lembrando que a National Academy of Sciences (2002) preconiza $600 \mu \mathrm{g} / \mathrm{dia}$, para indivíduos com idade entre 9 e 13 anos.

Ainda de acordo com a Tabela 13 observa-se que a pior situação, no tocante ao consumo da referida vitamina, foi identificada entre os escolares do município de Itaguarú (513, $\mu \mathrm{g}-\mathrm{DP}=567,3)$. Nos demais municípios, a ingestão se mostra mais favorável para a maioria dos alunos.

Trata-se, portanto, de resultado que pode ser considerado satisfatório, especialmente se for levada em consideração as condições socioeconômicas da população que integra a pesquisa.

Ramalho et al. (2002), revisando as publicações (entre 1970 a 2000) referente a carência de vitamina A, verificaram que a deficiência dessa vitamina comporta-se de 
forma igualitária em distintas regiões do território brasileiro. Comprova-se tal fato por meio das análises do consumo de vitamina A, que se revelou semelhante entre a população da Região Nordeste do Brasil e a moradora da Região Sudeste, considerada com maior atividade econômica e renda per capita.

Albuquerque \& Monteiro (2002), tendo por base dados de 247 escolares, com idade entre nove e dez anos de idade, pertencentes as escolas públicas do município de Maceió (Região Nordeste) encontrou baixa ingestão de vitamina A, sendo $349 \mu$ gRE para os meninos e $296 \mu \mathrm{gRE}$ para as garotas, valores que representam, de acordo com os autores, $50 \%$ e $42 \%$ respectivamente, do atendimento à recomendação. O reduzido consumo de vitamina A, observado pelos autores, pode estar associado ao provável hábito alimentar de parcela da população infanto-juvenil da região nordestina, que freqüentemente ingere pequena quantidade de alimentos, tais como, cenoura, mamão, laranja, manga, abóbora, fígado, folhas verde-escuras, consideradas fontes valiosas do nutriente analisado.

Vítolo et al. (2004), avaliando níveis séricos de retinol de 218 adolescentes (ambos os gêneros), com idade entre 10 e 19 anos, matriculados em um colégio da rede privada de ensino de São Paulo, verificaram que 30\% destes apresentavam níveis séricos abaixo do valor considerado adequado (1,05 $\mu \mathrm{mol} / \mathrm{L}$ ou $\geq 30 \mu \mathrm{g} / \mathrm{dL})$. Quanto à ingestão de vitamina A foram observados valores médios superiores à recomendação vigente para o grupo (valores medianos de 540,0 $\mu \mathrm{gEqRe}$ e 673,6 $\mu \mathrm{gEqRe}$ para meninas e meninos, respectivamente).

Andrade et al. (2003), analisaram, durante 1995 e 1996, o consumo de alimentos de 387 adolescentes com idade entre 12 e 17,9 anos (diagnosticados com e sem sobrepeso), residentes no município do Rio de Janeiro. Os autores observaram entre os meninos sem sobrepeso, valores de 11982 UI de vitamina A e entre aqueles classificados com sobrepeso, 7772 UI. No caso das meninas, verificaram que entre aquelas consideradas eutróficas, a ingestão alcançou 10802 UI e entre as meninas com distúrbio (sobrepeso), 14334 UI.

Estudo realizado por Albano (2000), tendo como amostra alunos com idade entre 11 a 17 anos, revelou para os meninos (94,8\%) consumo médio de vitamina A de 
945,76 $\mu$ g e para as meninas 753,41 $\mu$ g (94,2\%). Cabe mencionar que, de acordo com os autores, os percentuais identificados (94,8\% e 94,2\%) referem-se à proporção de atendimento às recomendações.

Tendo por base os dados da Tabela 13 é possível identificar que, de forma geral, a maioria dos escolares ingeriu (valores médios) vitamina E que podem ser considerados maiores que o valor preconizado (11 mg/dia) pela National Academy of Sciences (2002).

Exceção foi identificada entre os escolares do município de Tailândia, cuja ingestão (média) foi de 7,1 mg.

Situação similar também foi observada quando se analisou o consumo dos alunos de Joinville - SC. O consumo médio ( $8,4 \mathrm{mg} /$ dia), não atende à recomendação preconizada para o grupo. No mesmo estado, no município de Ponte Serrada, o consumo dos escolares alcançou 12,0 mg, praticamente a quantidade que deve conter a dieta diária para o atendimento da ingestão recomendada.

Uma das principais funções da vitamina $\mathrm{E}$ é a proteção que confere às membranas celulares contra a destruição oxidativa, provavelmente devido à atuação conjunta com pequenas moléculas e enzimas, para defender as células contra o dano causado pelos radicais de oxigênio (Oliveira \& Marchini, 1998).

Dados apresentados por Maestro (2002) revelam que 75\% dos escolares, de amostra de crianças e adolescentes apresentaram consumo inferior a 7,78 mg de vitamina E. Mesmo quando são analisados os dados relativos aos $10 \%$ de escolares com maior ingestão da referida vitamina, a ingestão identificada (10,33 mg para os meninos e 10,21 mg para as meninas) revela inferioridade com relação à recomendação. De acordo com o autor os valores observados se revelam insuficientes para o atendimento das necessidades nutricionais da maioria da população analisada. 


\section{CONCLUSÕES}

De forma geral o conteúdo energético médio (1503,4 kcal) da dieta dos escolares, se revelou inferior ao preconizado, especialmente quando são considerados os parâmetros, mais recentes, divulgados pelas agências responsáveis pela definição das recomendações de energia, para os dois grupos de idade e gêneros discriminados na presente pesquisa.

Contrariando as expectativas, os escolares de Joinville (SC), revelaram dietas cujo valor energético (1218,6 kcal) - o menor conteúdo - se mostrou semelhante aos valores verificados no Piauí (Região Nordeste): em Parnaíba (1297,0 kcal) e Brasileira (1236,3 kcal) - considerado um dos municípios mais pobres do Brasil. Em situação distinta foram identificados os escolares de Tailândia (Região Norte), que revelaram consumo energético de 1780,2 kcal (maior valor médio observado).

As análises envolvendo o estado nutricional mostraram que não foram identificados, nesta pesquisa, escolares com déficit de peso. A maioria (cerca de 92,6\%), revelou adequação do Índice de Massa Corporal - IMC e cerca de 7,4\% revelaram peso acima do normal. Nos municípios de Santa Catarina foi identificada a situação mais preocupante no tocante ao excesso de peso corporal: 14,7 \% e 16,3 \% (Joinville e Ponte Serrada, respectivamente) dos alunos foram classificados com IMC $\geq 95^{\circ}$ Percentil (indicativo de sobrepeso).

Merece destaque o fato da totalidade dos escolares de Brasileira (Piauí) terem sido classificados como eutróficos.

Cabe salientar que no tocante às análises relativas à participação dos macronutrientes no Valor Energético Total - VET, 54,6 \% dos escolares adotavam dietas classificadas como inadequadas. Essa situação prevaleceu entre 78,1\% dos alunos mais jovens (com menos de 9 anos de idade) de Brasileira - PI, e no município de Abaetetuba - PA, entre 69,8\% dos alunos com idade entre 9 a 13 anos - os mais velhos da amostra. 
Merece ser destacado que, persistindo possíveis déficits de consumo de energia e nutrientes, assim como a inadequação da participação dos macronutrientes no Valor Energético Total - VET da dieta durante a infância e adolescência, poderão ser gerados impactos negativos (e até irreversíveis), no desempenho do crescimento linear, entre outros aspectos e ainda, no futuro, ampliar a probabilidade de ocorrências, entre os membros desse grupo, de doenças crônicas, especialmente devido a qualidade da composição das dietas.

Quanto à presença dos lipídios totais, lipídios insaturados, colesterol e as fibras nas dietas analisadas merece atenção o reduzido conteúdo de fibras (valor muito pequeno, mesmo quando se considera os valores mínimos preconizados para o grupo) e consumo expressivo de lipídios insaturados . Cabe lembrar que o consumo de fibras na alimentação exerce um papel importante, tendo em vista que pode prevenir o câncer de cólon e diminuir a absorção do colesterol como também aumentar a saciedade, contribuindo assim para a diminuição da ingestão de alimentos.

Quanto ao consumo excessivo de lipidios insaturados é possível, por exemplo, ocorrer o favorecimento do câncer em pessoas com predisposição genética ao distúrbio.

No tocante ao conteúdo de minerais na dieta dos escolares, merece destaque a presença expressiva de selênio, cobre, manganês, zinco e ferro. Por outro lado, demanda atenção o reduzidíssimo consumo de cálcio (a maioria dos escolares consumiu metade do conteúdo preconizado), fato que indiscutivelmente demanda intervenção efetiva, tendo em vista que o referido mineral desempenha papel imprescindível na formação óssea.

Quanto ao conteúdo de vitaminas na dieta dos escolares foi possível verificar que, de forma geral, a maioria consumiu quantidades de vitamina $\mathrm{C}$, vitamina $\mathrm{E}$, tiamina (vitamina $\mathrm{B}_{1}$ ), vitamina $\mathrm{B}_{6}$, vitamina $\mathrm{B}_{12}$ que podem ser consideradas satisfatórias tendo em vista que os valores superam a ingestão recomendada. Exceção foi observada, quando se examinou a situação relativa ao consumo de folacina e ácido pantotênico, considerados inferiores à demanda.

Face ao exposto, é essencial que esforços sejam empreendidos, especialmente por meio da atuação dos gestores de políticas e programas de segurança alimentar e 
nutricional no sentido de implementar intervenções e de viabilizar o atendimento das necessidades nutricionais dos adolescentes. Nesse sentido o Programa Nacional de Alimentação Escolar - PNAE, que tem entre os seus principais objetivos "garantir o suprimento das necessidades nutricionais, por meio do oferecimento de, no mínimo, uma refeição diária balanceada” e também “promover hábitos alimentares saudáveis”, poderia constituir recurso valioso de intervenção, ao cumprir a totalidade de suas metas.

Não deve ser ignorado que no planejamento dos cardápios do referido Programa, os alimentos selecionados devem possuir reconhecido valor nutricional e ter boa aceitabilidade pelos escolares.

Tendo em vista a identificação de heterogeneidade da situação do estado nutricional e do consumo alimentar do grupo de crianças e adolescentes, matriculados nas unidades de ensino que integram a Rede Pública de Ensino do País sugere-se também que, na medida do possível, acréscimos nos valores dos repasses de recursos financeiros, destinados à aquisição de produtos alimentícios destinados à alimentação escolar, atualmente sob responsabilidade do governo federal devam ser autorizadas, com a maior brevidade possível e com foco dirigido, prioritariamente para as regiões mais pobres.

Não deve ser ignorada a urgência de discussões e reformulações relativas aos limites de atuação e especialmente no tocante à qualidade dos serviços, que viabilizam a comercialização de alimentos no âmbito das escolas, por meio das cantinas/lanchonetes, em substancial número de unidades de ensino da rede pública. Face ao exposto, enfatizase a importância do fornecimento de orientações aos alunos sobre o conteúdo nutricional e condições higiênicas e ainda, sobre os preços dos alimentos que são comercializados nos referidos estabelecimentos.

É indiscutível também que a escola é reconhecida como um espaço onde é viável, por meio de atividades incorporadas às atividades tradicionais, estimular o consumo de alimentos saudáveis por meio, por exemplo, de programas de educação nutricional, tendo em vista que é na infância e adolescência que podem ser consolidadas as práticas alimentares frequentemente mais difíceis de serem modificadas na idade adulta. 
ANEXOS 
Anexo A

Ministério da Ciência e Tecnologia - FINEP

Universidade de São Paulo - Escola Superior de Agricultura “Luiz de Queiroz”

Pesquisa: Avaliação do Programa de Alimentação Escolar - Módulo III

\section{RECORDATÓRIO DE 24 HORAS}

Nome do Aluno:

Escola: Município: Série que freqüenta:

Data da obtenção dos dados:

\begin{tabular}{|c|c|c|c|}
\hline Refeição & $\begin{array}{c}\text { Horário e local } \\
\text { da refeição }\end{array}$ & Alimentos & $\begin{array}{c}\text { Quantidade de alimentos } \\
\text { (em medidas caseiras) }\end{array}$ \\
\hline Café da manhã & & & \\
\hline $\begin{array}{c}\text { Lanche ou Merenda } \\
\text { da manhã* }\end{array}$ & & & \\
\hline Almoço & & & \\
\hline Lanche ou Merenda & & & \\
\hline da tarde* & & & \\
\hline Jantar & & & \\
\hline Lanche noturno & & & \\
\hline
\end{tabular}

*Informar se a refeição é a merenda oferecida na escola.

Responsável pelo preenchimento 
Anexo B

\section{MODELO DE MEDIDAS DE UTENSÍLIOS CASEIROS}
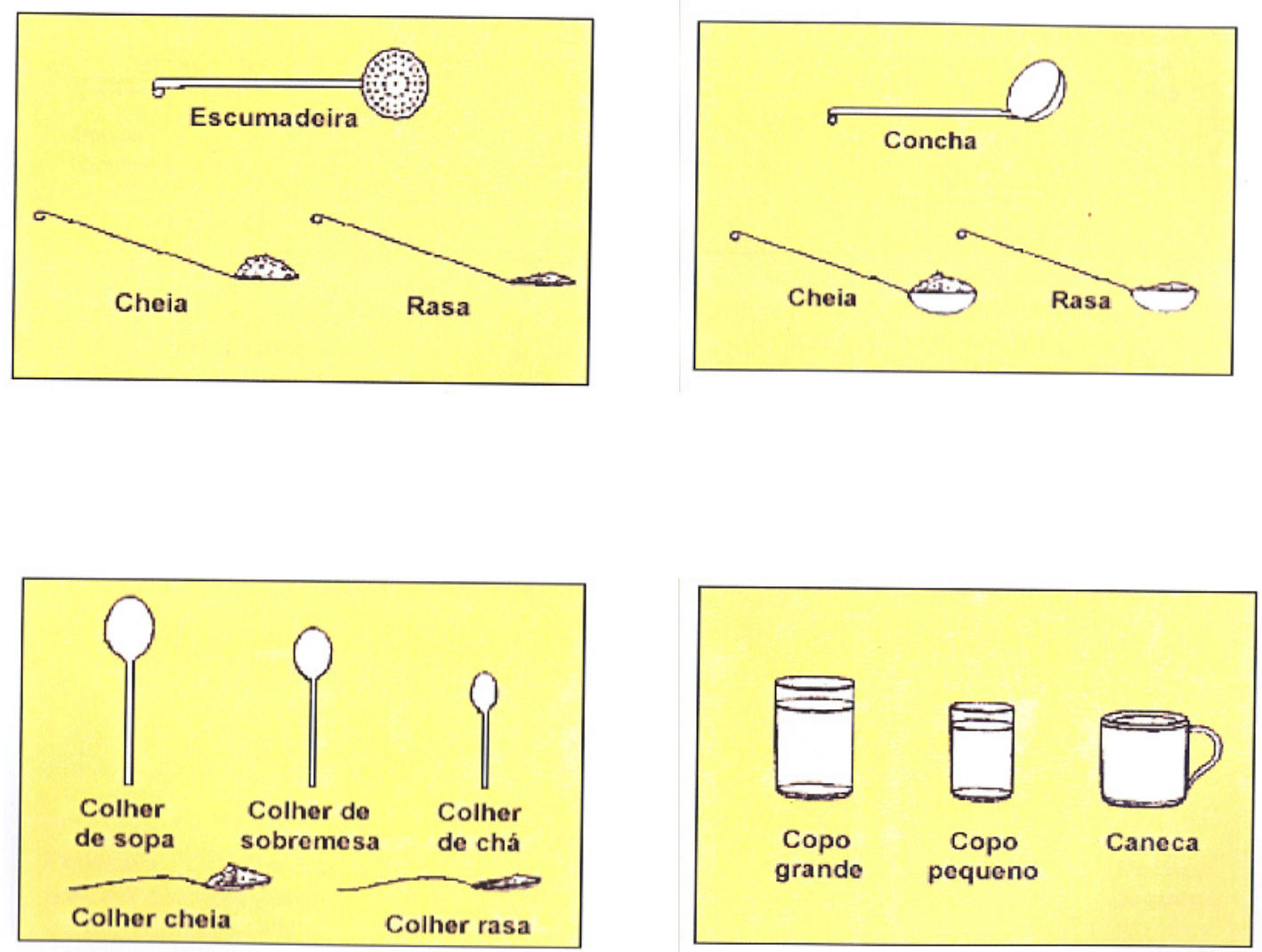




Pedaços de carne em prato raso



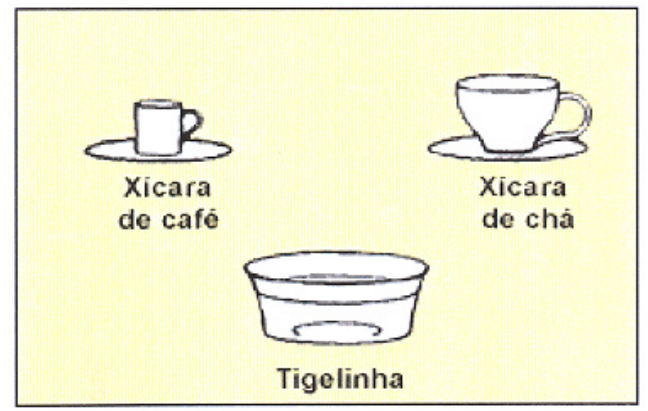

Pedaços de bolo ou doce em prato de sobremesa

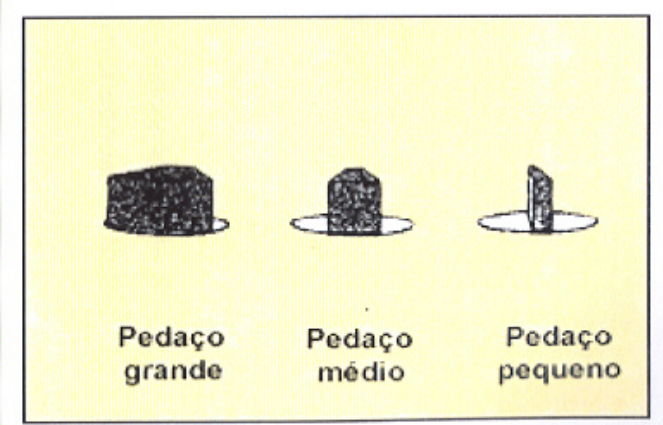




\section{REFERÊNCIAS BIBLIOGRÁFICAS}

ABREU, C.L.M. de; DIAS, L.R.P.; PASSOS, M.A., ALMEIDA, E. de; SOUZA, E.; BRANCO, LM. Consumo alimentar de adolescentes em escola privada do município de Cotia, São Paulo. Nutrição em Pauta, v.12, n 64, p.22-26, 2004.

ALBANO, R.D. Estado nutricional e consumo alimentar de adolescentes. São Paulo, 2000. 70p. Dissertação (Mestrado) - Faculdade de Saúde Pública, Universidade de São Paulo.

ALBANO, R.D.; SOUZA, S.B. Estado nutricional de adolescentes: "risco de sobrepeso" e "sobrepeso" em uma escola do município de São Paulo. Caderno de Saúde Pública, v.17, n.4, p.941-947, 2001.

ALBUQUERQUE, M. de F.M. de; MONTEIRO, A.M. Ingestão de alimentos e adequação de nutrientes no final da infância. Revista de Nutrição, v.15, n.3, p.291299, 2002.

ANDERSON, J.J.B. Características dos minerais. In: MAHAN, L.K.; ESCOTTSTUMP, S. Krause: alimentos, nutrição \& dietoterapia. São Paulo: Roca, 2002. p.106-145.

ANDERSON, L.; DIBBLE, M.V.; TURKKI, P.R.; MITCHELL, H.S.; RYNBERGEN, M.S. Nutrição. Rio de Janeiro: Guanabara, 1988. 737p. 
ANDRADE, R.G.; PEREIRA, R.A.; SICHIERI, R. Consumo alimentar de adolescentes com e sem sobrepeso do Município do Rio de Janeiro. Cadernos de Saúde Pública, v.19, n.5, p.1485-1495, 2003.

ANGELIS, R.C.; CTENAS, M.L.B. Boletim Sadia de recomendações nutricionais. São Paulo: Sadia, 1992. 34p.

ANGELIS, R.C.; CTENAS, M.L.B. Boletim Sadia de cuidados nutricionais cardiovasculares. São Paulo: Sadia, 1993. 31p.

ANJOS, L.A. dos; VEIGA, G.V. da; CASTRO, I.R.R. de Distribuição dos valores do índice de massa corporal da população brasileira até 25 anos. Revista Panamericana Salud Publica, v.3. n.3, p.164-173, 1998.

BLEIL, S.I. O padrão alimentar ocidental: considerações sobre a mudanças de hábitos no Brasil. Cadernos de Debate, v.6, p.1-25, 1998.

BRAGGÍON, G.F.; MATSUDO, S.M.M., MATSUDO, V.K.R. Consumo alimentar, atividade física e percepção da aparência corporal em adolescentes. Revista Brasileira de Ciência e Movimento, v.8, n.2, p.15-22, 2000.

BRASIL. Ministério da Saúde. Secretaria de Política de Saúde. Organização Pan Americana da Saúde. Guia alimentar para crianças menores de 2 anos. Brasília: Ministério da Saúde. 2002. 157 p. (Normas e Manuais Técnicas, 107).

BRASIL. Ministério da Saúde. Agência Nacional de Vigilância Sanitária de Alimentos. Resolução nº 344, de 13 de dezembro de 2002. Diário Oficial, 18 dez. 2002. Seção 1, p.58. 
BRICARELLO, L.P; GOULART, R.M.M. O papel das vitaminas em lactentes e crianças. Pediatria Moderna, v.35, n.10, p.797-807, 1999.

BULL, N.L.; PHIL., M. Dietary habits, food consumption, and nutrient intake during adolescence. Journal of Adolescence Health, v. 13, n.5, p. 384-388, 1992.

CAROBA, D.C.R.; SILVA, M.V.; PIPITONE, M.A.P.; STURION, G.L. Alimentos industrializados: uma análise da sua participação na dieta de escolares da rede pública de ensino. In: CONGRESSO BRASILEIRO DE CIÊNCIA E TECNOLOGIA DE ALIMENTOS, 17., Fortaleza, 2000. Resumos. Fortaleza: SBCTA, 2000, v.3, p.7.7.

CAROBA, D.C.R. A escola e o consumo alimentar de adolescentes matriculados na rede pública de ensino. Piracicaba, 2002. 162p. Dissertação (Mestrado) - Escola Superior de Agricultura “Luiz de Queiroz”, Universidade de São Paulo.

CARVALHO, C.M.R.G.; NOGUEIRA, A.M.T.; TELES, J.B.M.; PAZ; SOUSA, R.M.L. de. Consumo alimentar de adolescentes matriculados em um colégio particular de Teresina, Piauí, Brasil. Revista de Nutrição, v.14, n.2, p. 85-93, 2001.

CASOTTI, L.; RIBEIRO, A.; SANTOS, C.; RIBEIRO, P. Consumo de alimentos e nutrição: dificuldades práticas e teóricas. Cadernos de Debate, v.6, p.26-39, 1998.

CASTRO, F.A.F.; PEREIRA, C.A. dos S.; PRIORE, S.E.; RIBEIRO, S.M.R.; BITTENCOURT, M.C.B.; QUEIROZ, V.M.V. de. Educação nutricional: a importância da prática dietética. Nutrição em Pauta, v.10, n.52, p. 9-15, 2002. 
CHIARA, V.; SICHIERI, R.; CARVALHO, T.; ALVES, D. Padrão alimentar de adolescentes com sobrepeso. In: CONGRESSO NACIONAL DA SOCIEDADE BRASILEIRA DE ALIMENTAÇÃO E NUTRIÇÃO, 6., Florianópolis, 2001. Resumos. Florianópolis: SBAN, 2001. p.231

CINTRA, I.P.; OLIVEIRA, C.L.; FISBERG, M. Obesidade na infância e adolescência. In: Obesidade: Tratamento e Prevenção. Nutrição em Pauta, v. 9, n.50, p.10-17, 2001.

COMBS JUNIOR, G.F. Vitaminas. In: MAHAN, L.K.; STUMP, S.E. Krause: alimentos, nutrição \& dietoterapia. São Paulo: Roca, 2002. p.65-105.

CONSENSO BRASILEIRO SOBRE DISLIPIDEMIAS. Deteç̧ão-AvaliaçãoTratamento. Arquivos Brasileiros de Cardiologia, v.67, n.2. p-67-71, 1996.

CORONELLI, C.L.S.; MOURA, E.C. Hipercolesterolemia em escolares e seus fatores de risco. Revista de Saúde Pública, v.37, n.1, p.24-31, 2003.

COURT, J.M. Nutrition and adolescents: an overview of concerns in Western society. The Medical Journal of Australia, v.148, p.52-57, 1988. Special Suppplement.

DANELON, M.S. Segurança alimentar em áreas de preparo e consumo de alimentos. Piracicaba: Escola Superior de Agricultura Luiz de Queiroz/USP, 2004. $70 \mathrm{p}$.

DIETZ, W.H. Health consequences of obesity in youth: childhood predictors of adult disease. Pediatrics, v.101, n.3. p.518-525, 1998. Supplement. 
ELIAS, M.C.; ITO, M.T.; SLEIMAN, J. Atualizações no tratamento dietoterápico nas dislipidemias. Nutrição, Saúde \& Performance, v.3, n.13, 2001, p.5-8, 2001.

ETTINGER, S. Macronutrientes: carboidratos, proteínas e Lipídeos. In: MAHAN, L.K.; ESCOTT-STUMP, S. Krause: alimentos, nutrição \& dietoterapia. São Paulo: Roca. 2002, p. 30-64.

FERRAZ, L.; RODRIGUES, L. A influência da propaganda de alimentos na alimentação infantil. IN: CONGRESSO NACIONAL DA SOCIEDADE BRASILEIRA DE ALIMENTAÇÃO E NUTRIÇÃO, 6., Florianópolis, 2001. Resumos. Florianópolis: SBAN, 2001. p. 149.

FIGUEIREDO, C.A.; NOVA, E.M. V.; RIBEIRO, H.G.; CABRAL, M.G. A criança, a alimentação e a escola. Revista Portuguesa de Nutrição, v.6, n.2, p.5-52, 1994.

FISBERG, M. Pesquisa revela que cerca de 30\% das crianças brasileiras apresentam sobrepeso ou obesidade. Nutrição em Pauta, jul.2003, http://www.nutricaoempauta.com.br/novo/61/entrevista2.html, (06 jan. 2005a)

FISBERG. M. Cresce o déficit nutricional. jun. 2003, http://www.cfn.org.br/variavel/ultimas/nutricao_midia/nutri_midia927htm, (06 jan. 2005b).

FISBERG, M.; LIMA, M.A.; RHEIN, S.O.; NAUFEL, C.; RODRIGUES, C.; OLIVEIRA, S. de Feijão enriquecido com ferro na prevenção de anemia em préescolares. Nutrição em Pauta. v.11, n.59, p. 10-18, 2003. 
FOOD AND AGRICULTURE ORGANIZATION OF THE UNITED NATIONSFAO/ORGANIZACION MUNDIAL DE LA SALUD - OMS. Dieta, nutrición y prevención de enfermedades crónicas. Ginebra, Organización Mundial de la Salud, 2003 (OMS, Serie de Informes Técnicos, 916). ftp://ftp.fao.org/docrep/fao/006/ac911s/ac911s00.pdf, (06 jan. 2005).

FORTI, N.; ISSA, J.; DIAMENT, J. et al. Dislipidemias em crianças e adolescentes. bases para a terapêutica. Arquivos Brasileiros de Cardiologia, v.71, n.6, p.807-810, 1998

GAGLIARDI, J. Obesidade: conceito e avaliação. Revista Nutrição, Saúde \& Performance, v.3, n.14, p.5-7, 2001.

GALEAZZI, M.A.M.; DOMENE, S.M.A.; SICHIERI, R. Estudo multicêntrico sobre consumo de alimentos. Cadernos de Debate, p.1-62, 1997. volume especial.

GAMA, C.M. Hábito alimentar e condição nutricional de adolescentes de bom nível sócio econômico em São Paulo. São Paulo, 1997. 191p. Dissertação (Mestrado) Escola Paulista de Medicina, Universidade Federal de São Paulo.

GARCIA, G.C.B.; GAMBARDELLA, A.M.D.; FRUTUOSO, M.F.P. Estado nutricional e consumo alimentar de um centro de juventude de São Paulo. Revista de Nutrição, v.16, n.1, p.41-50, 2003.

GERBER, Z.R.; ZIELINSKY, P. Fatores de risco de aterosclerose na infância. Um estudo epidemiológico. Arquivos Brasileiros de Cardiologia, v. 69, n.4, p.231-236, 1997. 
GONZÁLEZ, I.C.M. Nutrição nos escolares e adolescentes. Nutrição em Pauta, v.10, n.53, p.23-26, 2002.

GOUVEIA, E.L.C. Nutrição, saúde \& comunidade. Rio de Janeiro: Revinter, 1999. 247p.

HOFFMANN, R. A insegurança alimentar no Brasil. Cadernos de Debate, v.11, n.2, p.1-11, 1994.

KAZAPI, I.M.; DI PIETRO, P.F.; AVANCINI, S.R.P.; FREITAS, S.F.T. de Consumo de energia e macronutrientes por adolescentes de escolas públicas e privadas. Revista de Nutrição, v.14, p.27-33, 2001. Suplemento.

KRAUSE, M.V.; MAHAN, L.K. Alimentos, nutrição e dietoterapia. São Paulo: Roca, 1985. 1052p.

KRUMMEL, D. Nutrição na doença cardiovascular. In: MAHAN, L.K.; ESCOTTSTUMP, S. Krause: alimentos, nutrição \& dietoterapia. São Paulo: Roca, 2002. p. 539-575.

JUZWIACK, C.R. Necessidades energéticas e distribuição de macronutrientes: novas DRI`s, 2002 - atualização. Nutrição - Saúde \& Performance, v.4, n.18, p. 15-16, 2002.

LEÃO, L.S.C.S.; ARAÚJO, L.M.B; MORAES, L.T.L.P.de; ASSIS, A. Prevalência de obesidade em escolares de Salvador, Bahia. Arquivos Brasileiros de Endocrinologia e Metabologia, v.47, n.2, p.151-157, 2003 
LERNER, B.R.A. Alimentação e anemia carencial em adolescentes. São Paulo, 1994. 90p. Tese (Doutorado) - Faculdade de Saúde Pública, Universidade de São Paulo.

MAESTRO, V. Padrão alimentar e estado nutricional: caracterização de escolares de município paulista. Piracicaba, 2002. 116p. Dissertação (Mestrado) - Escola Superior de Agricultura “Luiz de Queiroz”, Universidade de São Paulo.

MAHAN, L.K.; ARLIN, M.T. Krause: alimentos, nutrição e dietoterapia. São Paulo: Roca,1994. 957p.

MAHAN, L.K.; ESCOTT-STUMP, S. Krause: alimentos, nutrição \& dietoterapia. São Paulo: Roca, 2002. 1157p.

MARQUES, J. Florianópolis proíbe doces nas escolas. Folha de São Paulo, São Paulo, 02 ago. 2001, p.C-5.

MARTINS-FILHO, J.M. Masculino X Feminino: “os diferentes hábitos alimentares de crianças e jovens”. Nutrição Saúde \& Performance, v.3, n.10, p.31, 2001.

MATOS, C.H.de; GRILLO, L.P.; HENN, R.; GERMANI, A.C. Anemia ferropriva em adolescentes de escolas municipais de Balneário Camboriú - SC. Nutrição em Pauta, v. 11, n.60, p. 48-51, 2003.

MELLO, A.A.C.V. Estado nutricional de crianças nordestinas: estudo de algumas variáveis úteis à vigilância nutricional. Recife, 1996. 123p. Dissertação (Mestrado) Instituto Materno Infantil de Pernambuco, Universidade Federal de Pernambuco.

MONGE-ROJAS, R. Dietary intake as a cardiovascular risk factor in Costa Rican adolescents. Journal of Adolescent Health, v.28, n.4, p.328-337, 2001. 
MONTEIRO, C.A. Saúde e nutrição das crianças de São Paulo: diagnóstico, constrastes sociais e tendências. São Paulo: HUCITEC/EDUSP, 1988. 165p.

MONTEIRO, C.A. Fome diminui, mas nutrição piora. Folha de São Paulo, São Paulo, 17 dez. 2004, p. C-4.

MONTEIRO, C.A.; MONDINI, L.; COSTA, R.B.L. Mudanças na composição e adequação nutricional da dieta familiar nas áreas metropolitanas do Brasil (19881996). Revista de Saúde Pública, v.34, n.3, p.251-258, 2000.

MOURA, E.C.; NAKAMURA, S.Y.; ROMERO, V. de S.V. Níveis de colesterol em escolares da primeira série de uma escola pública de Campinas, São Paulo, Brasil. Revista de Nutrição, v.10, n.1, p-63-69, 1997.

MOURA, E.C. de; SONATI, J.G. Perfil lipídico de dietas e sua relação com os níveis de colesterolemia em escolares de uma escola pública de Campinas, São Paulo (Brasil). Revista de Nutrição, v.11, n.1, p.69-75, 1998.

NASCIMENTO, D. do; SIEBERT, A.N.; GRILLO, L.P.; GODRY, R.C. Características antropométricas e bioquímicas de atletas infanto-juvenis pertencentes ao projeto social “criança feliz no tênis, feliz na escola”. Nutrição em Pauta. v.12, n.67, p.4349, 2004.

NATIONAL ACADEMY OF SCIENCES Institute Of Medicine. Food And Nutrition Board. Dietary reference intakes: applications in dietary assessment. Washington: National Academy Press, 2000. 306p. http://www.nap.edu (21 Mar.2002) 
NATIONAL ACADEMY OF SCIENCES. Institute of Medicine. Food and Nutrition Board. Dietary reference intakes for energy, carbohydrates, fiber, fat, fatty acids, protein and amino acids (macronutrients). Washington: National Academy Press, 2002. 936p. http://www.nap.edu (11 Oct. 2002).

NATIONAL CENTER FOR HEALTH STATISTICS. Center for Disease Control and Prevention. Growth Charts. http://www.cdc.gov (14 Aug.2002).

NATIONAL RESEARCH COUNCIL National Academy of Sciences. Food and Nutrition Board. Recommended dietary allowances. 10.ed. Washington: National Academy Press, 1989. 284p.

NELSON, M. Assessment of food consumption and nutrients intake: past intake. In: MARGETTS, B.M., NELSON, M. Design concepts in nutritional epidemiology. New York: Oxford University Press, 1991, p.167-184.

NUNES, M.C.D.; MURATA, L.T.F.; ALCÂNTARA, M.R.da S. de; GERMANO, M.I.S.; GERMANO, P.M.L. Avaliação das sobremesas lácteas: características que podem comprometer a garantia de qualidade. Higiene Alimentar, v.12, n.58, p.4143, 1998.

NUNES, R.E.; JUNQUEIRA, A.; DIAS, L.C.G.D. Hábitos alimentares na adolescência. In: CONGRESSO NACIONAL DA SOCIEDADE BRASILEIRA DE ALIMENTAÇÃO E NUTRIÇÃO, 6., Florianópolis, 2001. Resumos. Florianópolis: SBAN, 2001. p. 217

OCHSENHOFER, K.; FIORES, E.G.; COSTA, E.C. Avaliação do estado nutricional de crianças e adolescentes institucionalizados. Nutrição em Pauta, v.12, n.65, p.22-27, 2004. 
OLIVEIRA, E.A.J.; VITALLE, M.S.de S.; AMÂNCIO, O.M.S. Estado nutricional no estirão pubertário. http://www.brazilpednews.org.br/set2002/estirão.pdf. (14 jan. 2005).

OLIVEIRA, J. O papel da merenda diária dos ingressantes no $1^{\circ}$ grau das escolas municipais de São Paulo. São Paulo, 1997. 132p. Dissertação (Mestrado) Faculdade de Ciências Farmacêuticas, Universidade de São Paulo.

OLIVEIRA, J.; PHILIPPI, S.T.; CYRILLO, D.C.; LAJOLO, F.M. A alimentação de escolares no município de São Paulo. In: CONGRESSO BRASILEIRO DE CIÊNCIA E TECNOLOGIA DE ALIMENTOS, 16., Rio de Janeiro, 1998. Alimentos, população e desenvolvimento. Rio de Janeiro: SBCTA, 1998. p.495498.

OLIVEIRA, J.E. de; MARCHINI, J.S. Ciências nutricionais. São Paulo: SARVIER, 1998. 403p.

ORTEGA, R.M.; ANDRÉS, P.; REQUEJO, A.M.; LÓPEZ-SOBALER, A.N.; REDONDO, M.R.; GONZÁLEZ-FERNÁNDEZ, M. Influence of the time spent watching television on the dietary habits, energy intake and nutrient intake of a group of spanish adolescents. Nutrition Research, v.16, n.9, p.1467-1470, 1996.

PEREIRA, M.A.; KARTASHOV, A.I.; EBBELING, C.B.; HORN, L.V.; SLATTERY, M.L.; JACOBS JR, D.R.; LUDWIG, D.S. Fast-food habits, weight gain, and insulin resistance (the CARDIA study): 15-year prospective analysis. The Lancet, v.365, n. 9453, p.36-42, 2005. 
PHILIPPI, S.T.; SZARFARC, S.C.; LATERZA, A.R. Virtual Nutri (software). Versão 1.0 for Windows. São Paulo: Faculdade de Saúde Pública, Universidade de São Paulo, 1996.

RAMALHO, R.A; FLORES, H.; SAUNDERS, C. Hipovitaminose A no Brasil: um Problema de saúde pública. Revista Panamericana Salud Publica, v.12, n.2., p.117122, 2002.

SANCHES, M. Hortaliças: consumo e preferências de escolares. Piracicaba, 2002. 143p. Dissertação (Mestrado). - Escola Superior de Agricultura "Luiz de Queiroz”, Universidade de São Paulo.

SAS INSTITUTE. The SAS System (software). Version 8. Cary: SAS, 1998.

SICHIERI, R.; COITINHO, D.C.; LEÃO, M.M.; RECINE, E.; EVERHART, J.E.E. High temporal, geografic and income variation in body mass index among adults in Brazil. American Journal Public Health, v.84, p.793-798, 1994.

SILVA, C.R.de M.; NAVES, M.M.V. Suplementação de vitaminas na prevenção de câncer. Revista de Nutrição, v.14, n.2, p.-135-143, 2001.

SILVA, M.V.; PIPITONE, M.A.P. Cantinas escolares e merenda escolar: convivência possível? Revista Brasileira Saúde Escolar, v.3, n.1/4, p.23-32, 1994.

SILVA, M.V. Mudanças dos hábitos alimentares da população brasileira. Alimentação e Nutrição, v.18, n 71, p 40-49, 1998. 
SILVA, M.V. Consumo de alimentos, programas de suplementação e estado nutricional de escolares. In: SILVA, M.V. da (Org.); PIPITONE, M.A.P.; STURION, G.L.; STURION, G.L.; PHILIPPI, S.T. Curso de atualização em alimentação e nutrição para professores da rede pública de ensino. Piracicaba: ESALQ, Depto. De Agroindústria, Alimentos e Nutrição/FAPESP, 2000. cap. 1, p.1-45.

SILVA, M.V.; STURION, G.L.; OMETTO, A.M.H.; PIPITONE, M.A.P.; FURTUOSO, M.C.O. Estado nutricional de escolares e seu acesso a programas sociais em dez municípios brasileiros. Nutrire, v. 23, p. 23-53, 2002.

SPEAR, B. A. Nutrição na adolescência. In: MAHAN, L.K.; STUMP, S.E. Krause: alimentos, nutrição \& dietoterapia. São Paulo: Roca. 2002, p. 247-260.

SODEXHO RESEARCH INSTITUTE. Gender difference in children's eating habits: a mayor trend in the food and management services industry. Alliance Sodexho. Paris: SODEXHO, 2000. 68 p.

STURION, G.L. Programa de alimentação escolar: avaliação do desempenho em dez municípios brasileiros. Campinas, 2002. 269p. Tese (Doutorado) - Faculdade de Engenharia de Alimentos, Universidade de Campinas.

URBANO, M.R.D.; VITALLE, M.S.S.; JULIANO, Y.; AMANCIO, O.M.S. Ferro, cobre e zinco em adolescentes no estirão pubertário. Jornal de Pediatria, v.78, n.4, p.327-334, 2002.

VANNUCCHI, H. (Coord.); MENEZES, E.W. de, CAMPANA, A.O.; LAJOLO, F.M. Aplicações das recomendações nutricionais adaptadas à população brasileira. Ribeirão Preto: SBAN, 1990. 156 p. (Cadernos de Nutrição, 2) 
VELÁSQUEZ-MELÉNDEZ, G., MARTINS, I.S.; CERVATO, A.M.; FORNÉS, N.S.; MARUCCI, M. de F.N. Consumo alimentar de vitaminas e minerais em adultos residentes em área metropolitana de São Paulo, Brasil. Revista de Saúde Pública, v.31, n.2, p.157-162, 1997.

VELLOZO, E.P.; FAGIOLI, D.; SILVA, R.da Pão enriquecido com ferro - Prevenção da anemia de crianças matriculadas em creches da prefeitura do município de São Paulo. Nutrição em Pauta, v.11, n.63, p. 32-42, 2003.

VIEIRA, V.C.R.; PRIORE, S.E. Hábitos alimentares e consumo de lanches. Nutrição em Pauta, v.9, n.46, p.14-20, 2001.

VILLAR, B.S. Desenvolvimento e validação de um questionário semi-quantitativo de freqüência alimentar para adolescentes. São Paulo, 2001. 133p. Tese (Doutorado) Faculdade de Saúde Pública, Universidade de São Paulo.

VÍTOLO, R.M; GAMA, C.M.; QUEIROZ, S.de S.; LOPEZ, F.A.; COLUGNATI, F.A.B. Retinol sérico de adolescentes de uma escola da cidade de São Paulo. Revista de Nutrição, v.17, n.3, p.291-299. 2004.

WORLD HEALTH ORGANIZATION - WHO. Physical status: The use and interpretation of anthropometry. Geneva, 1995. 452p. (Who Technical Report Series, 854)

ZIWIAN, Z.L.J. Educação nutricional na adolescência. Importância do comportamento alimentar na busca da saúde perfeita. Higiene Alimentar, v.13, n.61, p. 85-87, 1999. 